\title{
Polycycloiridals A-D, Four Iridal-Type Triterpenoids with an $\alpha$-terpineol moiety from Iris tectorum
}

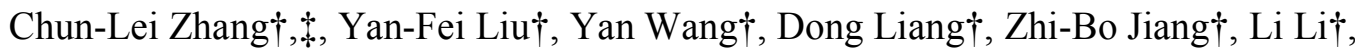

Zhi-You Hao†, Huan Luo†, Guo-Ru Shi†, Ruo-Yun Chen†, Zheng-Yu Caoł,* and

De-Quan Yưं,*

$\uparrow$ State Key Laboratory of Bioactive Substance and Function of Natural Medicines, Institute of Materia Medica, Chinese Academy of Medical Sciences and Peking Union Medical College, Beijing 100050, People's Republic of China

* Jiangsu Provincial Key Laboratory for TCM Evaluation and Translational Development, School of TCM, China Pharmaceutical University, Nanjing 211198, People's Republic of China

\section{Supporting Information}

*Corresponding author. Tel.: +86-25-86185157. Fax:+86-25-86185158. E-mail: zycao1999@hotmail.com

Tel.: +86-10-63165224. Fax: +86-10-63017757. E-mail: dqyu@imm.ac.cn 


\section{List of Contents}

\begin{tabular}{|c|c|c|}
\hline no. & content & page \\
\hline 1 & Experimental Section & $\mathrm{S} 4$ \\
\hline 2 & $\begin{array}{l}\text { Table S1. }{ }^{1} \mathrm{H} \text { and }{ }^{13} \mathrm{C} \text { NMR data and COSY, HMBC, and NOESY correlations of } \\
\text { compound } \mathbf{1}^{a}\end{array}$ & S6 \\
\hline 3 & $\begin{array}{l}\text { Table S2. }{ }^{1} \mathrm{H} \text { and }{ }^{13} \mathrm{C} \text { NMR data and COSY, HMBC, and NOESY correlations of } \\
\text { compound } \mathbf{2}^{a}\end{array}$ & S7 \\
\hline 4 & $\begin{array}{l}\text { Table S3. }{ }^{1} \mathrm{H} \text { and }{ }^{13} \mathrm{C} \text { NMR data and COSY, HMBC, and NOESY correlations of } \\
\text { compound } \mathbf{3}^{a}\end{array}$ & S8 \\
\hline 5 & $\begin{array}{l}\text { Table S4. }{ }^{1} \mathrm{H} \text { and }{ }^{13} \mathrm{C} \text { NMR data and COSY, HMBC, and NOESY correlations of } \\
\text { compound } \mathbf{4}^{a}\end{array}$ & S9 \\
\hline 6 & Figure S1.Values of $\Delta \delta_{S}-\Delta \delta_{R}$ of the MTPA esters of 1 & S10 \\
\hline 7 & Computational Section. & S11 \\
\hline 8 & $\begin{array}{l}\text { Table S5. Energies of the conformers with Boltzmann distribution over } \\
1 \% \text {. }\end{array}$ & $\mathrm{S} 12$ \\
\hline 9 & $\begin{array}{l}\text { Table S6. Energies and vibrational analysis of compounds } 1 \mathrm{a}, 1 \mathrm{~b}, \mathbf{4 a} \text {, and } \\
\text { 4b. }\end{array}$ & $\mathrm{S} 15$ \\
\hline 10 & $\begin{array}{l}\text { Figure S2. Experimental ECD spectrum of } 1 \text { and } 4 \text { calculated ECD } \\
\text { spectra of } 1 \mathrm{a}, \mathbf{1 b}, \mathbf{4} \text {, and } 4 \mathrm{~b} \text { in } \mathrm{MeOH} \text {. }\end{array}$ & S16 \\
\hline 11 & $\begin{array}{l}\text { Figure S3. The experimental UV spectrum of } 1 \text { and } 4 \text { and the calculated } \\
\text { UV spectrum of } 1 \mathrm{a} \text { and } \mathbf{4 b} \text {. }\end{array}$ & S16 \\
\hline 12 & $\begin{array}{l}\text { Figure S4. Molecular orbitals involved in key transitions in the } \\
\text { calculated ECD of } 1 \text { at B3LYP/6-311G** level in } \mathrm{MeOH} \text {. ( A, MO137; } \\
\mathrm{B}, \mathrm{MO} 139 \text { ) }\end{array}$ & S17 \\
\hline 13 & $\begin{array}{l}\text { Figure S5. Molecular orbitals involved in key transitions in the } \\
\text { calculated ECD of } 4 \text { at B3LYP/6-311G** level in MeOH.( A, MO137; B, } \\
\text { MO139; C, MO135; D,MO138) }\end{array}$ & S18 \\
\hline 14 & $\begin{array}{l}\text { Table S7. Hepatoprotective effects of compounds 1-4 (10 } \mu \mathrm{M}) \text { against } \\
\text { D-galactosamine-induced toxicity in HL-7702 cells. }\end{array}$ & S19 \\
\hline 15 & Figure S6. ${ }^{1} \mathrm{H}$ NMR spectrum of compound $1\left(600 \mathrm{MHz}, \mathrm{CDCl}_{3}\right)$ & S19 \\
\hline 16 & Figure S7. ${ }^{13} \mathrm{C}$ NMR spectrum of compound $1\left(150 \mathrm{MHz}, \mathrm{CDCl}_{3}\right)$ & $\mathrm{S} 20$ \\
\hline 17 & Figure S8. ${ }^{1} \mathrm{H}-{ }^{1} \mathrm{H}$ COSY spectrum of compound $\mathbf{1}$ & $\mathrm{S} 20$ \\
\hline 18 & Figure S9. HSQC spectrum of compound 1 & $\mathrm{~S} 21$ \\
\hline 19 & Figure S10. HMBC spectrum of compound 1 & $\mathrm{~S} 21$ \\
\hline 20 & Figure S11. NOESY spectrum of compound 1 & $\mathrm{~S} 22$ \\
\hline 21 & Figure S12. HRESIMS spectrum of compound 1 & S23 \\
\hline 22 & Figure S13. IR spectrum of compound 1 & $\mathrm{~S} 24$ \\
\hline 23 & Figure S14. UV spectrum of compound 1 & S24 \\
\hline 24 & Figure S15. CD spectrum of compound $\mathbf{1}(\mathrm{MeOH})$ & S25 \\
\hline
\end{tabular}




\begin{tabular}{|c|c|c|}
\hline 25 & Figure S16. ${ }^{1} \mathrm{H}$ NMR spectrum of compound $2\left(600 \mathrm{MHz}, \mathrm{CDCl}_{3}\right)$ & $\mathrm{S} 25$ \\
\hline 26 & Figure S17. ${ }^{13} \mathrm{C}$ NMR spectrum of compound $2\left(150 \mathrm{MHz}, \mathrm{CDCl}_{3}\right)$ & S26 \\
\hline 27 & Figure S18. ${ }^{1} \mathrm{H}-{ }^{1} \mathrm{H}$ COSY spectrum of compound 2 & S26 \\
\hline 28 & Figure S19. HSQC spectrum of compound 2 & S27 \\
\hline 29 & Figure S20. HMBC spectrum of compound 2 & S27 \\
\hline 30 & Figure S21. NOESY spectrum of compound 2 & $\mathrm{~S} 28$ \\
\hline 31 & Figure S22. HRESIMS spectrum of compound 2 & S29 \\
\hline 32 & Figure S23. IR spectrum of compound 2 & S29 \\
\hline 33 & Figure S24. UV Spectrum of compound 2 & S30 \\
\hline 34 & Figure S25. CD Spectrum of compound $2\left(\mathrm{CH}_{3} \mathrm{OH}\right)$ & S30 \\
\hline 35 & Figure S26. ${ }^{1} \mathrm{H}$ NMR spectrum of compound $3\left(600 \mathrm{MHz}, \mathrm{CDCl}_{3}\right)$ & $\mathrm{S} 31$ \\
\hline 36 & Figure S27. ${ }^{13} \mathrm{C}$ NMR spectrum of compound $3\left(150 \mathrm{MHz}, \mathrm{CDCl}_{3}\right)$ & S31 \\
\hline 37 & Figure S28. ${ }^{1} \mathrm{H}-{ }^{1} \mathrm{H}$ COSY spectrum of compound $\mathbf{3}$ & S32 \\
\hline 38 & Figure S29. HSQC spectrum of compound 3 & S32 \\
\hline 39 & Figure S30. HMBC spectrum of compound $\mathbf{3}$ & S33 \\
\hline 40 & Figure S31. NOESY spectrum of compound 3 & S33 \\
\hline 41 & Figure S32. HRESIMS spectrum of compound 3 & S34 \\
\hline 42 & Figure S33. IR spectrum of compound $\mathbf{3}$ & S34 \\
\hline 43 & Figure S34. UV spectrum of compound 3 & S35 \\
\hline 44 & Figure S35. CD spectrum of compound $3(\mathrm{MeOH})$ & S35 \\
\hline 45 & Figure S36. ${ }^{1} \mathrm{H}$ NMR spectrum of compound $4\left(600 \mathrm{MHz}, \mathrm{CDCl}_{3}\right)$ & S36 \\
\hline 46 & Figure S37. ${ }^{13} \mathrm{C}$ NMR spectrum of compound $4\left(150 \mathrm{MHz}, \mathrm{CDCl}_{3}\right)$ & S36 \\
\hline 47 & Figure S38. ${ }^{1} \mathrm{H}-{ }^{1} \mathrm{H}$ COSY spectrum of compound 4 & S37 \\
\hline 48 & Figure S39. HSQC spectrum of compound 4 & S37 \\
\hline 49 & Figure S40. HMBC spectrum of compound 4 & S38 \\
\hline 50 & Figure S41. NOESY spectrum of compound 4 & $\mathrm{~S} 38$ \\
\hline 51 & Figure S42. HRESIMS spectrum of compound 4 & S39 \\
\hline 52 & Figure S43. IR spectrum of compound 4 & S39 \\
\hline 53 & Figure S44. UV spectrum of compound 4 & S40 \\
\hline 54 & Figure S45. CD spectrum of compound $4(\mathrm{MeOH})$ & S40 \\
\hline 55 & Figure S46. ${ }^{1} \mathrm{H}$ NMR Spectrum of the $(R)$-MTPA ester $(\mathbf{1 r})$ of $\mathbf{1}$ & S41 \\
\hline 56 & Figure S47. ${ }^{1} \mathrm{H}-{ }^{1} \mathrm{H}$ COSY Spectrum of the $(R)$-MTPA ester $(\mathbf{1 r})$ of $\mathbf{1}$ & S41 \\
\hline 57 & Figure S48. ${ }^{1} \mathrm{H}$ NMR Spectrum of the $(S)$-MTPA ester $(\mathbf{1 s})$ of $\mathbf{1}$ & S42 \\
\hline 58 & Figure S49. ${ }^{1} \mathrm{H}-{ }^{1} \mathrm{H}$ COSY Spectrum of the $(S)$-MTPA ester $(\mathbf{1 s})$ of 1 & S42 \\
\hline
\end{tabular}




\section{EXPERIMENTAL SECTION}

General Experimental Procedures. Optical rotations were measured on a JASCO P-2000 polarimeter, and UV spectra with a JASCO V-650 spectrophotometer. IR spectra were recorded on a Nicolet 5700 spectrometer by an FT-IR microscope transmission method. NMR measurements were performed on VNS-600 spectrometers in $\mathrm{CDCl}_{3}$. HRESIMS were obtained using an Agilent 1100 series LC/MSD ion-trap mass spectrometer. Analytical HPLC was conducted on an Agilent 1260 infinity system equipped with a DAD-UV detector. Preparative HPLC was performed using a Shimadazu LC-6AD instrument with a SPD-20A detector and a YMC-Pack ODS-A column $(250 \times 20 \mathrm{~mm}, 5 \mu \mathrm{m})$. Silica gel (200-300 mesh, Qingdao Marine Chemical Factory, Qingdao, People's Republic of China), Sephadex LH-20 (GE), and ODS (50 $\mu \mathrm{m}, \mathrm{YMC}$, Japan) were used for column chromatography. TLC was carried out with GF254 plates (Qingdao Marine Chemical Factory).

Plant Material. The rhizomes of I. tectorum were purchased from a Chinese herbal medicine market in Chengdu, Sichuan province, China and authenticated by Professor Lin Ma, Institute of Materia Medica, Chinese Academy of Medical Sciences and Peking Union Medical College. A voucher specimen (ID-S-2469) was deposited at the Herbarium of the Department of Medicinal Plants, the Institute of Materia Medica, Chinese Academy of Medical Sciences, Beijing.

Extraction and Isolation. The air-dried powder of the rhizomes of I. tectorum (100 $\mathrm{kg}$ ) were exhaustively extracted with $95 \% \mathrm{EtOH}$ under reflux $(3 \times 100 \mathrm{~L})$. The extracts were combined and concentrated under vacuum to give a residue, which was suspended in water and partitioned with EtOAc and n-BuOH, successively. The EtOAc soluble fraction was applied to a macroporous resin column eluted with $40 \%$, $70 \%$, and $85 \%$ EtOH in $\mathrm{H}_{2} \mathrm{O}$, successively. After removing the solvent, the $70 \%$ EtOH eluate $(480 \mathrm{~g}$ ) was dissolved in $5000 \mathrm{~mL}$ methanol and then filtrated in order to remove undissolved flavones. After removing residual flavones in the filtrate using Sephadex LH-20 $\left(\mathrm{MeOH} / \mathrm{CHCl}_{3}, 1: 1\right)$, an iridals-enriched portion (100 g) was obtained, which was further chromatographed on a reversed-phase $\mathrm{C}_{18}$ silica gel 
column $(80 \times 6 \mathrm{~cm})$ eluted with $50 \%, 60 \%, 70 \%, 80 \%, 90 \%$, and $100 \% \mathrm{MeOH}$ in $\mathrm{H}_{2} \mathrm{O}$ to afford 6 fractions (F1-F6). Fraction $3(9 \mathrm{~g})$ was submitted to a silica gel column and eluted with $\mathrm{CH}_{2} \mathrm{Cl}_{2} / \mathrm{MeOH}$ (25:1-15:1) to produce four subfractions (F3a-F3d), F3b was purified by preparative $\mathrm{HPLC}\left(52 \% \mathrm{MeCN}\right.$ in $\left.\mathrm{H}_{2} \mathrm{O}, 5 \mathrm{~mL} / \mathrm{min}\right)$ to yield $1\left(12 \mathrm{mg}, t_{\mathrm{R}}=86.9 \mathrm{~min}\right)$ and $2\left(23 \mathrm{mg}, t_{\mathrm{R}}=83.6 \mathrm{~min}\right)$. F3d was purified by preparative $\mathrm{HPLC}\left(65 \% \mathrm{MeOH}\right.$ in $\left.\mathrm{H}_{2} \mathrm{O}, 5 \mathrm{~mL} / \mathrm{min}\right)$ to yield $3\left(25 \mathrm{mg}, t_{\mathrm{R}}=96.7 \mathrm{~min}\right)$ and $4\left(8 \mathrm{mg}, t_{\mathrm{R}}=93.3 \mathrm{~min}\right)$.

1. Polycycloiridal A: colorless gum; $[\alpha]^{20}{ }_{\mathrm{D}}-158.4(c 0.15, \mathrm{MeOH}) ; \mathrm{UV}(\mathrm{MeOH}) \lambda_{\max }$ $(\log \varepsilon) 250(4.28) \mathrm{nm} ;$ IR $v_{\max } 3423,2928,2868,1711,1661,1614,1449,1377 \mathrm{~cm}^{-1}$; ${ }^{1} \mathrm{H} \mathrm{NMR}\left(\mathrm{CDCl}_{3}, 600 \mathrm{MHz}\right)$ and ${ }^{13} \mathrm{C} \mathrm{NMR}\left(\mathrm{CDCl}_{3}, 150 \mathrm{MHz}\right)$ see Tables $\mathrm{S} 1$ and $\mathrm{S} 2$; (+)-HRESIMS $m / z 525.3184[\mathrm{M}+\mathrm{Na}]^{+}$(calcd for $\mathrm{C}_{30} \mathrm{H}_{46} \mathrm{O}_{6} \mathrm{Na}, 525.3187$ ).

2. Polycycloiridal B: colorless gum; $[\alpha]^{20}{ }_{\mathrm{D}}-174.4(c 0.15, \mathrm{MeOH}) ; \mathrm{UV}(\mathrm{MeOH}) \lambda_{\max }$ $(\log \varepsilon) 254(4.27) \mathrm{nm}$; IR $v_{\max } 3448,2928,2871,1712,1660,1614,1445,1376 \mathrm{~cm}^{-1}$; ${ }^{1} \mathrm{H}$ NMR $\left(\mathrm{CDCl}_{3}, 600 \mathrm{MHz}\right)$ and ${ }^{13} \mathrm{C} \mathrm{NMR}\left(\mathrm{CDCl}_{3}, 150 \mathrm{MHz}\right)$ see Tables $\mathrm{S} 1$ and $\mathrm{S} 2$; (+)-HRESIMS $m / z 525.3172[\mathrm{M}+\mathrm{Na}]^{+}$(calcd for $\mathrm{C}_{30} \mathrm{H}_{46} \mathrm{O}_{6} \mathrm{Na}, 525.3187$ ).

3. Polycycloiridal C: colorless gum; $[\alpha]^{20}{ }_{\mathrm{D}}+152.1$ (c 0.15, $\left.\mathrm{MeOH}\right)$; UV $(\mathrm{MeOH})$ $\lambda_{\max }(\log \varepsilon) 249(4.15) \mathrm{nm}$; IR $v_{\max } 3418,2929,2873,1709,1662,1614,1448,1378$ $\mathrm{cm}^{-1} ;{ }^{1} \mathrm{H}$ NMR $\left(\mathrm{CDCl}_{3}, 600 \mathrm{MHz}\right)$ and ${ }^{13} \mathrm{C} \mathrm{NMR}\left(\mathrm{CDCl}_{3}, 150 \mathrm{MHz}\right)$ Tables S1 and S2; (+)-HRESIMS m/z 525.3174 [M + Na] $]^{+}$(calcd for $\mathrm{C}_{30} \mathrm{H}_{46} \mathrm{O}_{6} \mathrm{Na}, 525.3187$ ).

4. Polycycloiridal D: colorless gum; $[\alpha]^{20}{ }_{\mathrm{D}}+101.6 .3(c$ 0.15, $\mathrm{MeOH})$; UV $(\mathrm{MeOH})$ $\lambda_{\max }(\log \varepsilon) 250(4.30) \mathrm{nm} ;$ IR $v_{\max } 3455,2927,2870,1710,1661,1614,1446,1369$ $\mathrm{cm}^{-1} ;{ }^{1} \mathrm{H}$ NMR $\left(\mathrm{CDCl}_{3}, 600 \mathrm{MHz}\right)$ and ${ }^{13} \mathrm{C} \mathrm{NMR}\left(\mathrm{CDCl}_{3}, 150 \mathrm{MHz}\right)$ see Tables $\mathrm{S} 1$ and S2; (+)-HRESIMS m/z 525.3173 [M + Na] $]^{+}$(calcd for $\mathrm{C}_{30} \mathrm{H}_{46} \mathrm{O}_{6} \mathrm{Na}, 525.3187$ ). 
Table S1. ${ }^{1} \mathrm{H}$ and ${ }^{13} \mathrm{C}$ NMR data and COSY, HMBC, and NOESY correlations of compound $1^{a}$

\begin{tabular}{|c|c|c|c|c|c|}
\hline no. & $\delta_{\mathrm{H}}$ & $\delta_{\mathrm{C}}$ & $\operatorname{COSY}(\mathrm{H} \leftrightarrow \mathrm{H})$ & $\mathrm{HMBC}(\mathrm{H} \rightarrow \mathrm{C})$ & $\operatorname{NOESY}(\mathrm{H} \leftrightarrow \mathrm{H})$ \\
\hline 1 & $1.83, \mathrm{~s}$ & 10.8 & & $2,7,25$ & 6 \\
\hline 2 & & 129.2 & & & \\
\hline \multirow[t]{2}{*}{3} & $4.16, \mathrm{dt}(12.0,2.4)$ & 70.1 & $3 b, 4$ & 5,26 & $3 \mathrm{~b}, 4 \mathrm{a}$ \\
\hline & $3.58, \operatorname{td}(12.0,2.4)$ & & $3 \mathrm{a}$ & & $3 a, 4 b, 26$ \\
\hline \multirow[t]{2}{*}{4} & $1.76, \mathrm{~m}$ & 32.2 & $3 a$ & 5 & $3 a$ \\
\hline & $1.72, \mathrm{~m}$ & & & & $3 b, 5$ \\
\hline \multirow[t]{2}{*}{5} & $2.93, \mathrm{~m}$ & 31.4 & 6 & 11 & $6,4 \mathrm{~b}$ \\
\hline & $1.37, \mathrm{~m}$ & & & & \\
\hline 6 & $3.11, \mathrm{~d}(10.2)$ & 48.9 & $5 \mathrm{a}$ & $2,5,7,8,10,11,12$ & $1,5 \mathrm{a}, 12 \mathrm{~b}$ \\
\hline 7 & & 165.6 & & & \\
\hline \multirow[t]{2}{*}{8} & $3.23, \mathrm{~m}$ & 20.4 & $8 b, 9$ & 9 & $8 b, 9,25$ \\
\hline & $2.60, \mathrm{~m}$ & & $8 \mathrm{a}$ & & $8 \mathrm{a}, 9$ \\
\hline 9 & $1.67, \mathrm{~m}$ & 39.2 & $8 \mathrm{a}, 8 \mathrm{~b}$ & $8,10,11$ & $8 \mathrm{a}, 8 \mathrm{~b}$ \\
\hline 10 & & 74.2 & & & \\
\hline 11 & & 60.2 & & & \\
\hline \multirow[t]{2}{*}{12} & $1.53, \mathrm{~m}$ & 38.4 & 13 & $6,11,13$ & 14 \\
\hline & $1.27, \mathrm{~m}$ & & 13 & & $6,13,14$ \\
\hline 13 & $4.37, \mathrm{~m}$ & 79.8 & $12 \mathrm{a}, 12 \mathrm{~b}, 14$ & & $12 \mathrm{a}, 12 \mathrm{~b}, 14,28$ \\
\hline 14 & $3.88, \mathrm{~d}(5.4)$ & 78.0 & 13 & $12,13,15,16$ & $12,13,16,27$ \\
\hline 15 & & 132.0 & & & \\
\hline 16 & $5.48, \mathrm{~d}(10.2)$ & 127.5 & 17 & $14,17,22$ & 14 \\
\hline 17 & $3.19, \mathrm{~m}$ & 35.2 & 16,18 & $16,18,19,22$ & $18,24,28,30$ \\
\hline 18 & $5.04, \mathrm{~d}(4.8)$ & 122.8 & 17 & $17,20,22,29$ & 17,29 \\
\hline 19 & & 134.0 & & & \\
\hline 20 & 2.01, brd (5.4) & 31.3 & $21 \mathrm{a}$ & $18,19,21,22$ & 29 \\
\hline \multirow[t]{2}{*}{21} & $1.77, \mathrm{~m}$ & 19.3 & 20 & & \\
\hline & $1.68, \mathrm{~m}$ & & & & \\
\hline 22 & $1.57, \mathrm{~m}$ & 47.7 & 17 & 17 & \\
\hline 23 & & 72.4 & & & \\
\hline 24 & $1.19, \mathrm{~s}$ & 28.8 & & $22,23,30$ & 17 \\
\hline 25 & $10.19, \mathrm{~s}$ & 190.8 & & 1,2 & $8 \mathrm{a}$ \\
\hline 26 & $5.42, \mathrm{~s}$ & 109.6 & & $3,10,11,12,13$ & $3 b, 27$ \\
\hline 27 & $1.24, \mathrm{~s}$ & 27.8 & & $9,10,11$ & 14,26 \\
\hline 28 & $1.73, \mathrm{~s}$ & 13.3 & & $14,15,16$ & 13,17 \\
\hline 29 & $1.59, \mathrm{~s}$ & 23.3 & & $18,19,20$ & 18,20 \\
\hline 30 & $1.19, \mathrm{~s}$ & 28.2 & & $22,23,24$ & 17 \\
\hline
\end{tabular}

${ }^{a 1} \mathrm{H}$ NMR data $(\delta)$ were measured in $\mathrm{CDCl}_{3}$ at $600 \mathrm{MHz}$ 
Table S2. ${ }^{1} \mathrm{H}$ and ${ }^{13} \mathrm{C}$ NMR data of and COSY, HMBC, and NOESY correlations of compound $2^{a}$

\begin{tabular}{|c|c|c|c|c|c|}
\hline no. & $\delta_{\mathrm{H}}$ & $\delta_{\mathrm{C}}$ & $\operatorname{COSY}(\mathrm{H} \leftrightarrow \mathrm{H})$ & $\mathrm{HMBC}(\mathrm{H} \rightarrow \mathrm{C})$ & $\operatorname{NOESY}(\mathrm{H} \leftrightarrow \mathrm{H})$ \\
\hline 1 & 10.29, s & 190.2 & & $2,7,25$ & 6 \\
\hline 2 & & 129.1 & & & \\
\hline \multirow[t]{2}{*}{3} & 4.14, brd $(12.0)$ & 70.1 & $3 b, 4$ & 5,26 & $3 b, 4$ \\
\hline & $3.59, \operatorname{td}(12.0,1.8)$ & & $3 a$ & & $3 a, 4,5 a, 26$ \\
\hline 4 & $1.68, \mathrm{~m}$ & 31.4 & $3 a$ & 5 & $3 a, 3 b$ \\
\hline \multirow[t]{2}{*}{5} & $3.01, \mathrm{~m}$ & 32.4 & 6 & 6,11 & $3 b, 4,5 b, 6$ \\
\hline & $1.45, \mathrm{~m}$ & & & & $5 \mathrm{a}, 6$ \\
\hline 6 & $3.75, \mathrm{~d}(10.4)$ & 44.8 & $5 \mathrm{a}$ & $2,5,7,8,10,11,12$ & $1,5 \mathrm{a}, 5 \mathrm{~b}, 12 \mathrm{a}$ \\
\hline 7 & & 165.5 & & & \\
\hline \multirow[t]{2}{*}{8} & $2.63, \operatorname{td}(14.8,7.8)$ & 24.3 & $8 b, 9$ & $6,7,9,10$ & $8 b$ \\
\hline & 2.50, brd $(14.8)$ & & $8 \mathrm{a}$ & & $8 \mathrm{a}, 25$ \\
\hline 9 & $1.57, \mathrm{~m}$ & 38.5 & $8 \mathrm{a}, 8 \mathrm{~b}$ & 10,11 & \\
\hline 10 & & 74.0 & & & \\
\hline 11 & & 60.2 & & & \\
\hline \multirow[t]{2}{*}{12} & $1.71, \mathrm{~m}$ & 38.4 & 13 & $6,10,11,14$ & \\
\hline & $1.35, \mathrm{~m}$ & & 13 & & 6,13 \\
\hline 13 & $4.35, \mathrm{~m}$ & 79.4 & $12 \mathrm{a}, 12 \mathrm{~b}, 14$ & & $12 b, 14,28$ \\
\hline 14 & $3.87, \mathrm{~d}(4.2)$ & 77.7 & 13 & $12,13,15,16,28$ & $13,16,27$ \\
\hline 15 & & 132.1 & & & \\
\hline 16 & $5.46, \mathrm{~d}(10.2)$ & 127.2 & 17 & $14,17,22,28$ & 14,17 \\
\hline 17 & $3.17, \mathrm{~m}$ & 35.2 & $16,18,22$ & $15,16,18,19,21,22$ & $16,18,24,28,30$ \\
\hline 18 & $5.03, \mathrm{~d}(4.8)$ & 122.9 & 17 & $17,20,22,29$ & 17,29 \\
\hline 19 & & 133.9 & & & \\
\hline 20 & 2.00, brd (5.4) & 31.4 & & $18,19,21,22$ & 29 \\
\hline \multirow[t]{2}{*}{21} & $1.81, \mathrm{~m}$ & 19.3 & & & \\
\hline & $1.75, \mathrm{~m}$ & & & & \\
\hline 22 & $1.54, \mathrm{~m}$ & 47.5 & 17 & 17,23 & \\
\hline 23 & & 72.5 & & & \\
\hline 24 & $1.18, \mathrm{~s}$ & 28.8 & & $22,23,30$ & 17 \\
\hline 25 & $1.77, \mathrm{~s}$ & 10.7 & & $1,2,7$ & $8 \mathrm{~b}$ \\
\hline 26 & $5.44, \mathrm{~s}$ & 109.5 & & $3,10,11,12,13$ & $3 b, 27$ \\
\hline 27 & $1.23, \mathrm{~s}$ & 27.9 & & $9,10,11$ & 14,26 \\
\hline 28 & $1.71, \mathrm{~s}$ & 13.4 & & $14,15,16$ & 13,17 \\
\hline 29 & $1.59, \mathrm{~s}$ & 23.3 & & $18,19,20$ & 18,20 \\
\hline 30 & $1.17, \mathrm{~s}$ & 28.1 & & $22,23,24$ & 17 \\
\hline
\end{tabular}

${ }^{a} \mathrm{H}_{\mathrm{NMR}}$ data $(\delta)$ were measured in $\mathrm{CDCl}_{3}$ at $600 \mathrm{MHz}$ 
Table S3. ${ }^{1} \mathrm{H}$ and ${ }^{13} \mathrm{C}$ NMR data of and COSY, HMBC and NOESY correlations of compound $3^{a}$

\begin{tabular}{|c|c|c|c|c|c|}
\hline no. & $\delta_{\mathrm{H}}$ & $\delta_{\mathrm{C}}$ & $\operatorname{COSY}(\mathrm{H} \leftrightarrow \mathrm{H})$ & $\mathrm{HMBC}(\mathrm{H} \rightarrow \mathrm{C})$ & $\operatorname{NOESY}(\mathrm{H} \leftrightarrow \mathrm{H})$ \\
\hline 1 & $1.76, \mathrm{~s}$ & 10.7 & & $2,7,25$ & 6 \\
\hline 2 & & 129.1 & & & \\
\hline \multirow[t]{2}{*}{3} & $4.14, \mathrm{dt}(12.0,1.8)$ & 69.6 & $3 b, 4$ & 4,26 & $3 b, 4$ \\
\hline & $3.57, \operatorname{td}(12.0,2.4)$ & & $3 a$ & & $3 a, 4,5 a, 26$ \\
\hline 4 & $1.73, \mathrm{~m}$ & 31.4 & $3 \mathrm{a}$ & 6 & $3 a, 3 b, 5 a$ \\
\hline \multirow[t]{2}{*}{5} & $2.92, \mathrm{~m}$ & 31.0 & $4,5 b$ & $4,6,11$ & $3 b, 4,5 b$ \\
\hline & $1.36, \mathrm{~m}$ & & $5 \mathrm{a}$ & & $5 \mathrm{a}, 6$ \\
\hline 6 & $3.06, \mathrm{~d}(10.2)$ & 48.6 & $5 b$ & $2,5,7,8,10,11,12$ & $1,5 b, 12 b, 13$ \\
\hline 7 & & 165.9 & & & \\
\hline \multirow[t]{2}{*}{8} & $3.20, \mathrm{~m}$ & 20.4 & $8 b, 9$ & $2,6,7,9,10$ & $8 b, 9,25$ \\
\hline & $2.58, \mathrm{~m}$ & & $8 \mathrm{a}$ & & $8 \mathrm{a}$ \\
\hline 9 & $1.68, \mathrm{~m}$ & 39.3 & $8 \mathrm{a}, 8 \mathrm{~b}$ & $7,8,10,11$ & $8 a$ \\
\hline 10 & & 74.5 & & & \\
\hline 11 & & 59.8 & & & \\
\hline \multirow[t]{2}{*}{12} & $1.60, \mathrm{~m}$ & 35.7 & 13 & $6,10,11,14,26$ & \\
\hline & $1.04, \mathrm{~m}$ & & 13 & & 6,13 \\
\hline 13 & $4.45, \mathrm{~m}$ & 79.7 & $12 \mathrm{a}, 12 \mathrm{~b}$ & 14 & $6,12 b, 28$ \\
\hline 14 & 4.34, brs & 74.0 & & $12,13,15,16,28$ & 16,27 \\
\hline 15 & & 130.9 & & & \\
\hline 16 & $5.56, \mathrm{~d},(10.2)$ & 125.3 & 17 & $14,17,22,28$ & 14,17 \\
\hline 17 & $3.13, \mathrm{~m}$ & 35.1 & $16,18,22$ & $15,16,18,19,21,22$ & $16,18,24,28,30$ \\
\hline 18 & $5.06, \mathrm{~d}(4.8)$ & 122.9 & 17 & $17,20,22,29$ & 17,29 \\
\hline 19 & & 133.8 & & & \\
\hline 20 & 1.97, brd $(6.0)$ & 31.9 & & $18,19,21,22$ & 29 \\
\hline \multirow[t]{2}{*}{21} & $1.76, \mathrm{~m}$ & 19.2 & & & \\
\hline & $1.58, \mathrm{~m}$ & & & & \\
\hline 22 & $1.56, \mathrm{~m}$ & 47.6 & 17 & $17,21,23$ & \\
\hline 23 & & 72.5 & & & \\
\hline 24 & $1.06, \mathrm{~s}$ & 28.5 & & $22,23,30$ & 17 \\
\hline 25 & $10.17, \mathrm{~s}$ & 190.9 & & 1,2 & $8 \mathrm{a}$ \\
\hline 26 & $5.40, \mathrm{~s}$ & 109.8 & & $3,10,11,12,13$ & $3 b, 27$ \\
\hline 27 & $1.26, \mathrm{~s}$ & 27.5 & & $9,10,11$ & 14,26 \\
\hline 28 & $1.65, \mathrm{~s}$ & 13.9 & & $14,15,16$ & 13,17 \\
\hline 29 & $1.59, \mathrm{~s}$ & 23.3 & & $18,19,20$ & 18,20 \\
\hline 30 & $1.00, \mathrm{~s}$ & 27.5 & & $22,23,24$ & 17 \\
\hline
\end{tabular}

${ }^{a}{ }^{1} \mathrm{H}$ NMR data $(\delta)$ were measured in $\mathrm{CDCl}_{3}$ at $600 \mathrm{MHz}$ 
Table S4. ${ }^{1} \mathrm{H}$ and ${ }^{13} \mathrm{C}$ NMR data of and COSY, HMBC, and NOESY correlations of compound $4^{a}$

\begin{tabular}{|c|c|c|c|c|c|}
\hline no. & $\delta_{\mathrm{H}}$ & $\delta_{\mathrm{C}}$ & $\operatorname{COSY}(\mathrm{H} \leftrightarrow \mathrm{H})$ & $\mathrm{HMBC}(\mathrm{H} \rightarrow \mathrm{C})$ & $\operatorname{NOESY}(\mathrm{H} \leftrightarrow \mathrm{H})$ \\
\hline 1 & $10.26, \mathrm{~s}$ & 189.9 & & 2,25 & 6 \\
\hline 2 & & 129.3 & & & \\
\hline \multirow[t]{2}{*}{3} & $4.17, \mathrm{dt}(12.0,2.4)$ & 70.0 & $3 b, 4 a$ & 5,26 & $3 b, 4 a$ \\
\hline & $3.58, \operatorname{td}(12.0,3.0)$ & & $3 a, 4 b$ & & $3 a, 4 b, 5 a, 26$ \\
\hline \multirow[t]{2}{*}{4} & $1.75, \mathrm{~m}$ & 31.4 & $3 a$ & 5 & $3 a$ \\
\hline & $1.71, \mathrm{~m}$ & & $3 b$ & & $3 b$ \\
\hline \multirow[t]{2}{*}{5} & $2.98, \mathrm{~m}$ & 32.3 & $5 b, 6$ & 6,11 & $3 b, 4 b, 5 b, 26$ \\
\hline & $1.48, \mathrm{~m}$ & & $5 \mathrm{a}$ & & $5 a, 6$ \\
\hline 6 & $3.75, \mathrm{~d}(10.2)$ & 44.5 & $5 \mathrm{a}$ & $2,5,7,8,10,11,12$ & $1,5 a, 5 b, 12 b, 13$ \\
\hline 7 & & 165.1 & & & \\
\hline \multirow[t]{2}{*}{8} & $2.62, \mathrm{~m}$ & 24.3 & $8 b, 9$ & $2,6,7,9,10$ & $8 b, 9$ \\
\hline & $2.52, \mathrm{~m}$ & & $8 a, 9$ & & $8 a, 9,25$ \\
\hline 9 & $1.65, \mathrm{~m}$ & 38.6 & $8 \mathrm{a}, 8 \mathrm{~b}$ & $8,10,11$ & $8 \mathrm{a}, 8 \mathrm{~b}$ \\
\hline 10 & & 74.7 & & & \\
\hline 11 & & 59.7 & & & \\
\hline \multirow[t]{2}{*}{12} & $1.60, \mathrm{~m}$ & 36.1 & 13 & $6,11,14$ & \\
\hline & $1.15, \mathrm{~m}$ & & 13 & & 6,13 \\
\hline 13 & $4.47, \mathrm{~m}$ & 79.3 & $12 a, 12 b$ & 14 & $6,12 b, 14,28$ \\
\hline 14 & 4.36 , brs & 74.0 & & $12,13,15,16$ & $13,16,27$ \\
\hline 15 & & 131.0 & & & \\
\hline 16 & $5.61, \mathrm{~d}(10.2)$ & 125.0 & 17 & $14,17,28$ & 14,17 \\
\hline 17 & $3.14, \mathrm{~m}$ & 35.1 & $16,18,22$ & $15,16,19,21$ & $16,18,29,30$ \\
\hline 18 & $5.08, \mathrm{~d}(4.8)$ & 122.9 & 17 & $17,20,22,29$ & 17,29 \\
\hline 19 & & 133.9 & & & \\
\hline 20 & 1.99, brd $(5.4)$ & 31.3 & & $18,19,22$ & 29 \\
\hline \multirow[t]{2}{*}{21} & $1.78, \mathrm{~m}$ & 19.3 & & & \\
\hline & $1.63, \mathrm{~m}$ & & & & \\
\hline 22 & $1.57, \mathrm{~m}$ & 47.6 & 17 & $17,21,23$ & \\
\hline 23 & & 72.5 & & & \\
\hline 24 & $1.08, \mathrm{~s}$ & 28.6 & & $22,23,30$ & \\
\hline 25 & $1.80, \mathrm{~s}$ & 10.8 & & $1,2,7$ & $8 b$ \\
\hline 26 & $5.42, \mathrm{~s}$ & 109.8 & & $3,10,11,12,13$ & $3 \mathrm{~b}, 5 \mathrm{a}, 27$ \\
\hline 27 & $1.26, \mathrm{~s}$ & 28.0 & & $9,10,11$ & 14,26 \\
\hline 28 & $1.65, \mathrm{~s}$ & 14.2 & & $14,15,16$ & 13,17 \\
\hline 29 & $1.61, \mathrm{~s}$ & 23.4 & & $18,19,20$ & $17,18,20$ \\
\hline 30 & $1.01, \mathrm{~s}$ & 27.5 & & $22,23,24$ & 17 \\
\hline
\end{tabular}

${ }^{a}{ }^{1} \mathrm{H}$ NMR data $(\delta)$ were measured in $\mathrm{CDCl}_{3}$ at $600 \mathrm{MHz}$ 
Preparation of the $(\boldsymbol{R})$ - and $(\boldsymbol{S})$-MTPA Ester Derivatives. Compound $1(1.5 \mathrm{mg})$ was transferred into a clean NMR tube and was dried completely under vacuum. Pyridine- $d_{5}(0.5 \mathrm{~mL})$ and $(R)$-MTPA chloride $(2 \mu \mathrm{L})$ were added into the NMR tube immediately under $\mathrm{N}_{2}$ gas stream, and then the NMR tube was shaken carefully to mix the sample and MTPA chloride evenly. The reaction NMR tube was conserved in a water bath at $40^{\circ} \mathrm{C}$ for $12 \mathrm{~h} .{ }^{1} \mathrm{HNMR}$ data of the $(S)$-MTPA ester $(\mathbf{1 s})$ of $\mathbf{1}(600 \mathrm{MHz}$, pyridine- $d_{5}$, data were assigned on the basis of the correlation of the ${ }^{1} \mathrm{H}-{ }^{1} \mathrm{H}$ COSY spectrum): $\delta_{\mathrm{H}} 10.433(1 \mathrm{H}, \mathrm{s}, \mathrm{H}-25), 6.058(1 \mathrm{H}, \mathrm{d}, J=10.2 \mathrm{~Hz}, \mathrm{H}-16), 5.888(1 \mathrm{H}, \mathrm{d}, J$ $=8.4 \mathrm{~Hz}, \mathrm{H}-14), 5.826(1 \mathrm{H}, \mathrm{s}, \mathrm{H}-26), 5.077(1 \mathrm{H}, \mathrm{d}, J=4.8 \mathrm{~Hz}, \mathrm{H}-18), 4.932(1 \mathrm{H}, \mathrm{m}$, H-13), 3.322 (1H, m, H-17), 1.872 (3H, s, H-28), 1.669 (H, m, H-12a), 1.595 (1H, m , H-12b). The (R)-MTPA ester (1r) of 1 was prepared using $(S)$-MTPA chloride $(2 \mu \mathrm{L})$ by the same procedure mentioned above. ${ }^{1} \mathrm{H}$ NMR data of $1 \mathbf{r}\left(600 \mathrm{MHz}\right.$, pyridine- $\left.d_{5}\right)$ : $\delta_{\mathrm{H}} 10.435(1 \mathrm{H}, \mathrm{s}, \mathrm{H}-25), 6.018(1 \mathrm{H}, \mathrm{d}, J=10.2 \mathrm{~Hz}, \mathrm{H}-16), 5.872(1 \mathrm{H}, \mathrm{s}, \mathrm{H}-26), 5.820$ $(1 \mathrm{H}, \mathrm{d}, J=8.4 \mathrm{~Hz}, \mathrm{H}-14), 5.030(1 \mathrm{H}, \mathrm{d}, J=4.8 \mathrm{~Hz}, \mathrm{H}-18), 4.958(1 \mathrm{H}, \mathrm{m}, \mathrm{H}-13)$, 3.262 (1H, m, H-17), 1.688 (3H, s, H-28), 1.691 (H, m, H-12a), 1.581 (H, m, H-12b). Chemical shift differences $\left(\Delta \delta_{S-R}\right)$ indicated the absolute configuration of C-14 of 1 to be $R$.

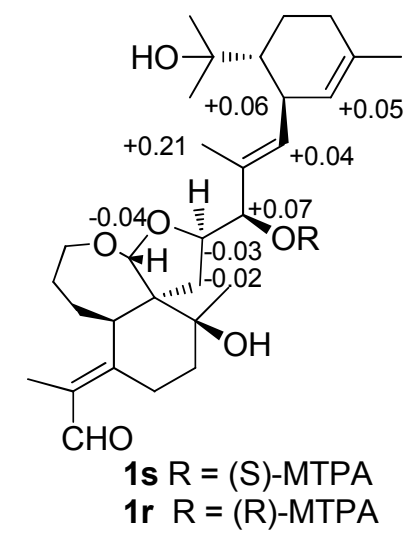

Figure S1. Values of $\Delta \delta_{S}-\Delta \delta_{R}$ of the MTPA esters of 1. 


\section{Computational Section.}

Systematic conformational analyses for compounds $\mathbf{1}$ and $\mathbf{4}$ were performed via Confab using the MMFF94 force field calculation. Conformers with Boltzmann distribution over $1 \%$ were chosen as the beginning for ECD calculations. Ground-state geometries were optimized at the B3LYP/6-311G** level by the Gaussian09 program package and vibrational analysis was done to confirm these minima. TD-DFT at the same level was employed to calculate excitation energy and rotatory strength. The predicted rotatory strengths were simulated into an ECD curve by using the Gaussian function

$$
\Delta \varepsilon(\lambda)=\frac{1}{2.297 \times 10^{-39}} \frac{1}{\sigma \sqrt{\pi}} \sum_{i=1}^{n} \lambda_{i} R_{i} \exp \left[-\left\{\frac{\left(\lambda-\lambda_{i}\right)}{\sigma}\right\}^{2}\right]
$$

Where $\lambda$ is the wavelength in $\mathrm{nm}, R_{i}$ are the rotatory strengths for transition $i$, respectively. $\sigma$ is the half width of the band at $1 / e$ height and $\sigma=0.4 \mathrm{eV}$ was used. The Self-Consistent Reaction Field method (SCRF) with the C-Polarizable Continuum Model (CPCM) was further employed to perform the conformational analysis and ECD calculation in methanol solution at B3LYP/6-311G** level. The overall theoretical ECD spectra were obtained based on the Boltzmann weighting of each conformers. Finally, the molecular orbitals (MOs) were generated by GaussView 5.0 for further analysis of Cotton effect. 
Table S5. Energies of the conformers with Boltzmann distribution over $1 \%$.

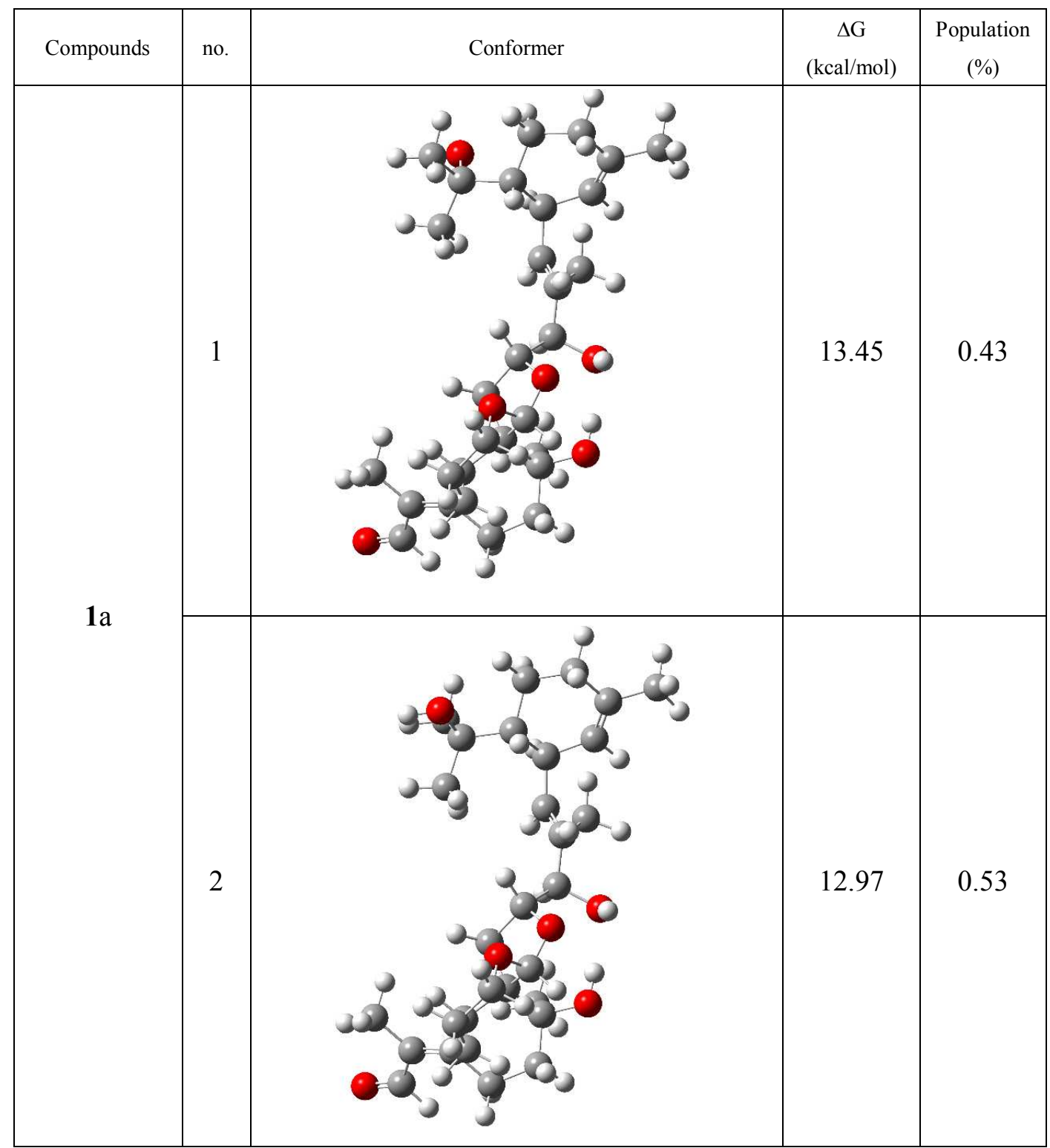




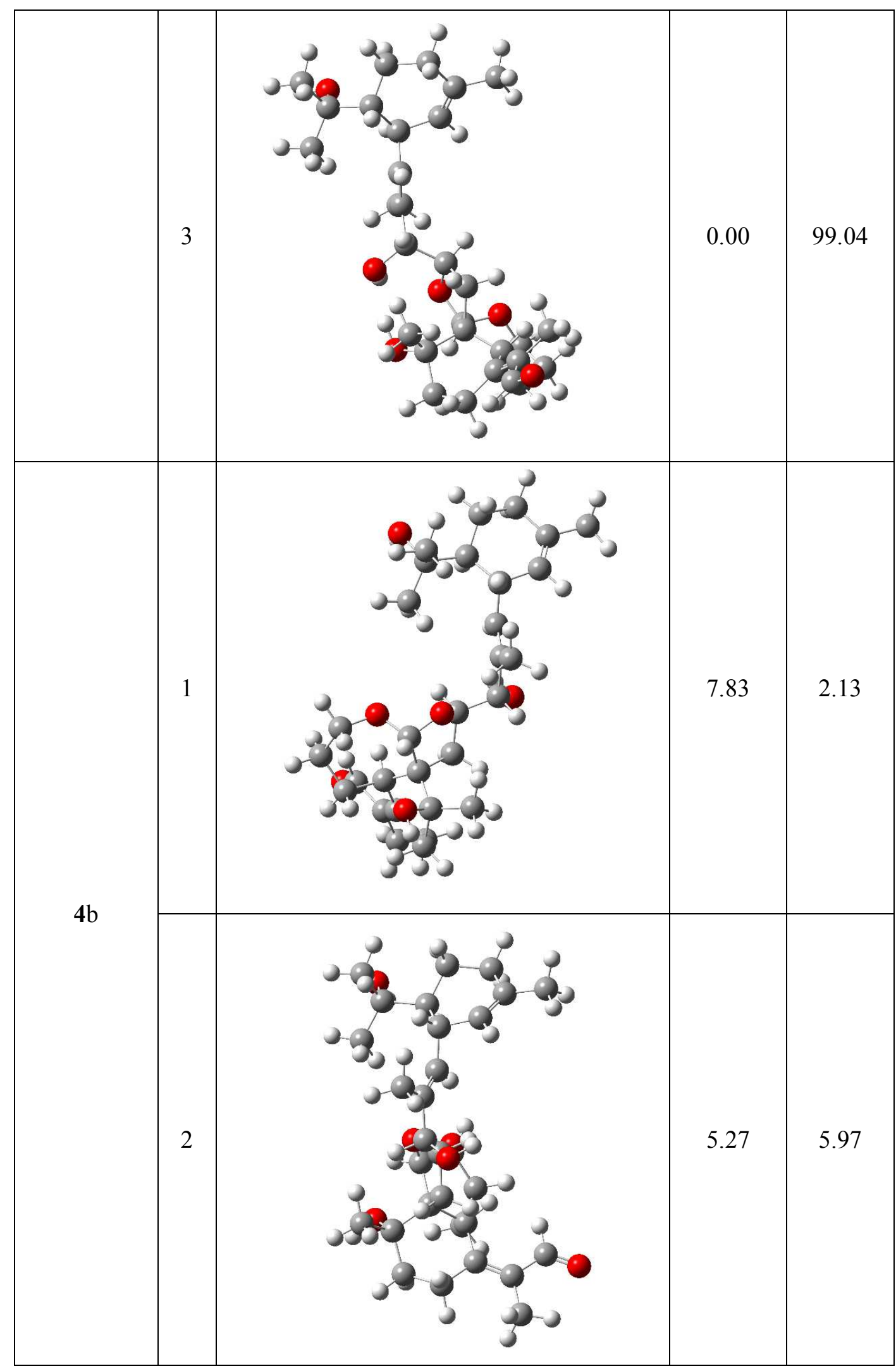




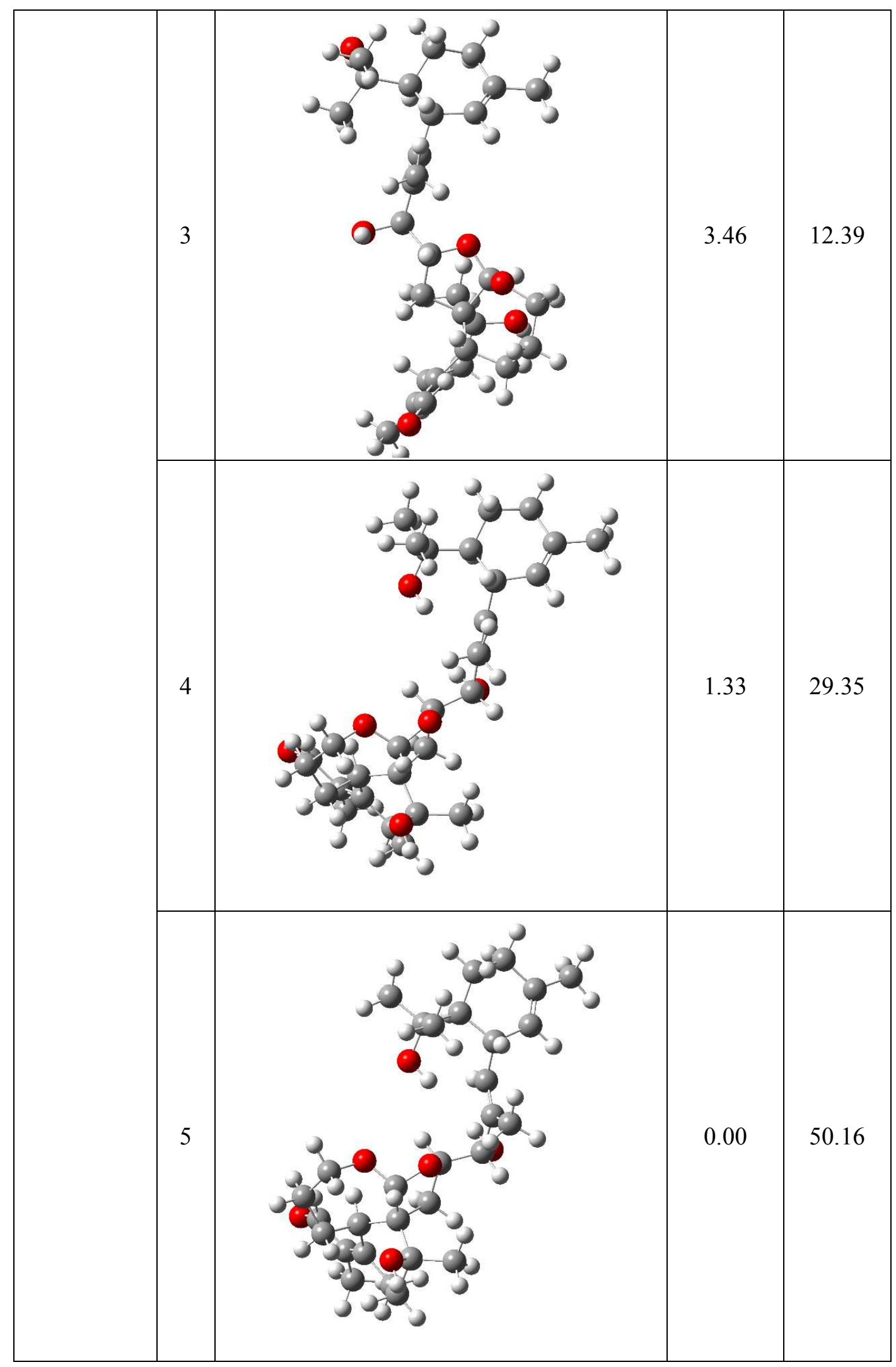


Table S6. Energies and vibrational analysis of compounds 1a, 1b, 4a, and $4 \mathrm{~b}$.

\begin{tabular}{|c|c|c|c|c|c|}
\hline Compounds & Conformation & Energy (A.U.) & $\begin{array}{c}\text { Energy } \\
(\mathrm{kcal} / \mathrm{mol})\end{array}$ & $\begin{array}{c}\text { Boltzmann } \\
(\%)\end{array}$ & $\begin{array}{l}\text { Number of } \\
\text { imaginary } \\
\text { frequencies }\end{array}$ \\
\hline \multirow[t]{3}{*}{ 1a } & 1 & -1622.6045822 & -1018199.740 & 0.43 & 0 \\
\hline & 2 & -1622.6047661 & -1018199.855 & 0.53 & 0 \\
\hline & 3 & -1622.6097052 & -1018199.855 & 99.04 & 0 \\
\hline \multirow[t]{3}{*}{$1 b$} & 1 & -1622.6116216 & -1018204.157 & 40.25 & 0 \\
\hline & 2 & -1622.6085107 & -1018202.205 & 1.49 & 0 \\
\hline & 3 & -1622.6119706 & -1018204.376 & 58.26 & 0 \\
\hline \multirow[t]{3}{*}{$4 a$} & 1 & -1622.6046805 & -1018199.801 & 0.64 & 0 \\
\hline & 2 & -1622.6046805 & -1018199.801 & 0.64 & 0 \\
\hline & 3 & -1622.6094315 & -1018202.783 & 98.72 & 0 \\
\hline \multirow{6}{*}{$4 b$} & 1 & -1622.6103297 & -1018203.346 & 2.13 & 0 \\
\hline & 2 & -1622.6113041 & -1018203.958 & 5.97 & 0 \\
\hline & 3 & -1622.6119930 & -1018204.390 & 12.39 & 0 \\
\hline & 4 & -1622.6128066 & -1018204.901 & 29.35 & 0 \\
\hline & 5 & -1622.6133124 & -1018205.218 & 50.16 & 0 \\
\hline & 6 & -1622.5895300 & -1018190.294 & -- & 1 \\
\hline
\end{tabular}


A

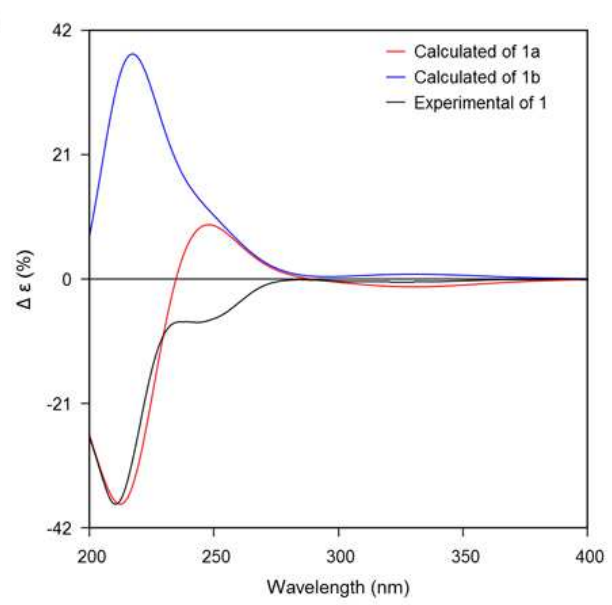

B

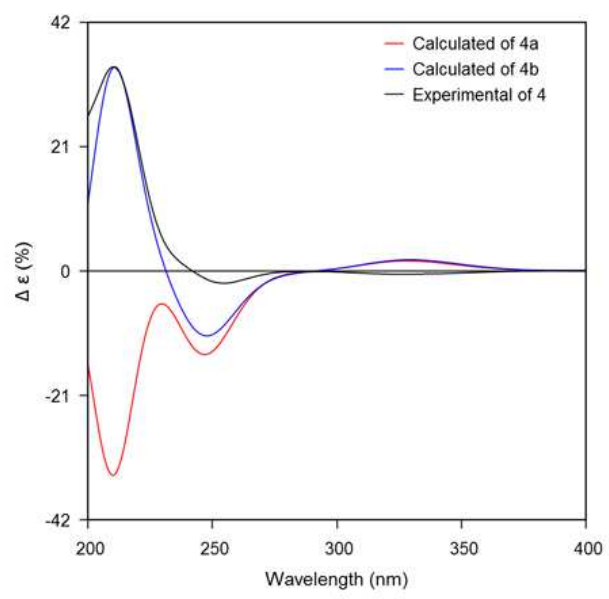

Figure S2. Experimental ECD spectrum of 1 and 4 calculated ECD spectra of 1a, $1 \mathrm{~b}, 4 \mathrm{a}$, and $4 \mathrm{~b}$ in $\mathrm{MeOH}$.

A

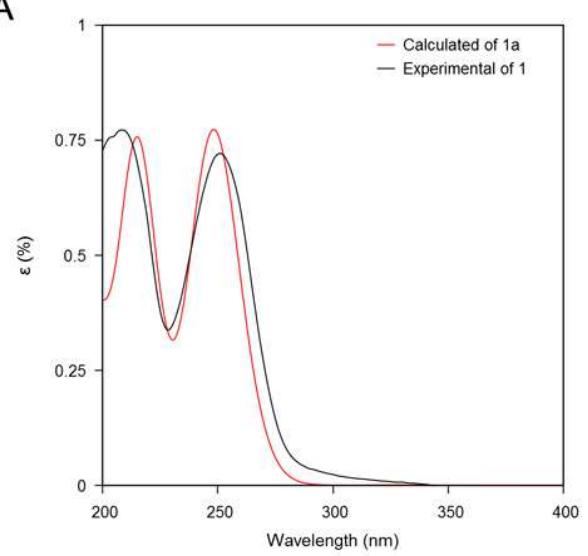

B

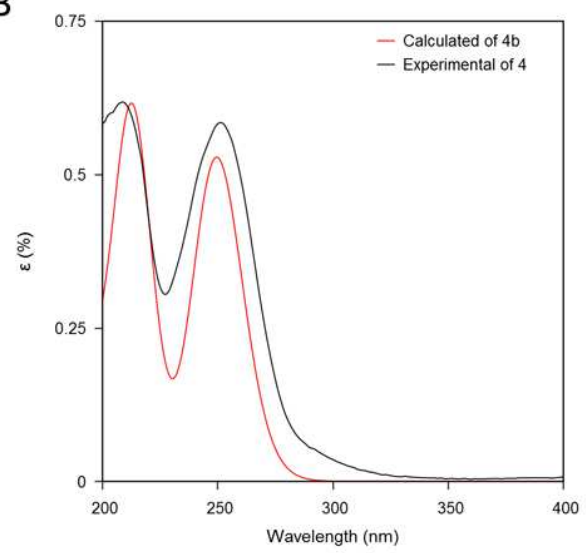

Figure S3. The experimental UV spectrum of 1 and 4 and the calculated UV spectrum of $1 \mathrm{a}$ and $4 \mathrm{~b}$.

The calculated UV and ECD spectra of 1a were in good agreement with the experimental UV and ECD spectra of 1 (Figure S2 and Figure S3). This allowed the assignment of the $(17 S, 22 R)$-configuration for the $\alpha$-terpineol moiety in $\mathbf{1}$. The calculated UV and ECD spectra of $4 \mathrm{~b}$ were in accord with the experimental data of 4 . Thus, the absolute configuration of the $\alpha$-terpineol moiety in $\mathbf{4}$ were determined as $(17 R, 22 S)$.

The molecular orbitals involved in key transitions for the ECD of $\mathbf{4}$ are shown in Figure S5. The negative at about $254 \mathrm{~nm}$ was typically associated with $\pi \rightarrow \pi^{*}$ 
electronic transition of conjugated carbonyl group from MO135 to MO138. The positive Cotton effect around $210 \mathrm{~nm}$ is a contribution from the $\pi \rightarrow \pi^{*}$ electronic transition of the two isolated double bonds from MO137 to MO139. The molecular orbitals involved in key transitions for the ECD of $\mathbf{1}$ are shown in Figure S4. As the case of 4 , the negative Cotton effect around $210 \mathrm{~nm}$ resulted from the $\pi \rightarrow \pi^{*}$ electronic transition of the two isolated double bonds from MO137 to MO139. However, the optical rotatory strength of the 10th excited state of 4 was 86.1516 , while that of the corresponding 9th excited state of 1 was -136.7562 . Thus, they possess different signs of Cotton effects at $210 \mathrm{~nm}$.
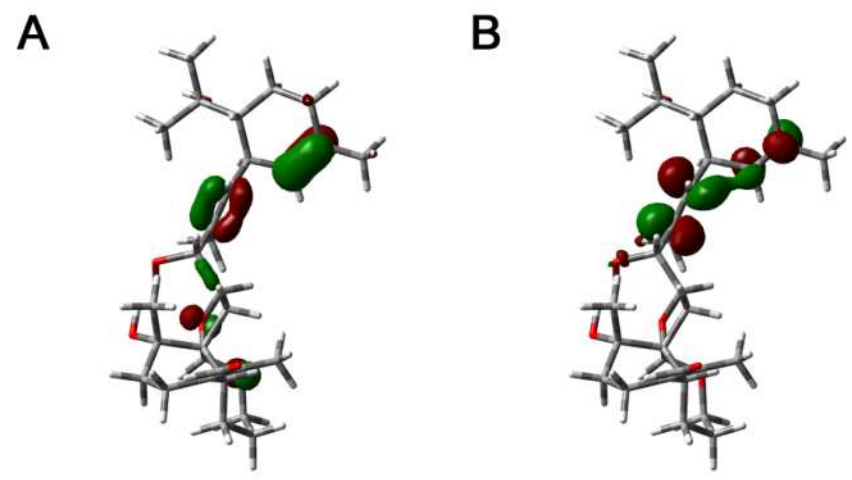

Figure S4. Molecular orbitals involved in key transitions in the calculated ECD of 1at B3LYP/6-311G** level in MeOH. ( A, MO137; B, MO139) 
A

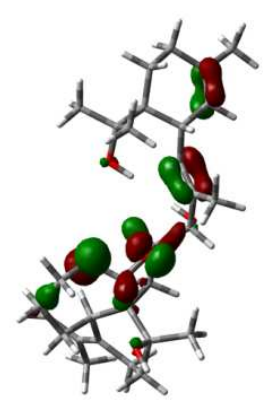

C

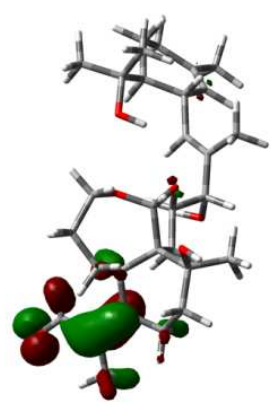

B

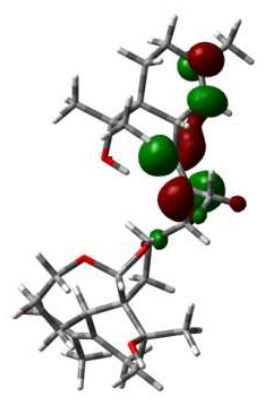

D

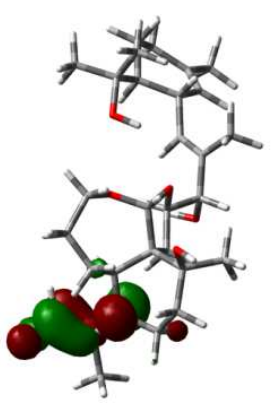

Figure S5. Molecular orbitals involved in key transitions in the calculated ECD of 4 at B3LYP/6-311G** level in MeOH. ( A, MO137; B, MO139; C, MO135; D, MO138)

Protective Effect on Cytotoxicity Induced by D-Galactosamine in HL-7702 Cells.

The hepatoprotective effects of compounds $\mathbf{1}$ and $\mathbf{2}$ were assessed by the MTT assay in HL-7702 cells. Each cell suspension supplemented with fetal calf serum (10\%), penicillin $(100 \mathrm{U} / \mathrm{mL})$, and streptomycin $(100 \mu \mathrm{g} / \mathrm{mL})$ was planted in a 96-well microplate and precultured for $24 \mathrm{~h}$ at $37{ }^{\circ} \mathrm{C}$ under a $5 \% \mathrm{CO}_{2}$ atmosphere. The cells were cultured for another $1 \mathrm{~h}$ after addition of fresh medium $(100 \mu \mathrm{L})$ containing bicyclol and test samples. Then, the cultured cells were exposed to $25 \mathrm{mM}$ D-galactosamine for $24 \mathrm{~h}$. Then, $100 \mu \mathrm{L}$ of $0.5 \mathrm{mg} / \mathrm{mL}$ MTT was added to each well after the withdrawal of the culture medium and incubated for an additional $4 \mathrm{~h}$. The resulting formazan was dissolved in $150 \mu \mathrm{L}$ of DMSO after aspiration of the culture medium. The optical density (OD) of the formazan solution was measured on a microplate reader at $492 \mathrm{~nm}$. Inhibition (\%) was obtained by the following formula:

Inhibition of D-galactosamine toxicity $(\%)=[(\mathrm{OD}($ sample $)-\mathrm{OD}($ control $)) /(\mathrm{OD}($ normal $)$ $-\mathrm{OD}($ control $))] \times 100$ 
Table S7. Hepatoprotective effects of compounds 1-4 (10 $\mu \mathrm{M})$ against D-galactosamine-induced toxicity in HL-7702 cells ${ }^{a}$

\begin{tabular}{ccc}
\hline Compounds & \% Cell survival & \% Inhibition of D-galactosamine toxicity \\
\hline Normal & $100 \pm 1.0$ & - \\
Control $^{b}$ & $70 \pm 1.9$ & - \\
Bicyclol $^{b}$ & $89 \pm 2.6^{* * *}$ & 65.0 \\
$1^{b}$ & $92 \pm 10.0^{*}$ & 77.0 \\
$2^{b}$ & $98 \pm 6.3^{* *}$ & 96.5 \\
$3^{b}$ & $94 \pm 7.0^{* *}$ & 84.1 \\
$4^{b}$ & $89 \pm 3.6^{* *}$ & 65.0 \\
\hline
\end{tabular}

${ }^{a}$ Results are expressed as means $\pm \mathrm{SD}(\mathrm{n}=3$; for normal and control, $\mathrm{n}=6)$; bicyclol was used as appositive control $(10 \mu \mathrm{M}) .{ }^{*} \mathrm{P}<0.05,{ }^{* *} \mathrm{p}<0.01,{ }^{* * *} p<0.001$. Normal (not exposed to compounds or D-galactosamine). Control (exposed to D-galactosamine but not compounds)

${ }^{b}$ In the presence of D-galactosamine.

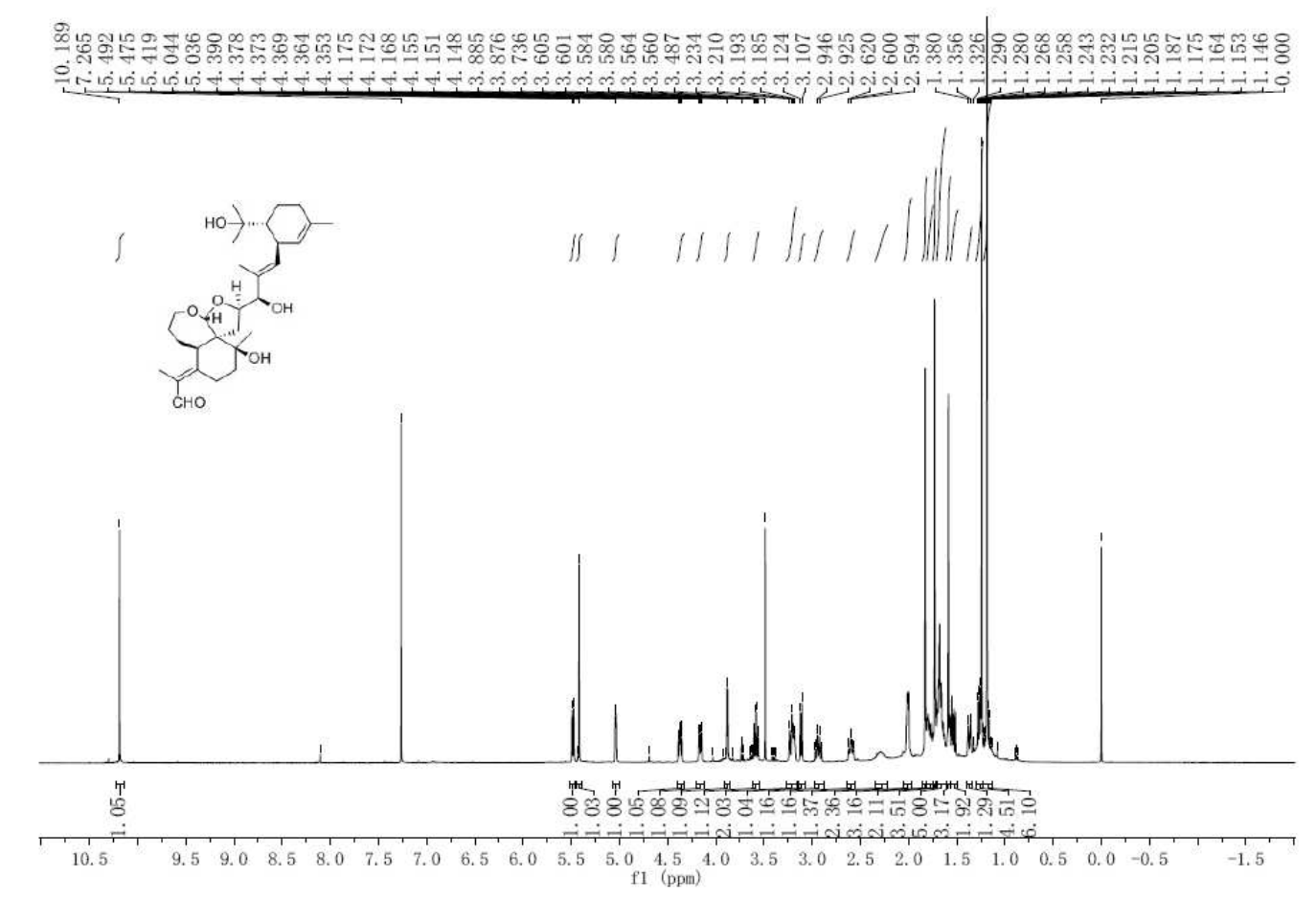

Figure S6. ${ }^{1} \mathrm{H}$ NMR spectrum of compound $1\left(600 \mathrm{MHz}, \mathrm{CDCl}_{3}\right)$ 

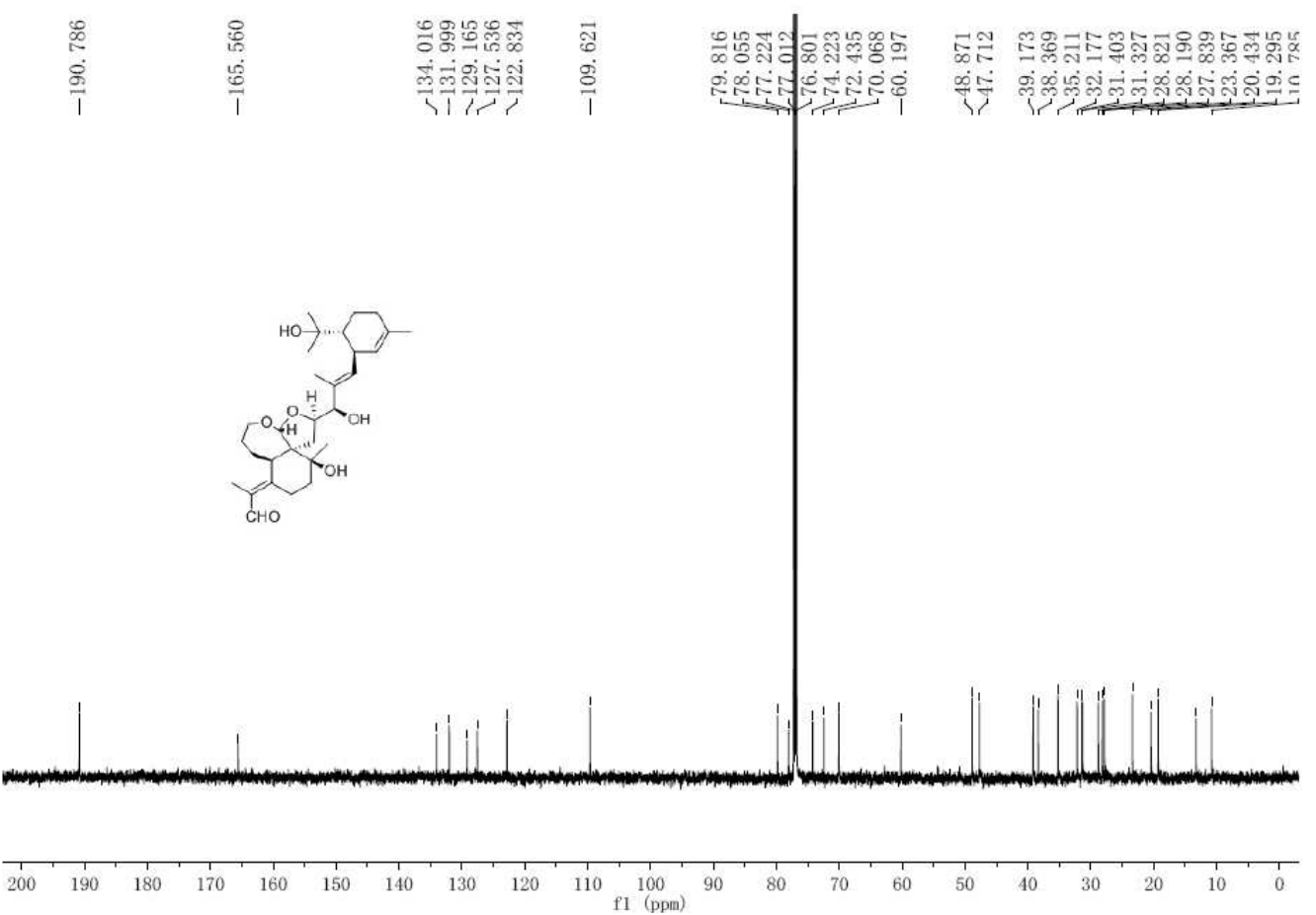

Figure S7. ${ }^{13} \mathrm{C}$ NMR spectrum of compound $1\left(150 \mathrm{MHz}, \mathrm{CDCl}_{3}\right)$

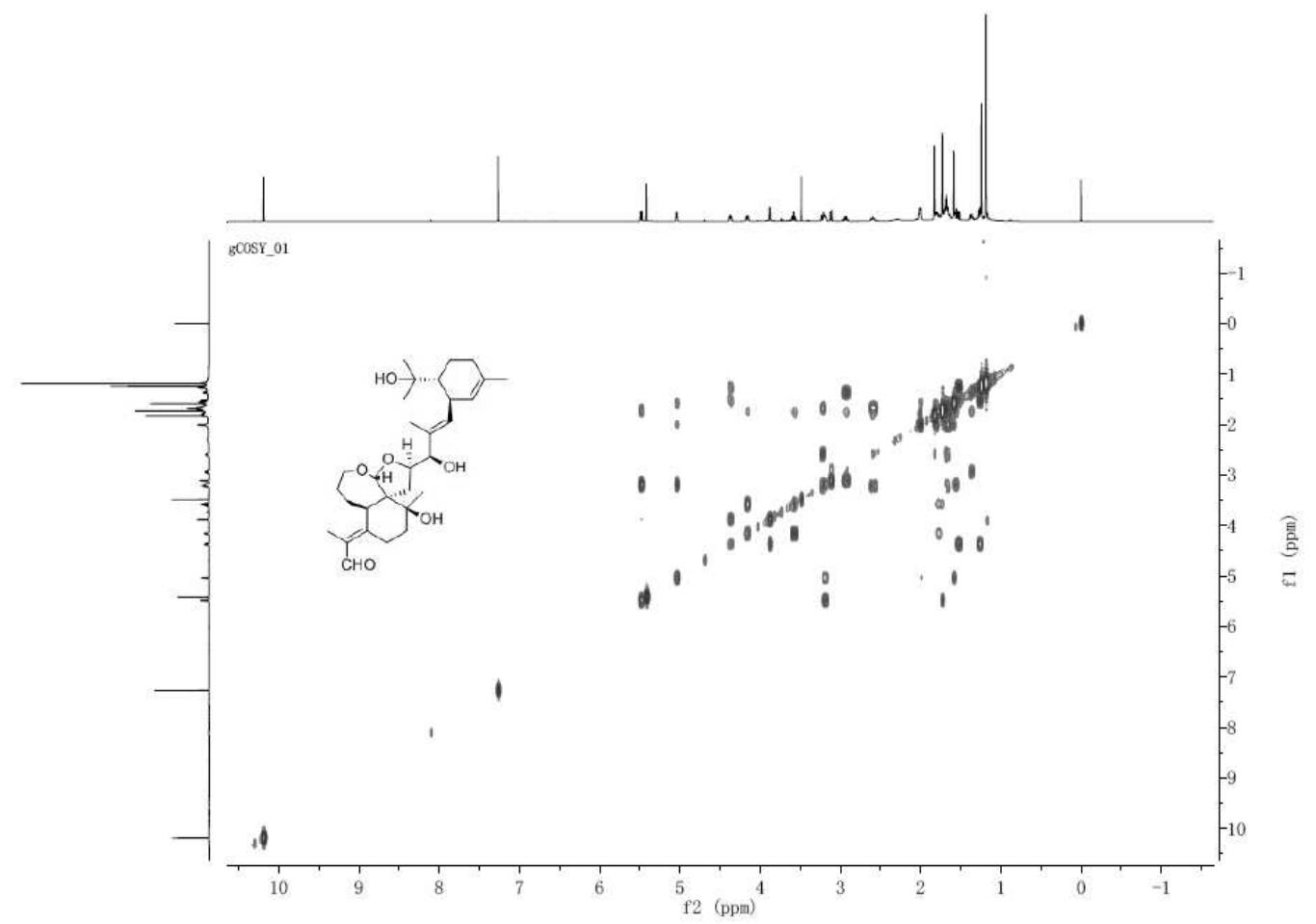

Figure S8. ${ }^{1} \mathrm{H}-{ }^{1} \mathrm{H}$ COSY spectrum of compound 1 


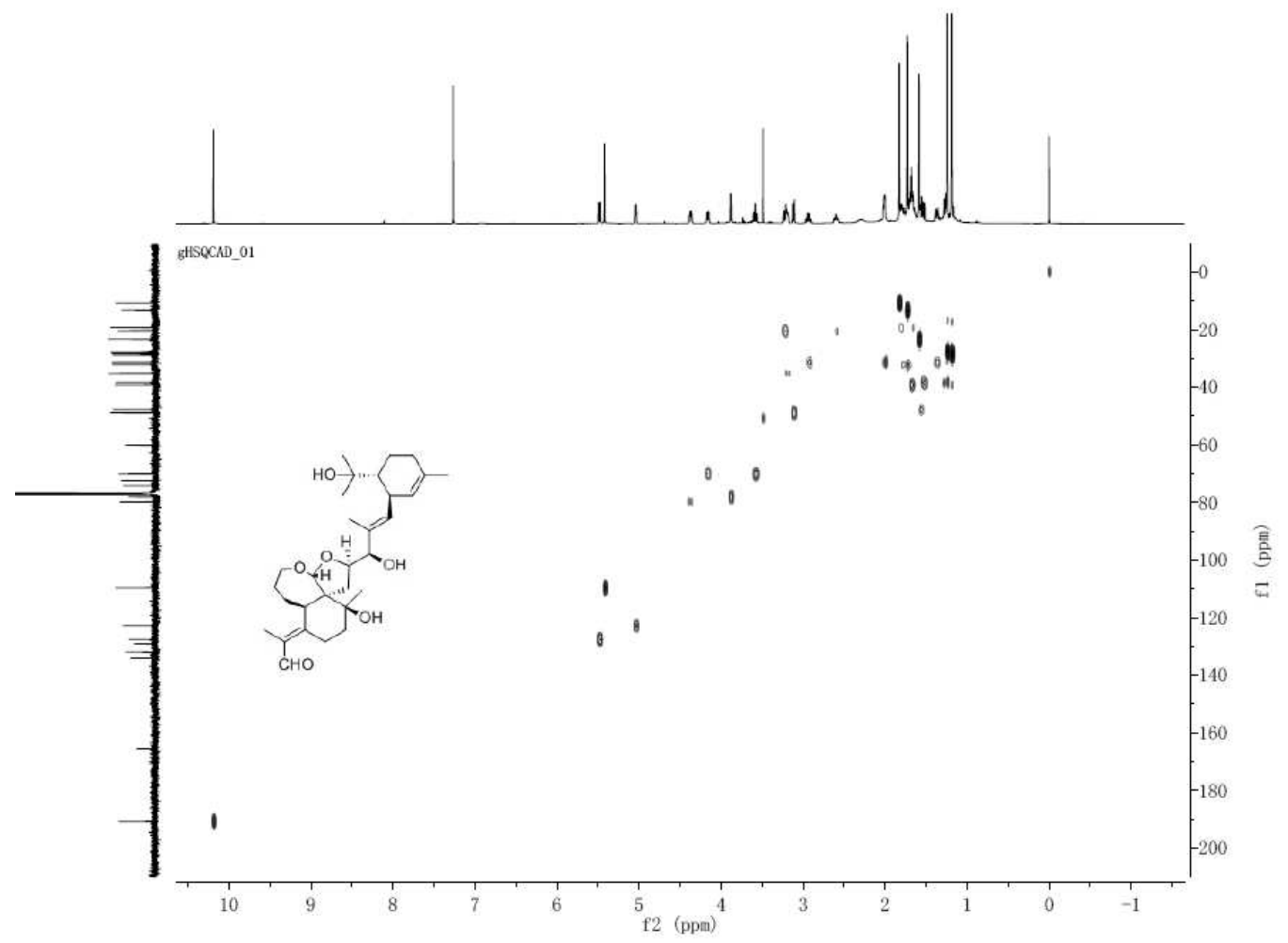

Figure S9. HSQC spectrum of compound 1

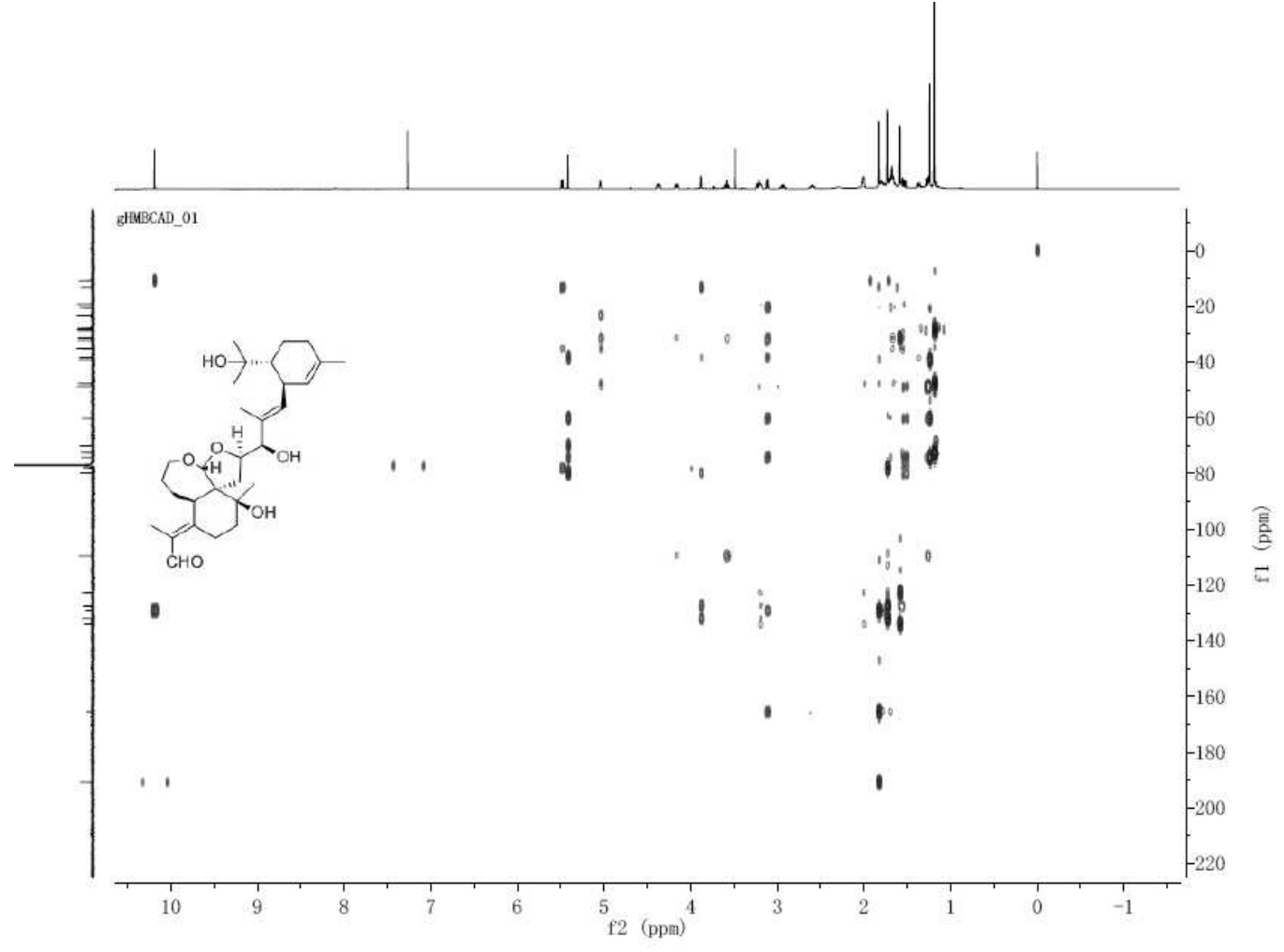

Figure S10. HMBC spectrum of compound 1 


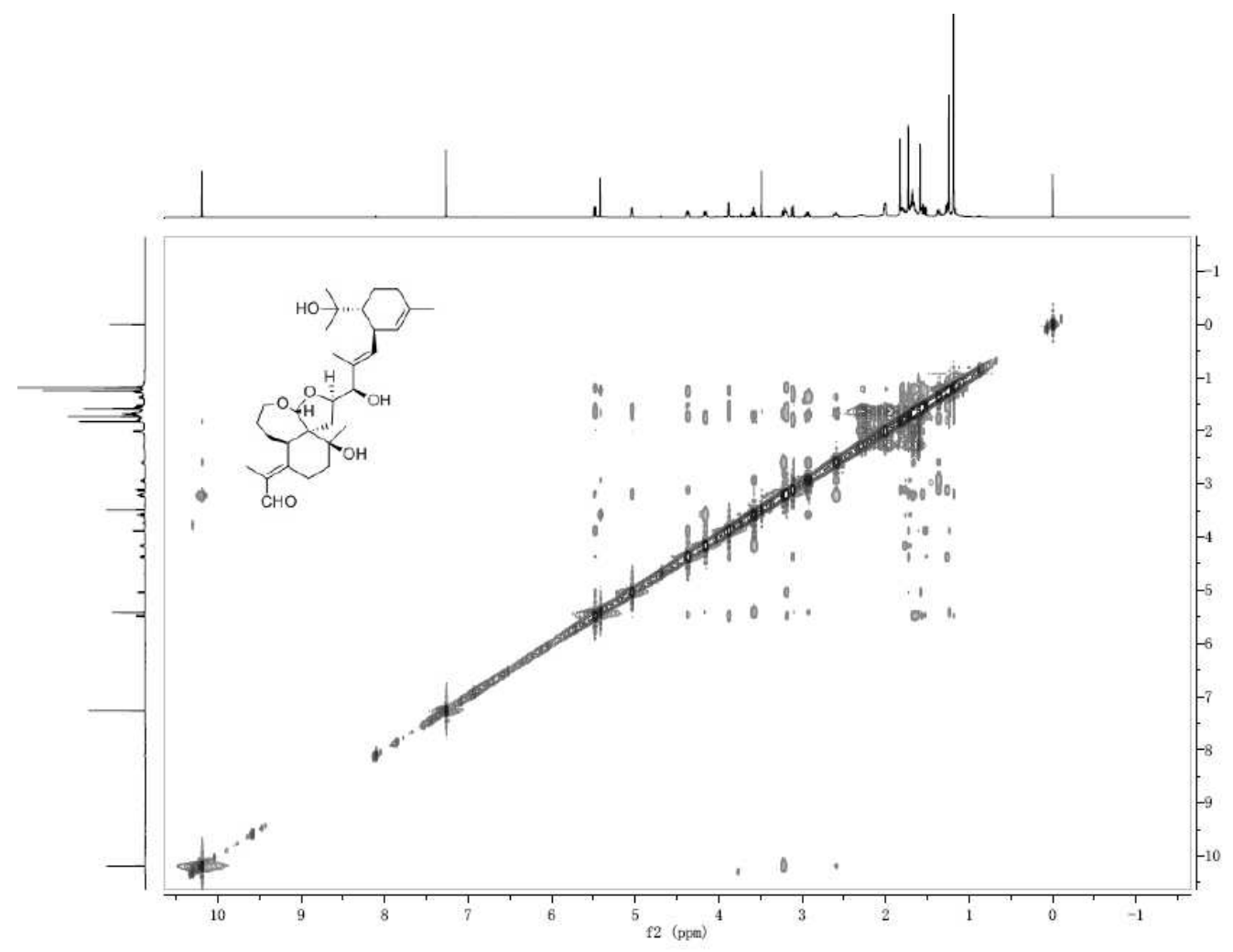

Figure S11. NOESY spectrum of compound 1 


\section{Qualitative Analysis Report}

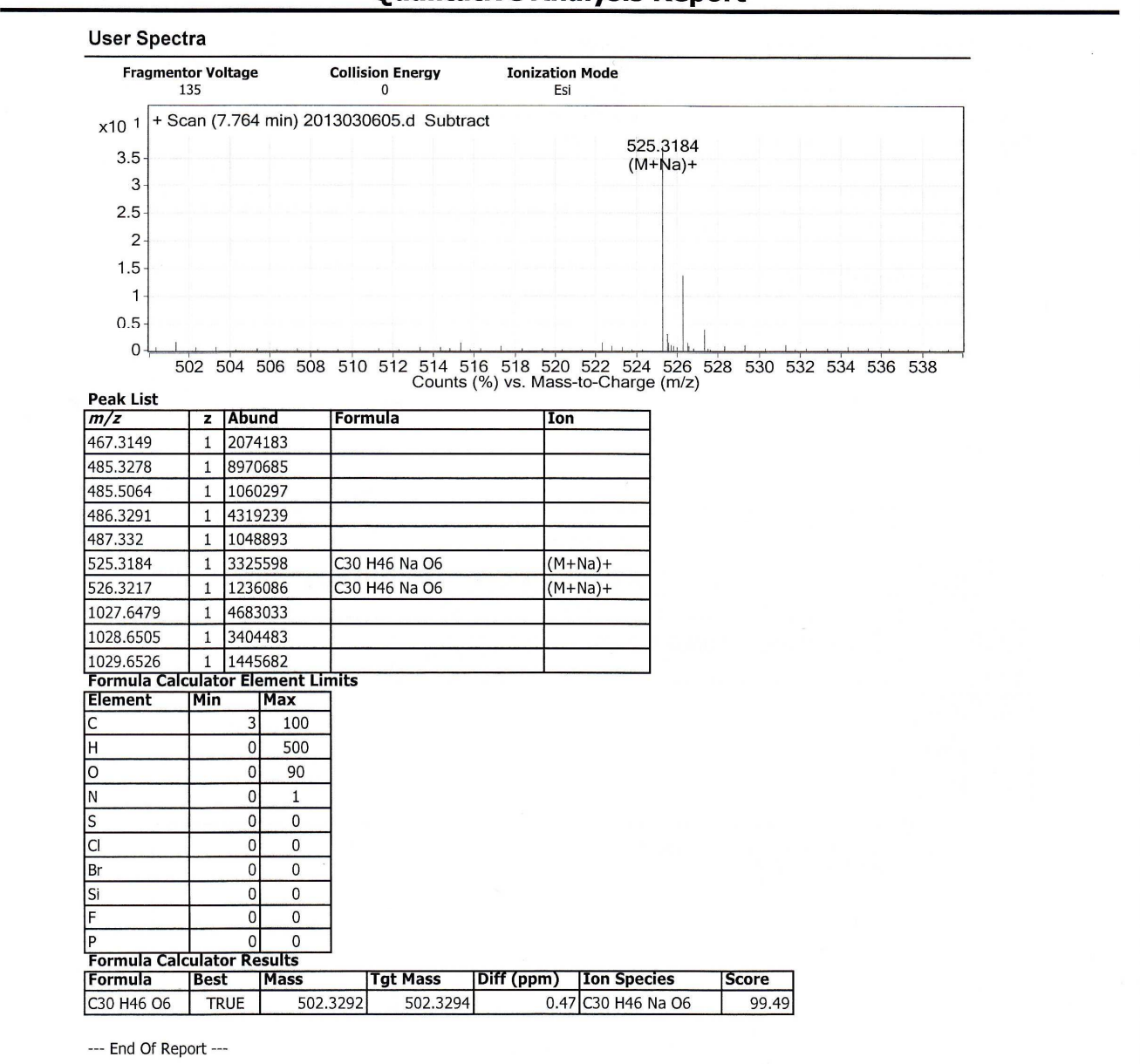

MS Formula Results: + Scan (7.764 min) Sub (2013030605.d)

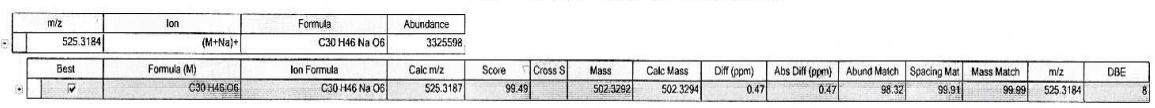

Figure S12. HRESIMS spectrum of compound 1 


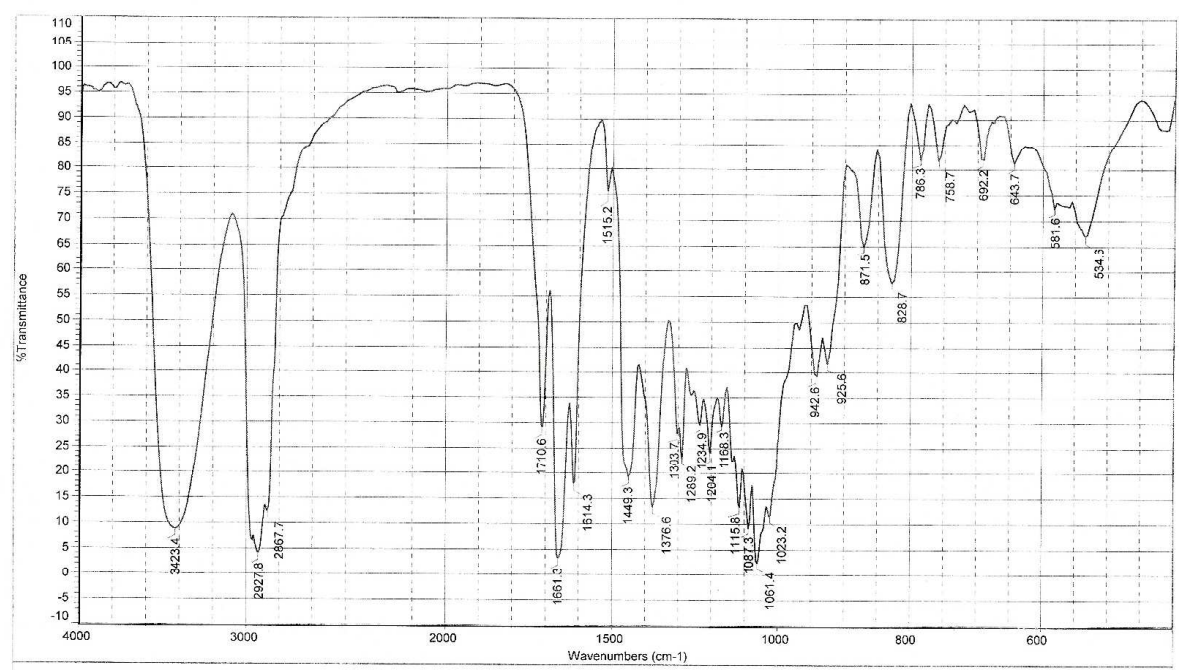

Figure S13. IR spectrum of compound 1

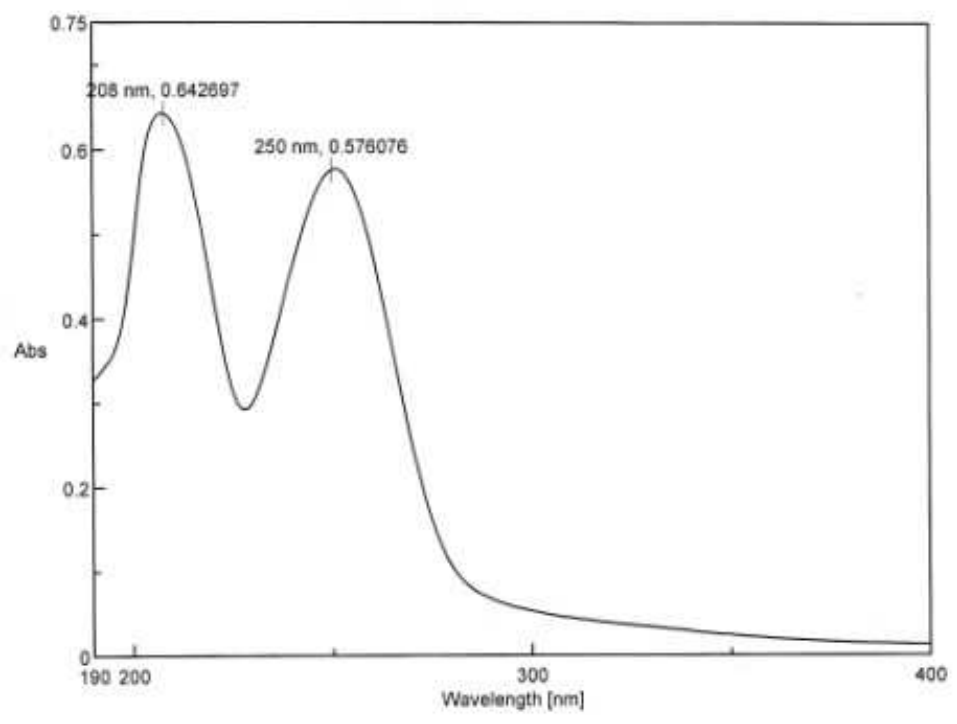

Figure S14. UV spectrum of compound 1 


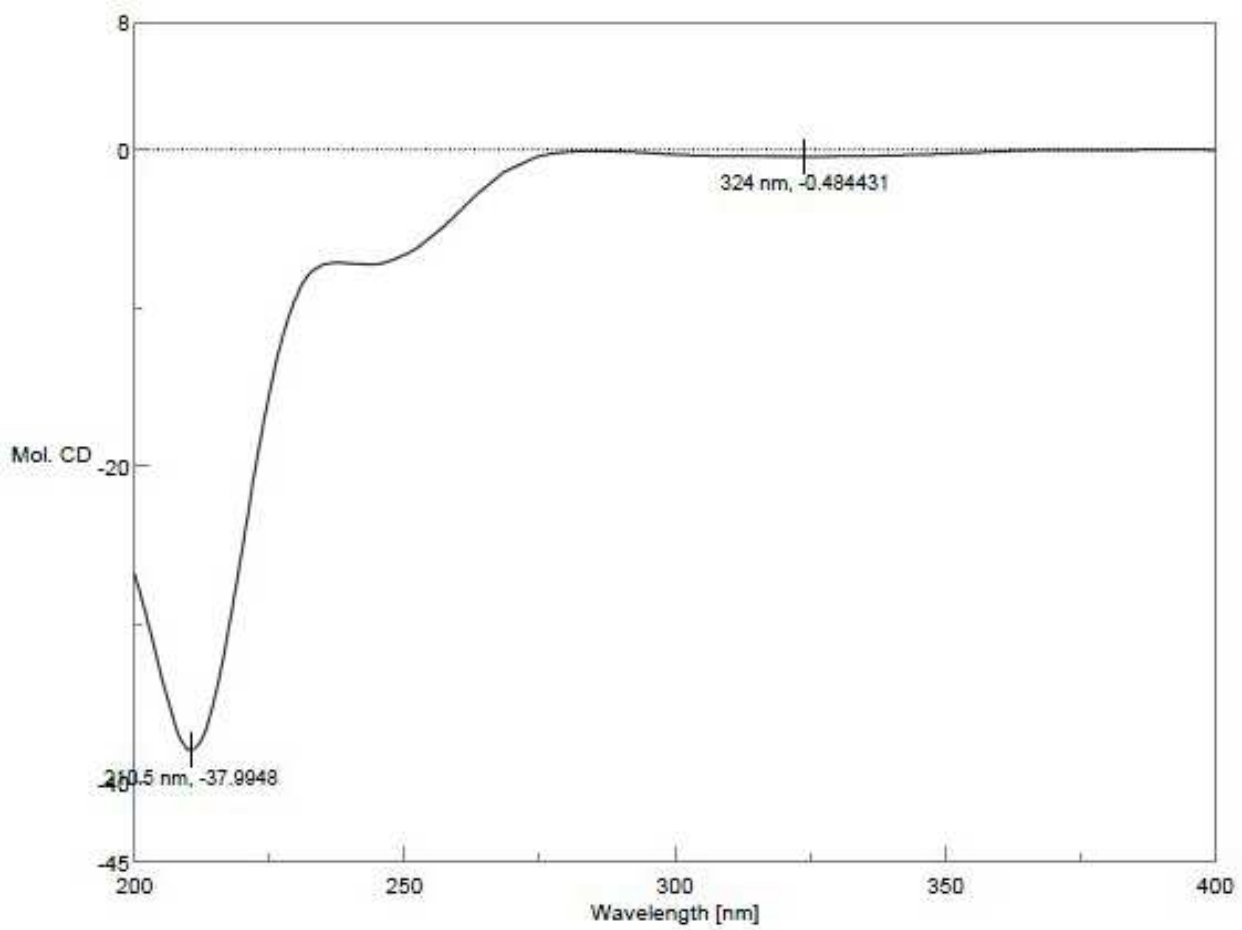

Figure S15. CD spectrum of compound 1 (MeOH)

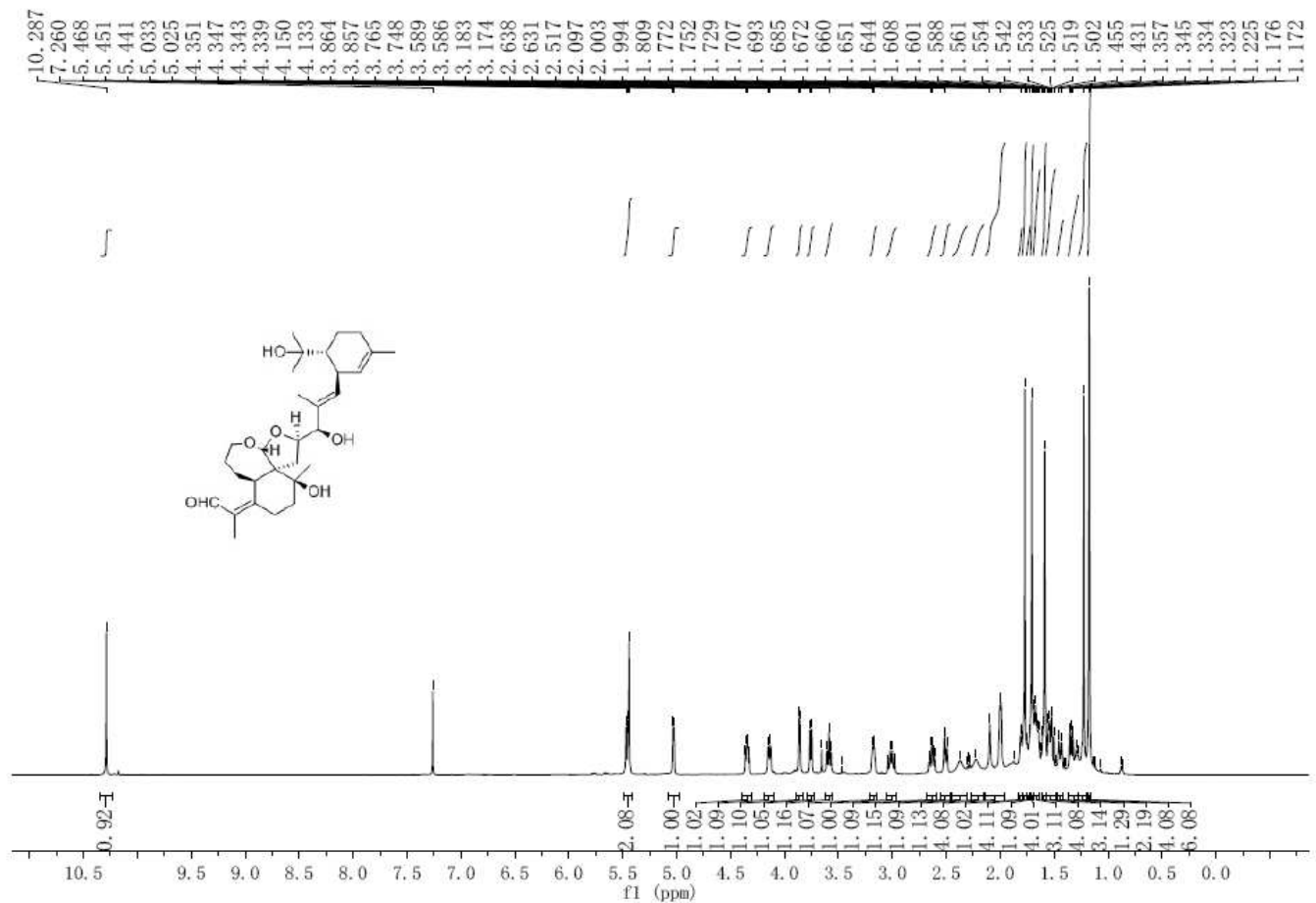

Figure S16. ${ }^{1} \mathrm{H}$ NMR spectrum of compound $2\left(600 \mathrm{MHz}, \mathrm{CDCl}_{3}\right)$ 

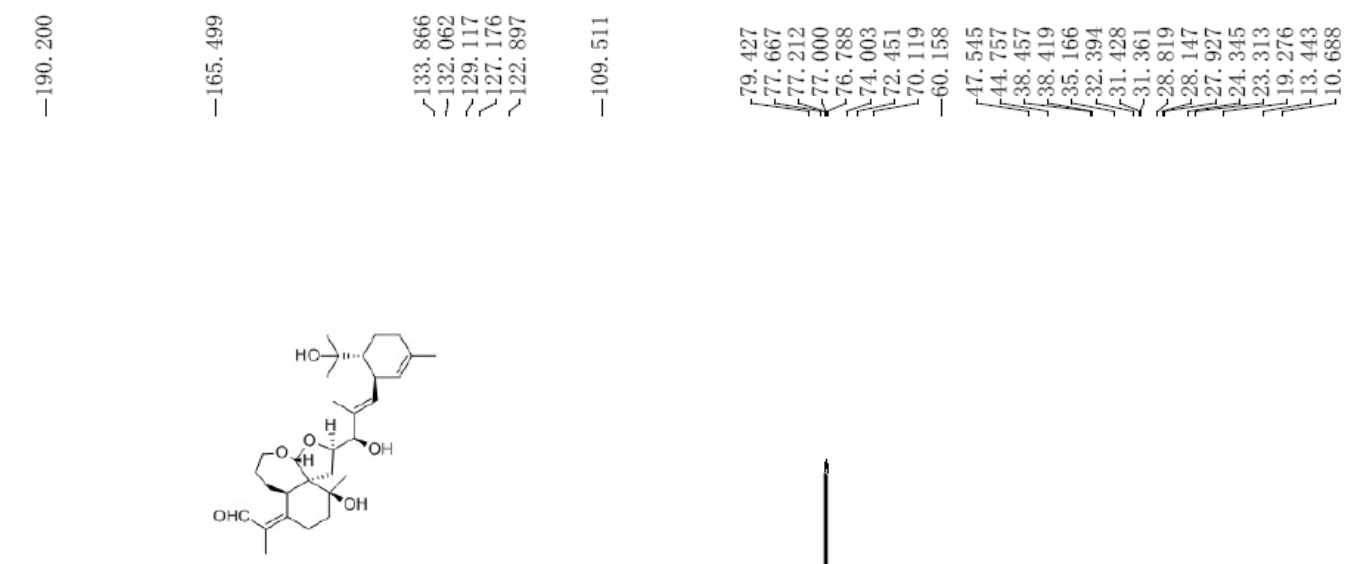

Figure S17. ${ }^{13} \mathrm{C}$ NMR spectrum of compound $2\left(150 \mathrm{MHz}, \mathrm{CDCl}_{3}\right)$

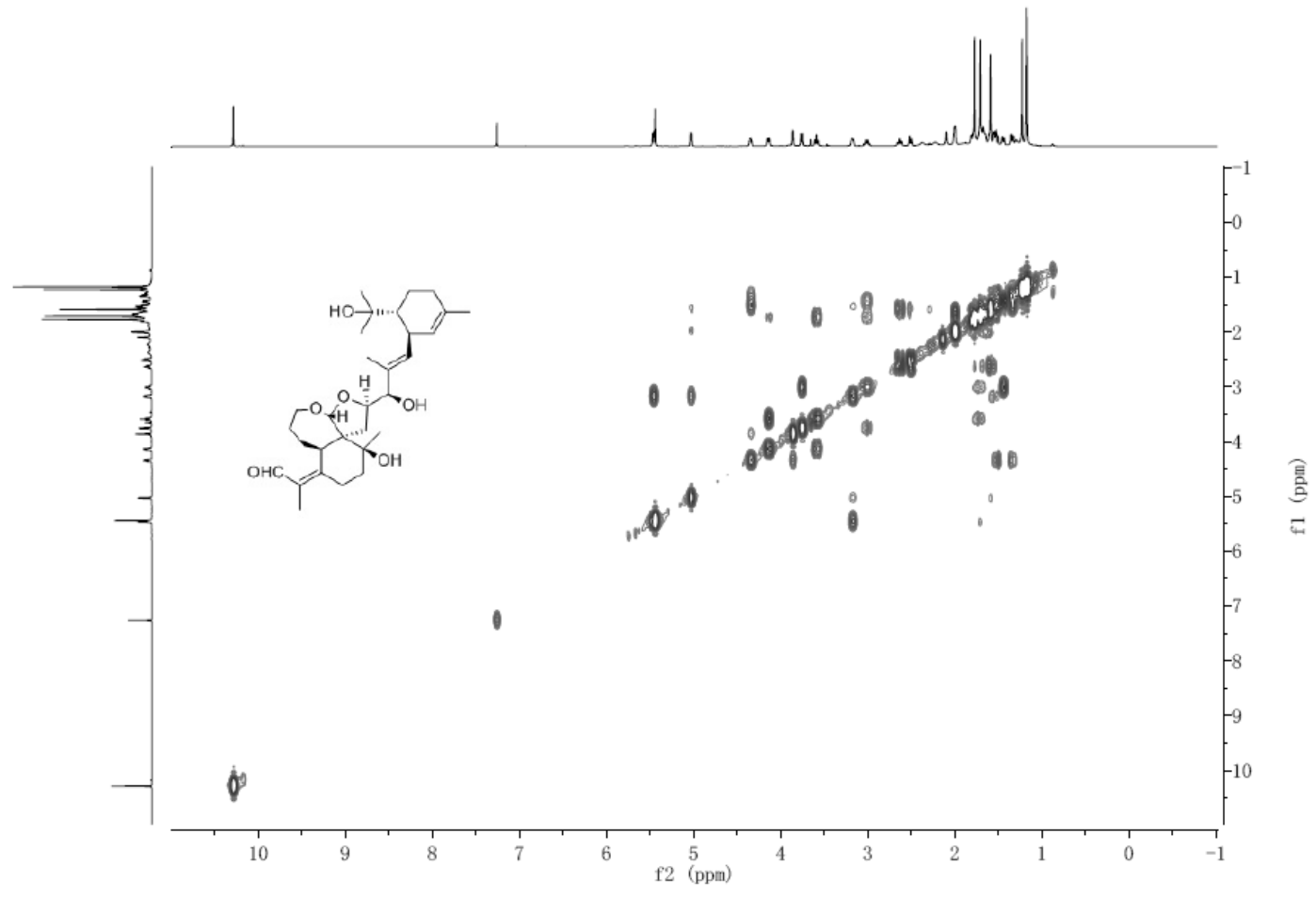

Figure S18. ${ }^{1} \mathrm{H}-{ }^{1} \mathrm{H}$ COSY spectrum of compound 2 


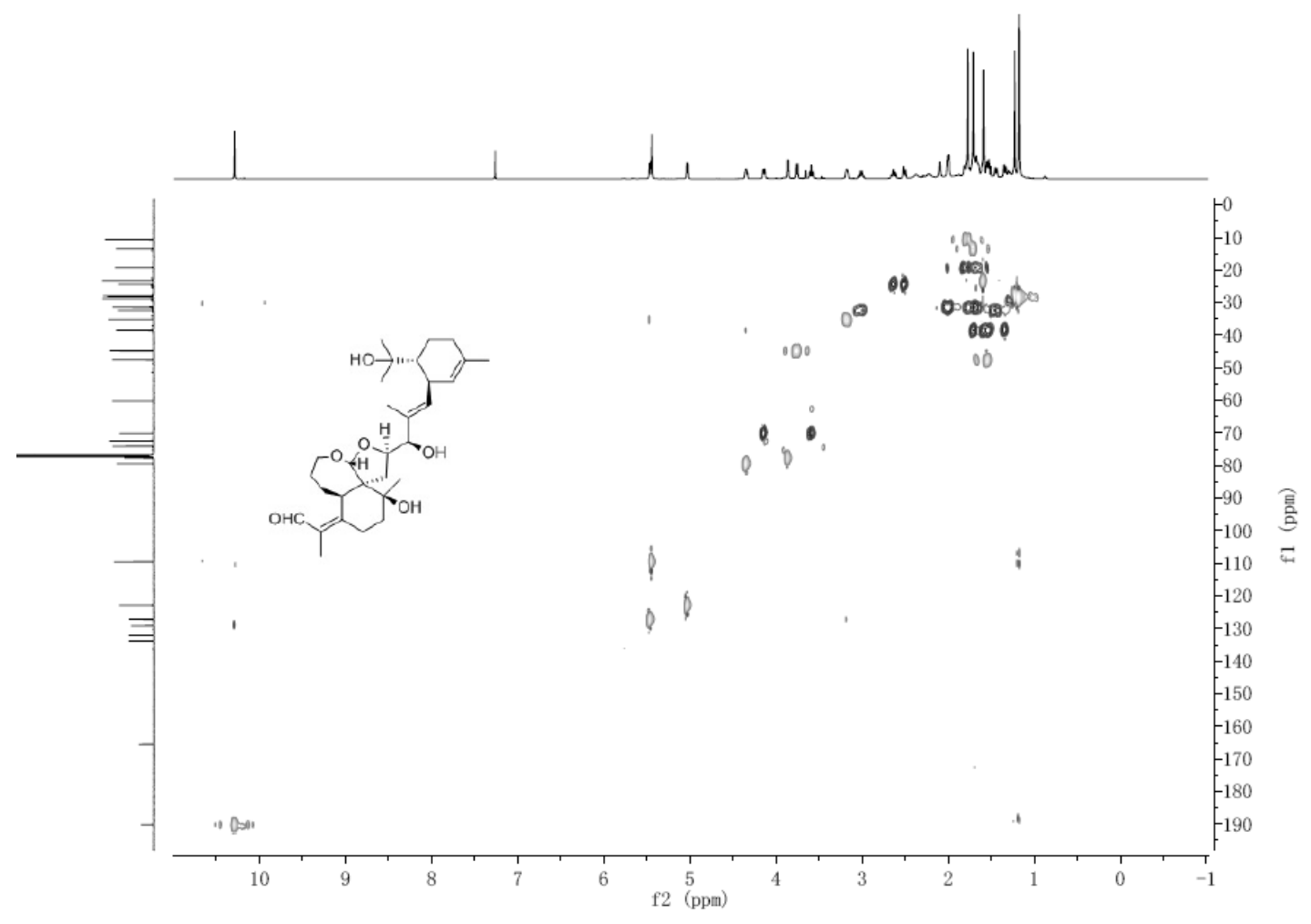

Figure S19. HSQC spectrum of compound 2

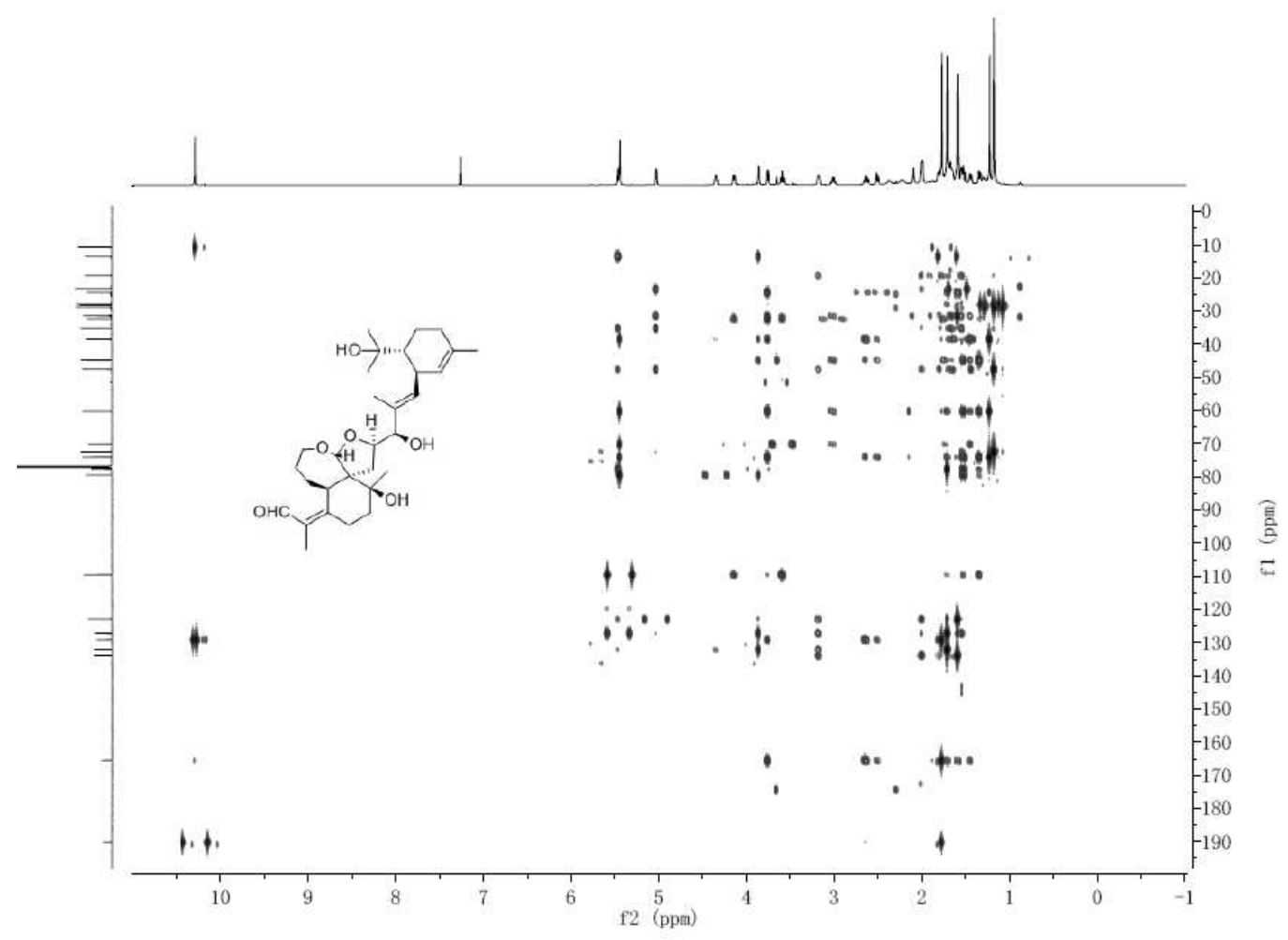

Figure S20. HMBC spectrum of compound 2 


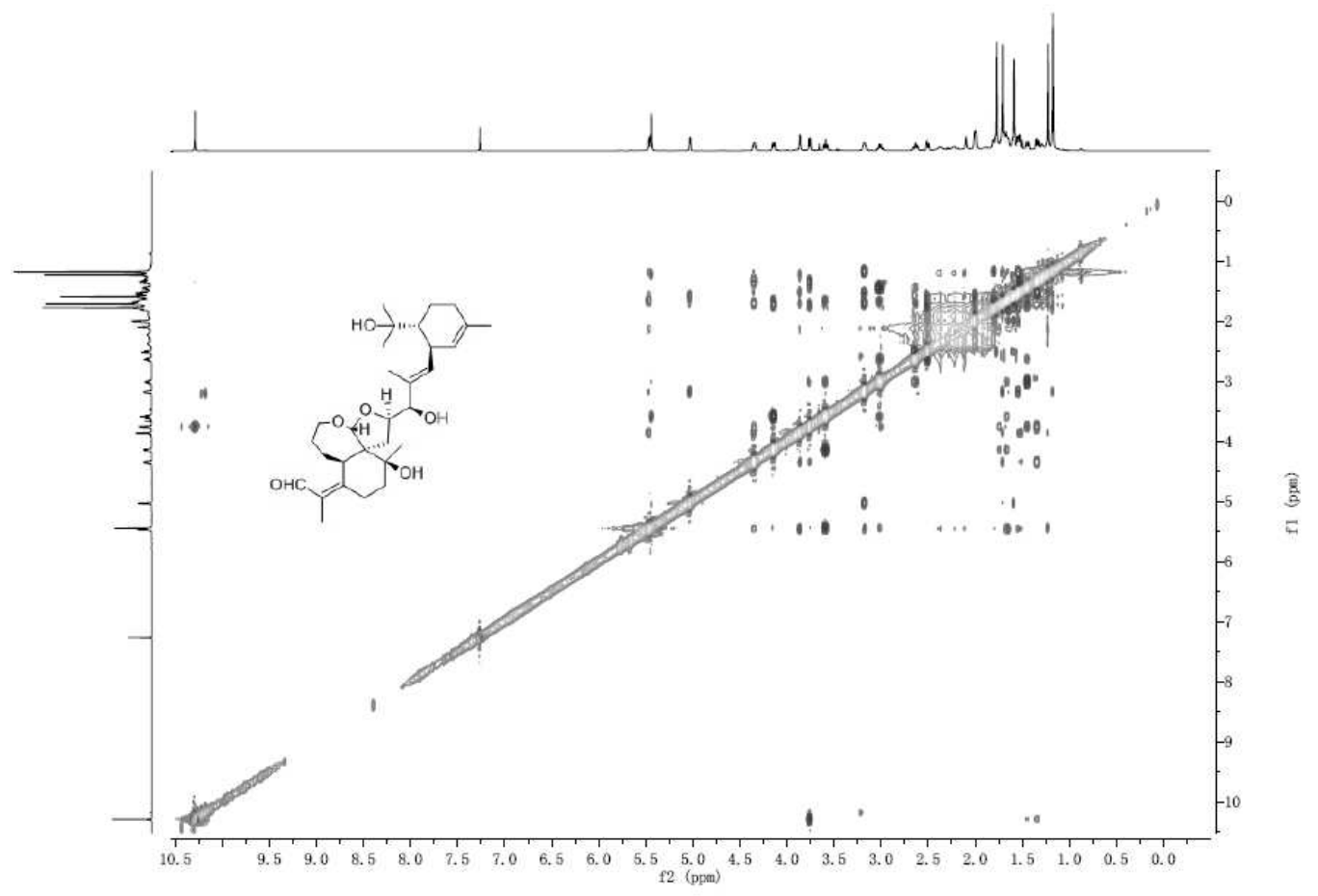

Figure S21. NOESY spectrum of compound 2 
Qualitative Analysis Report

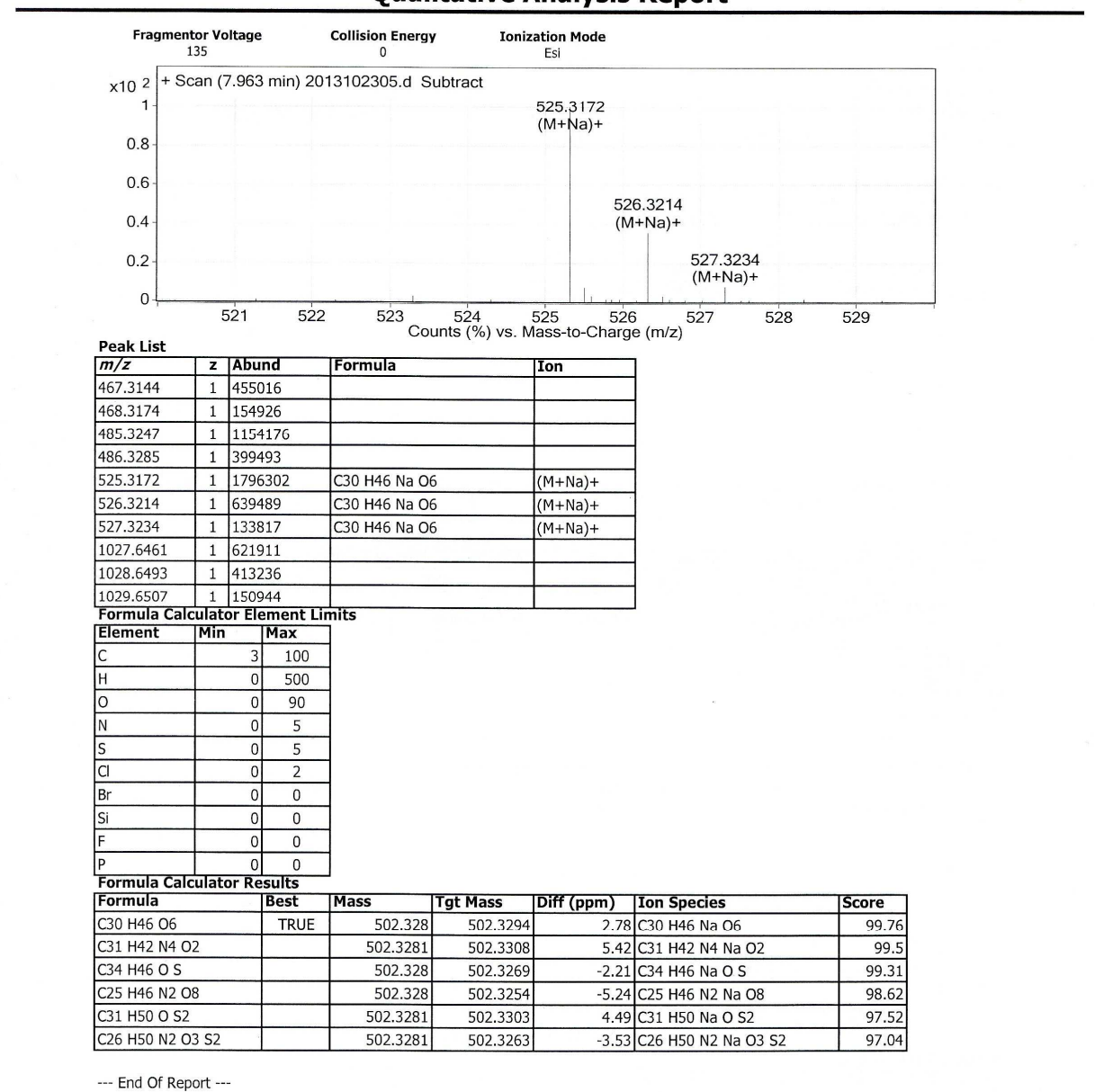

Figure S22. HRESIMS spectrum of compound 2

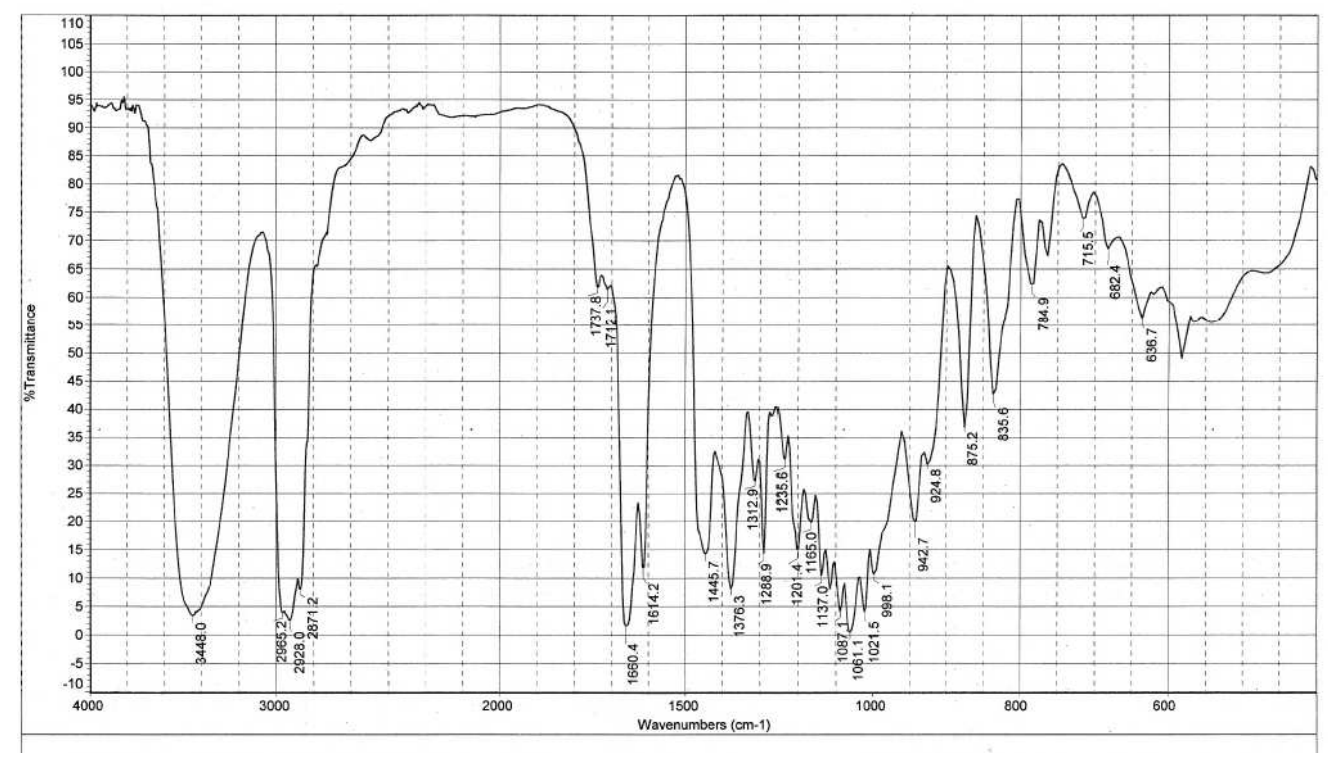

Figure S23. IR spectrum of compound 2 


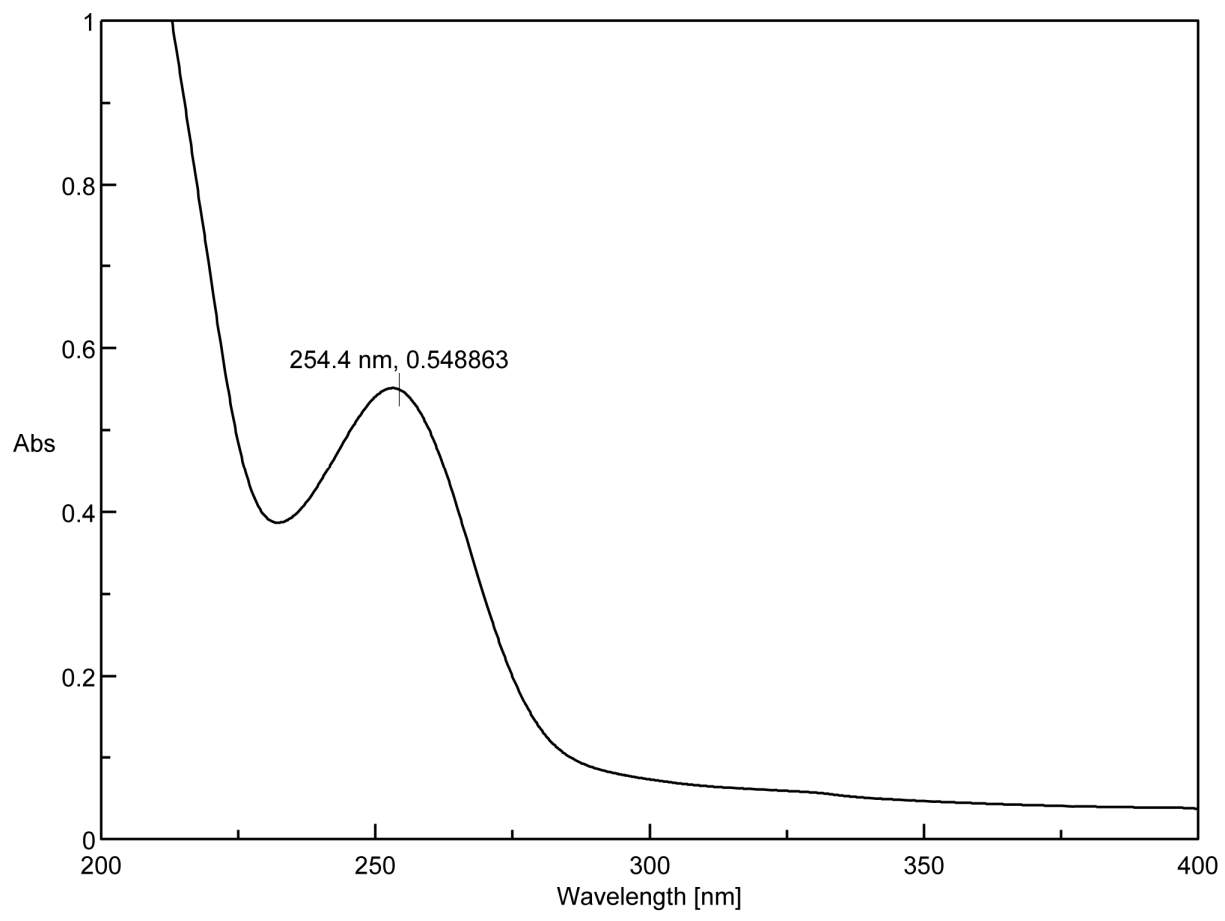

Figure S24. UV Spectrum of compound 2

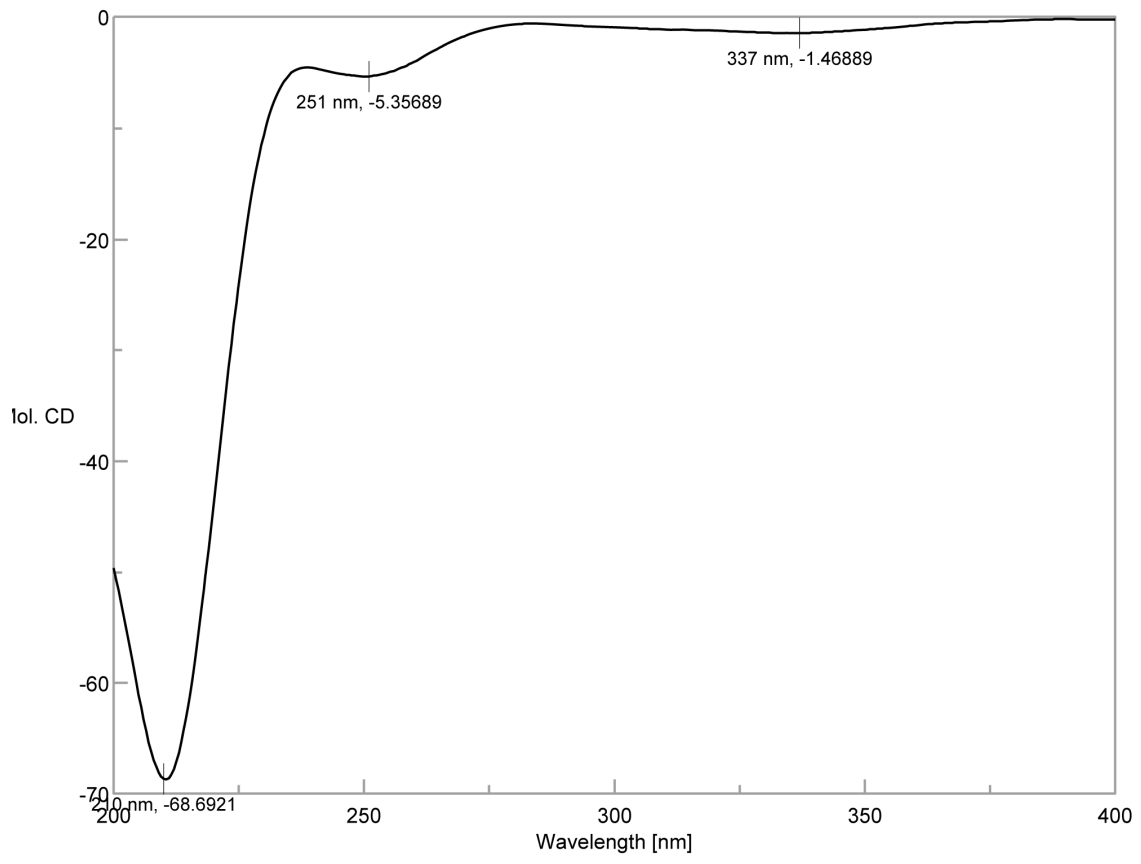

Figure S25. CD Spectrum of compound $2\left(\mathrm{CH}_{3} \mathrm{OH}\right)$ 


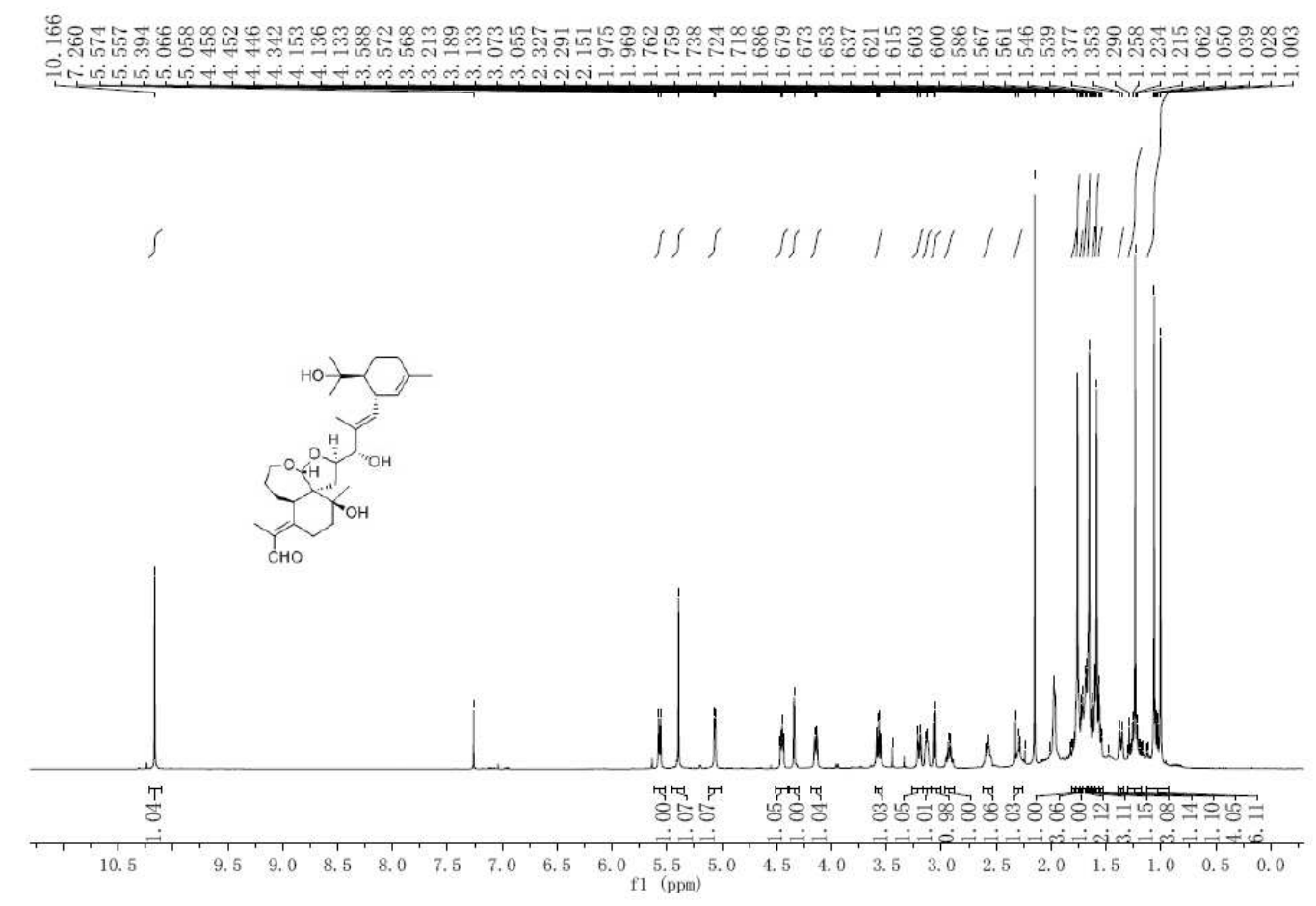

Figure S26. ${ }^{1} \mathrm{H}$ NMR spectrum of compound $3\left(600 \mathrm{MHz}, \mathrm{CDCl}_{3}\right)$
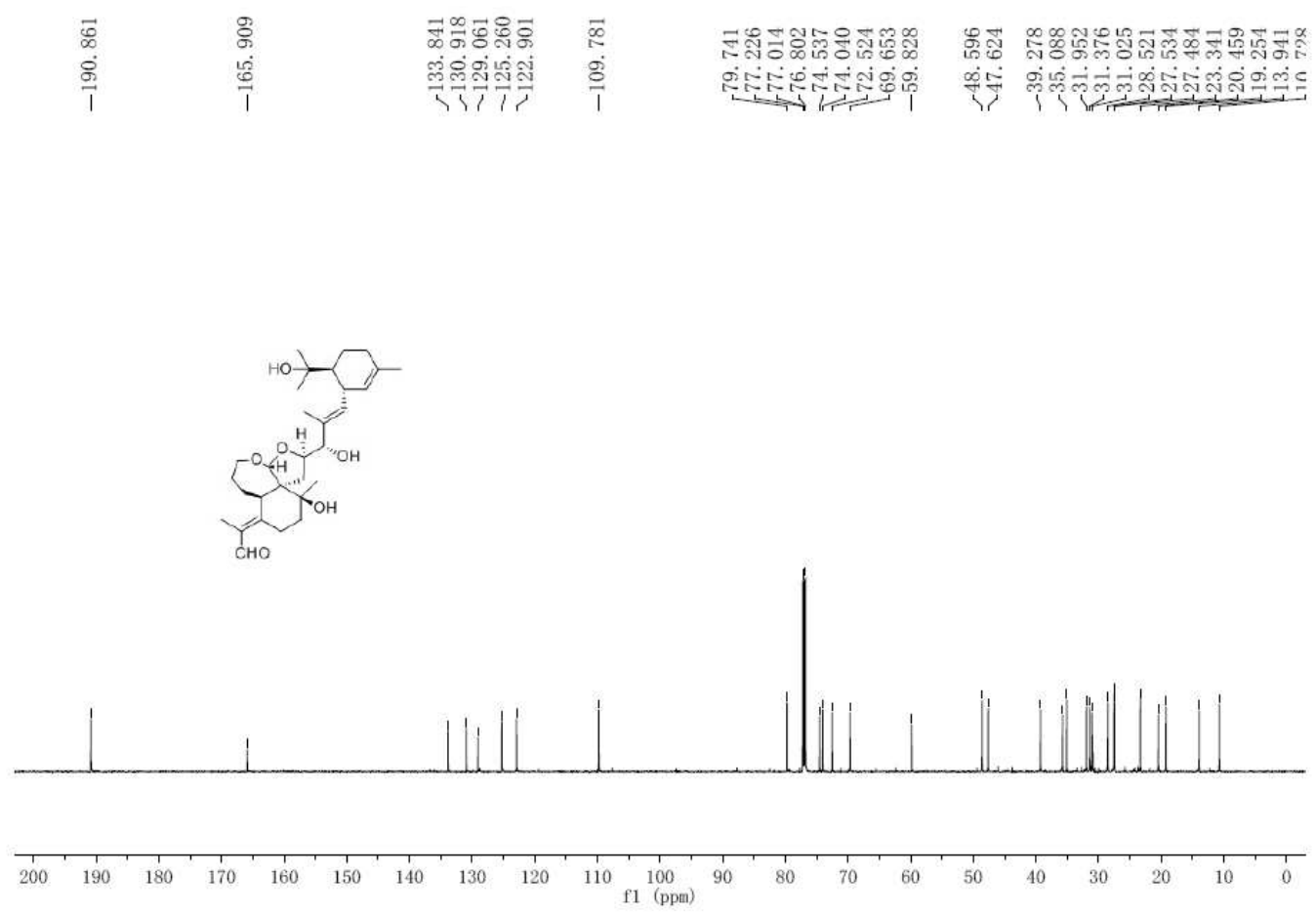

Figure S27. ${ }^{13} \mathrm{C}$ NMR spectrum of compound $3\left(150 \mathrm{MHz}, \mathrm{CDCl}_{3}\right)$ 


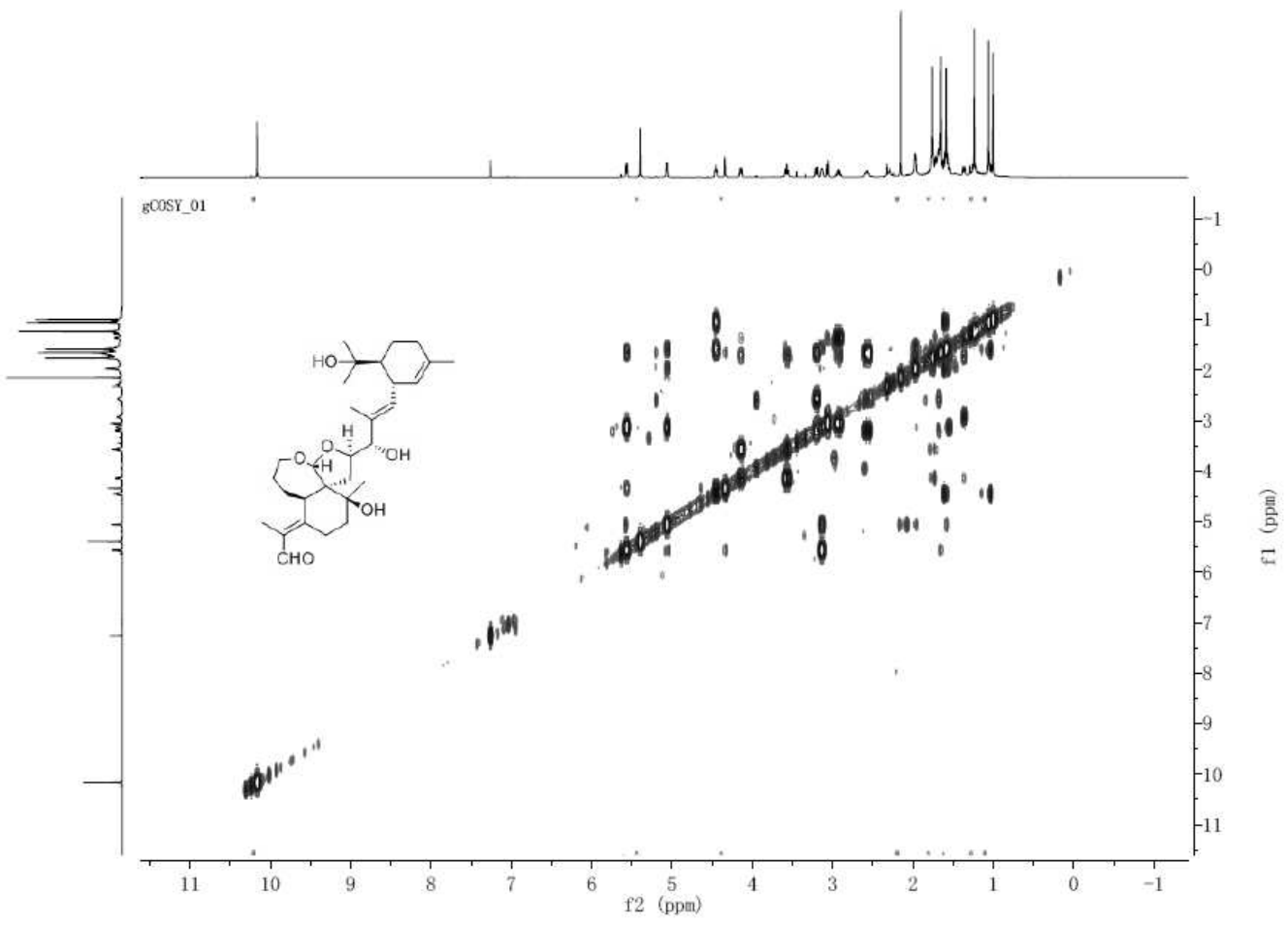

Figure S28. ${ }^{1} \mathrm{H}-{ }^{1} \mathrm{H}$ COSY spectrum of compound 3

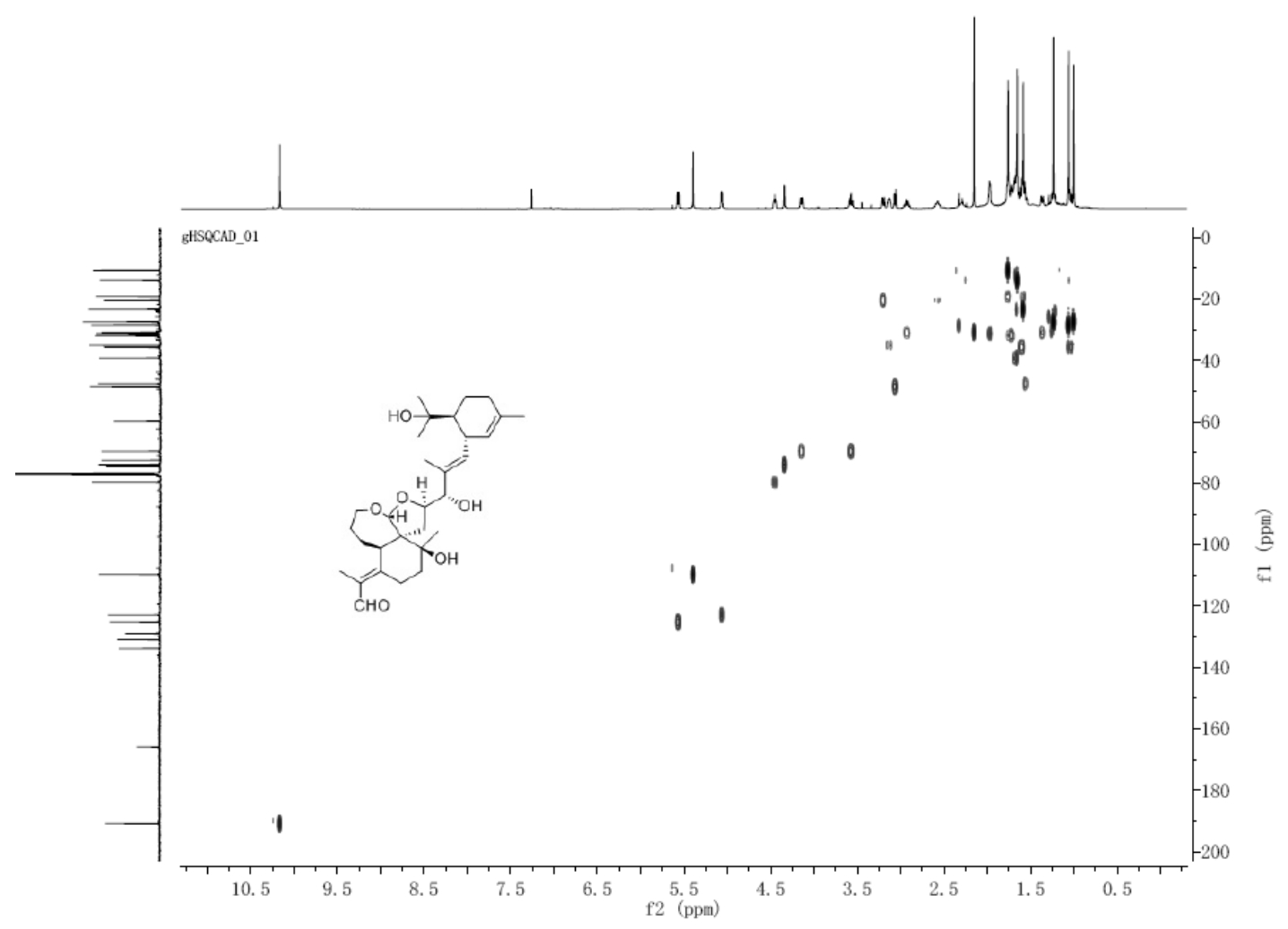

Figure S29. HSQC spectrum of compound 3 


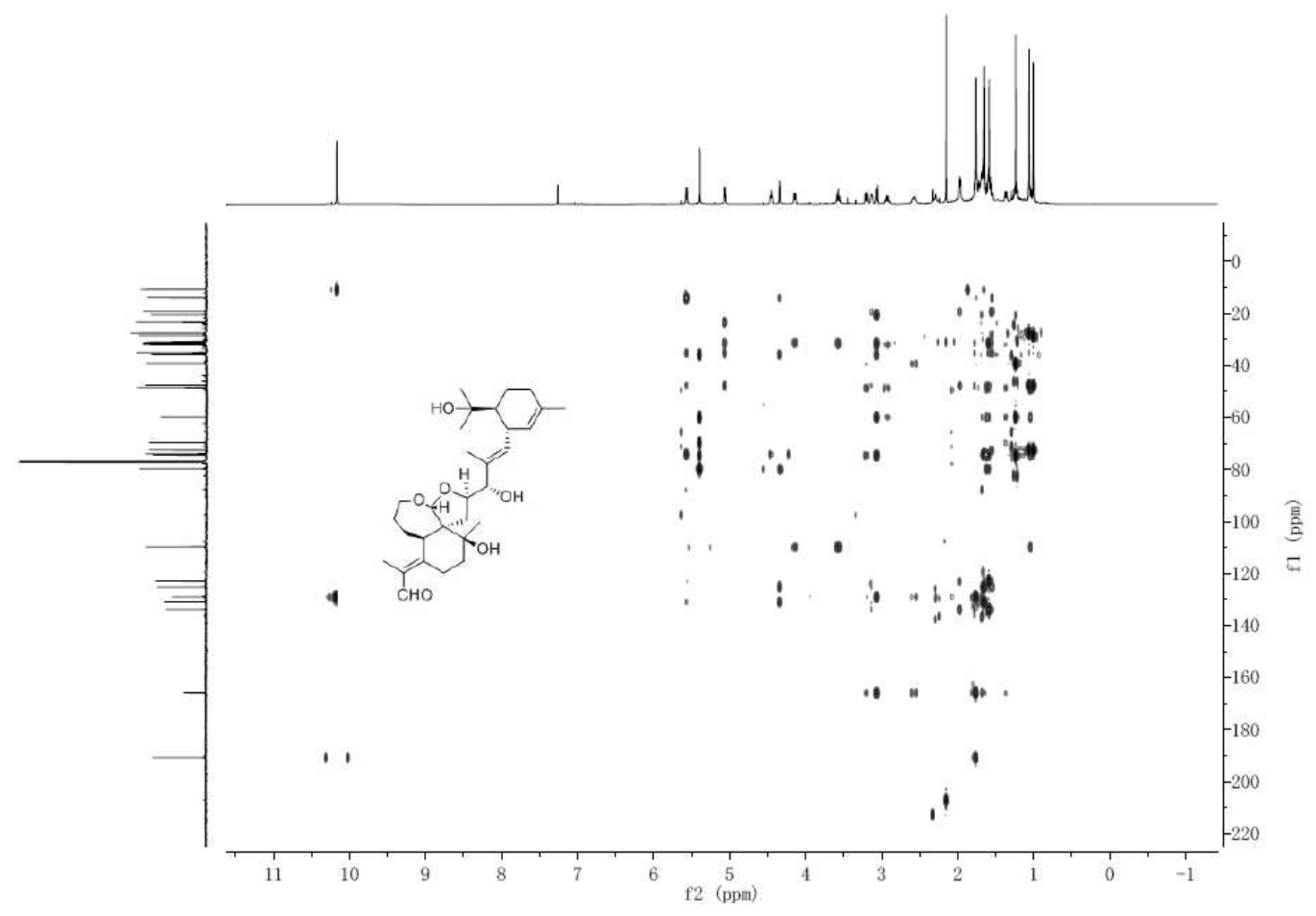

Figure S30. HMBC spectrum of compound 3

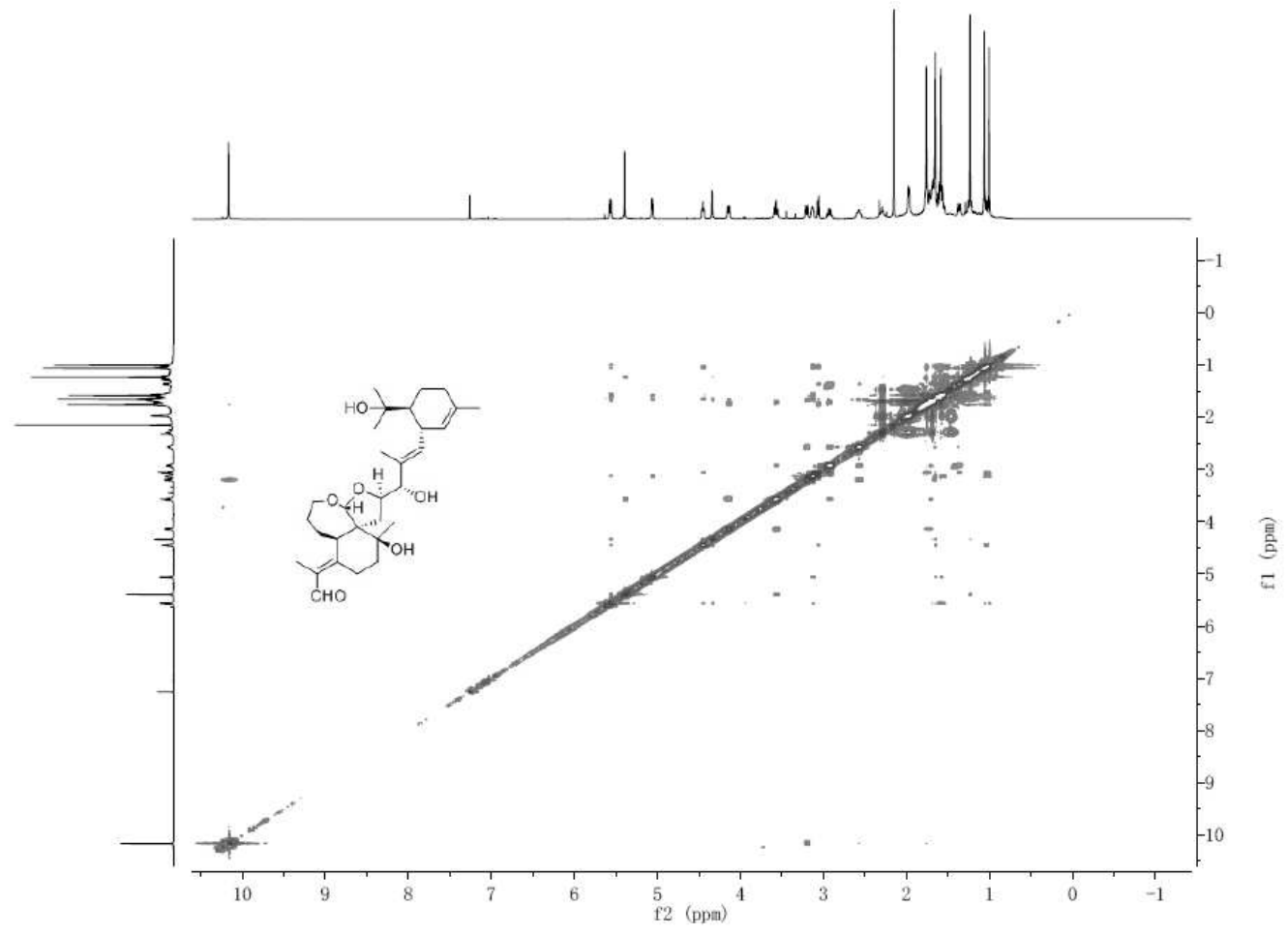

Figure S31. NOESY spectrum of compound 3 
Qualitative Analysis Report

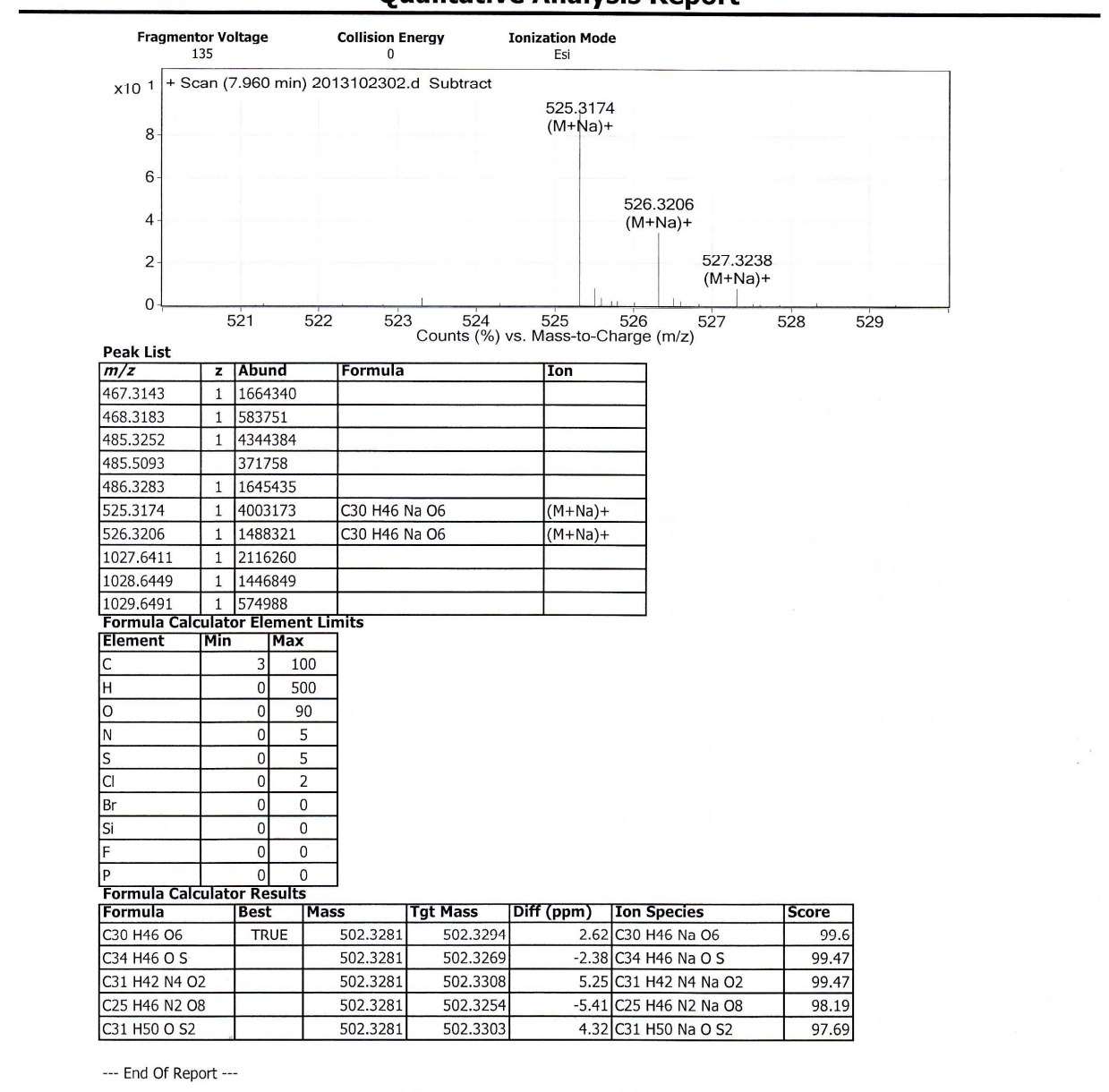

Figure S32. HRESIMS spectrum of compound 3

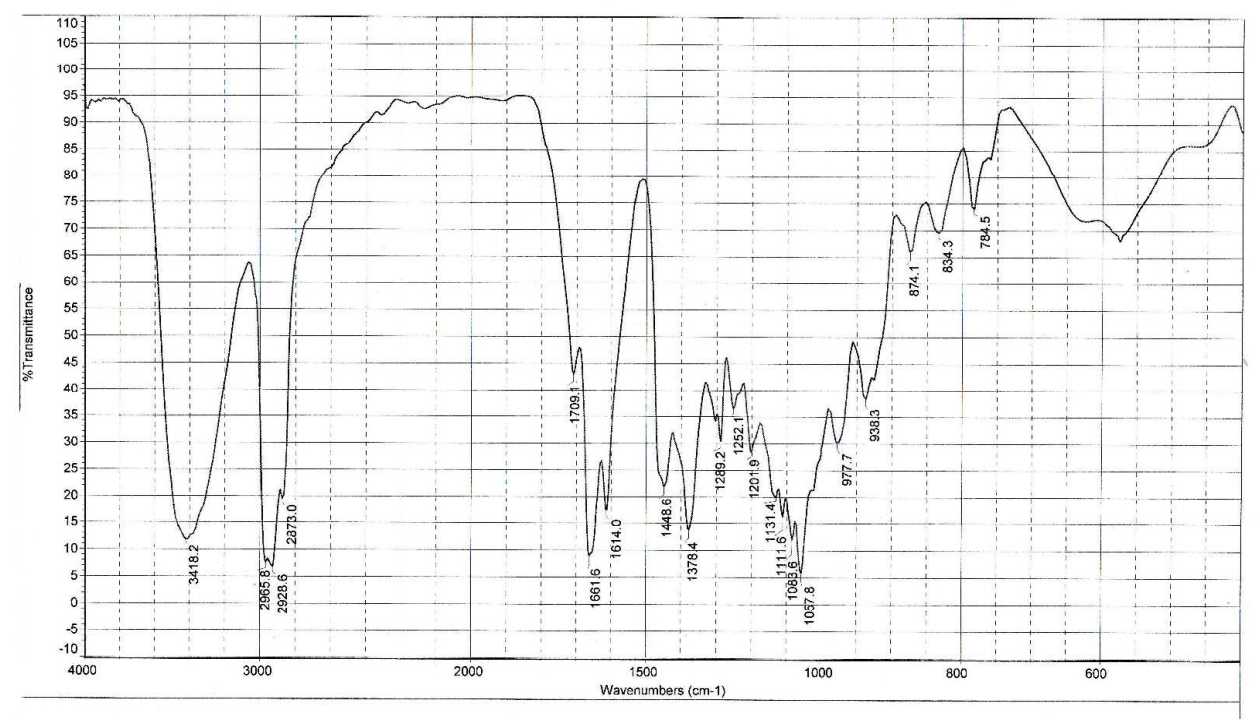

Figure S33. IR spectrum of compound 3 


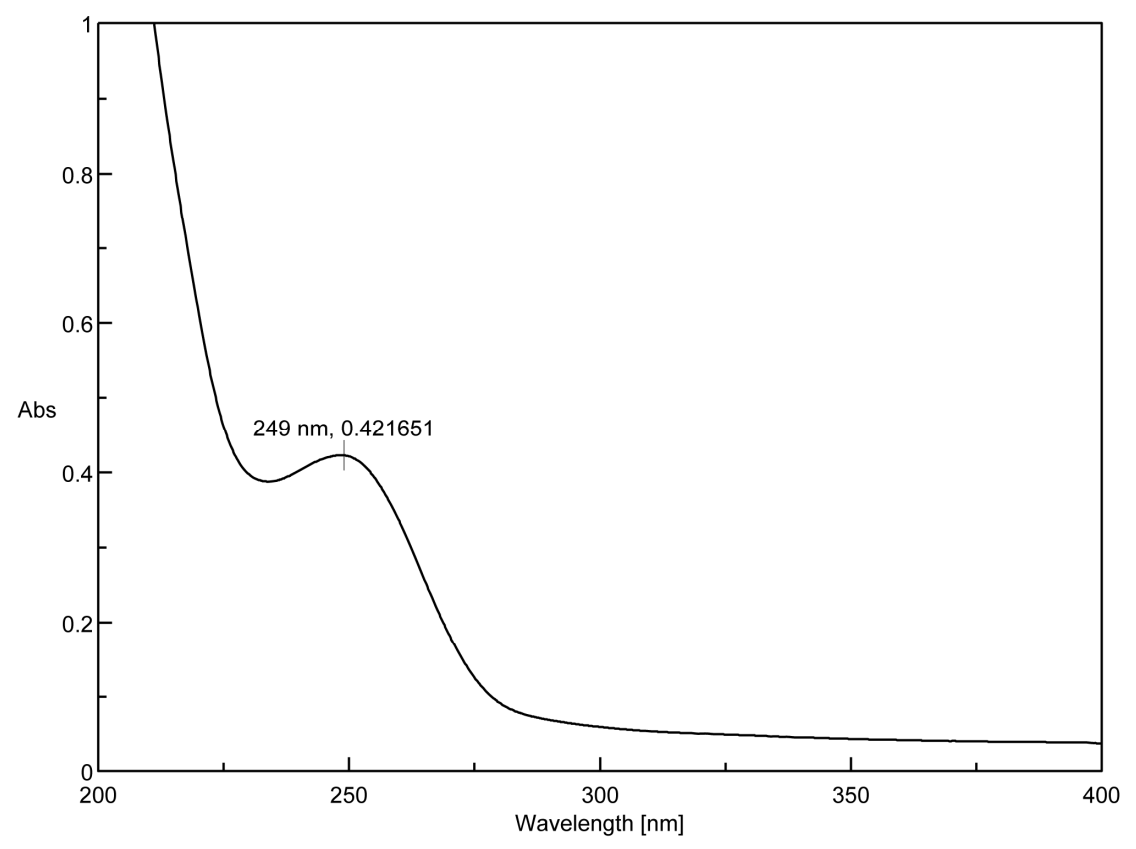

Figure S34. UV spectrum of compound 3

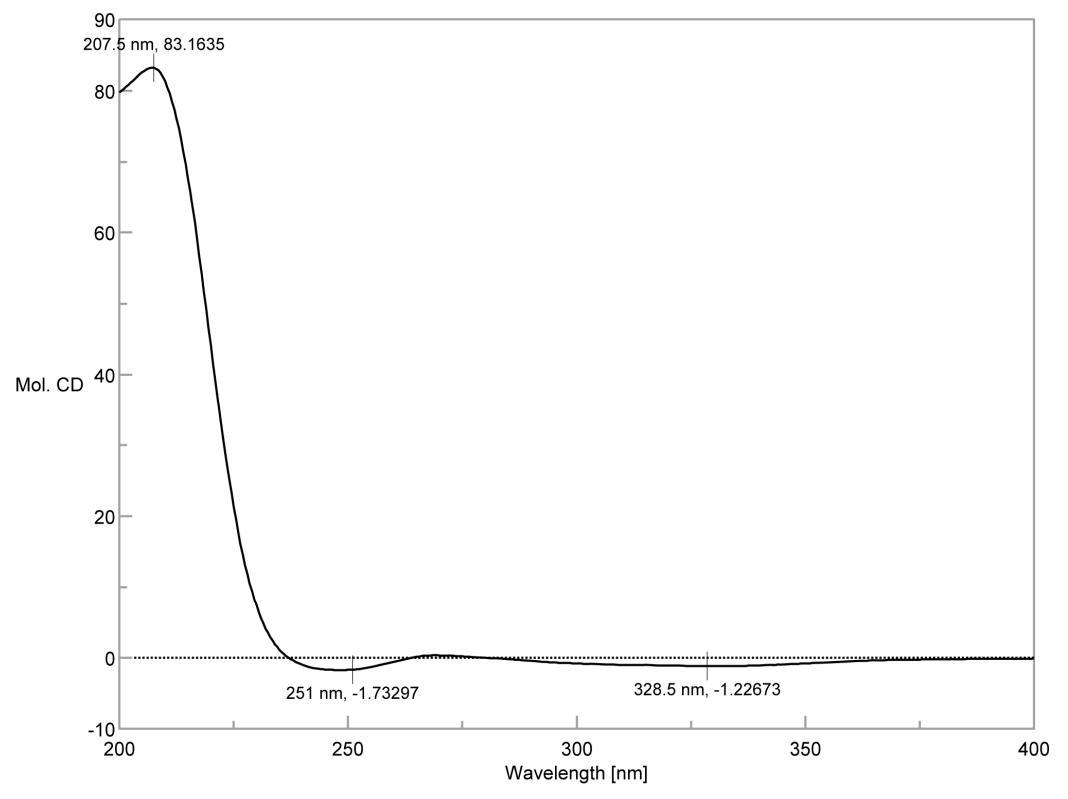

Figure S35. CD spectrum of compound $3(\mathrm{MeOH})$ 


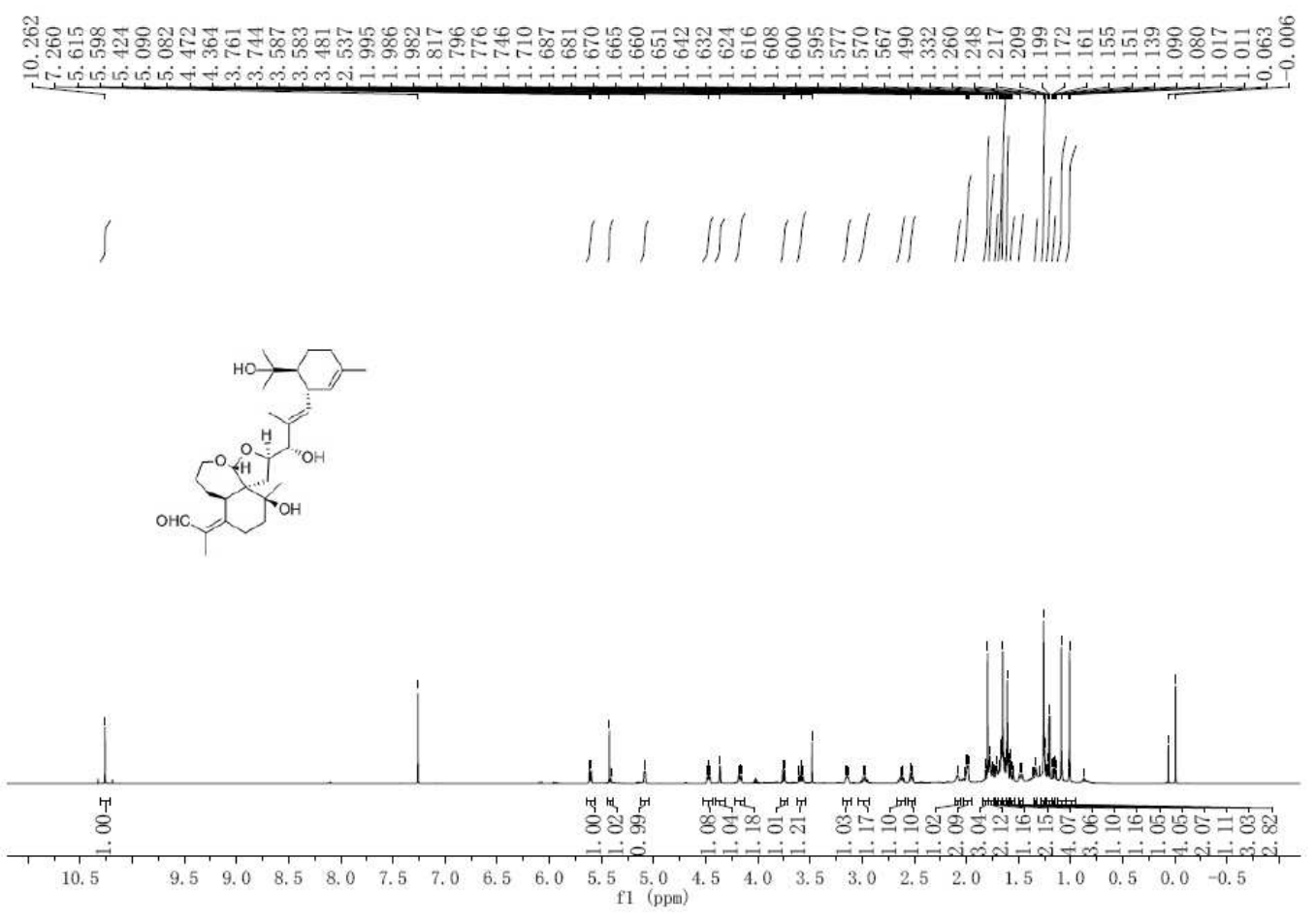

Figure S36. ${ }^{1} \mathrm{H}$ NMR spectrum of compound $4\left(600 \mathrm{MHz}, \mathrm{CDCl}_{3}\right)$
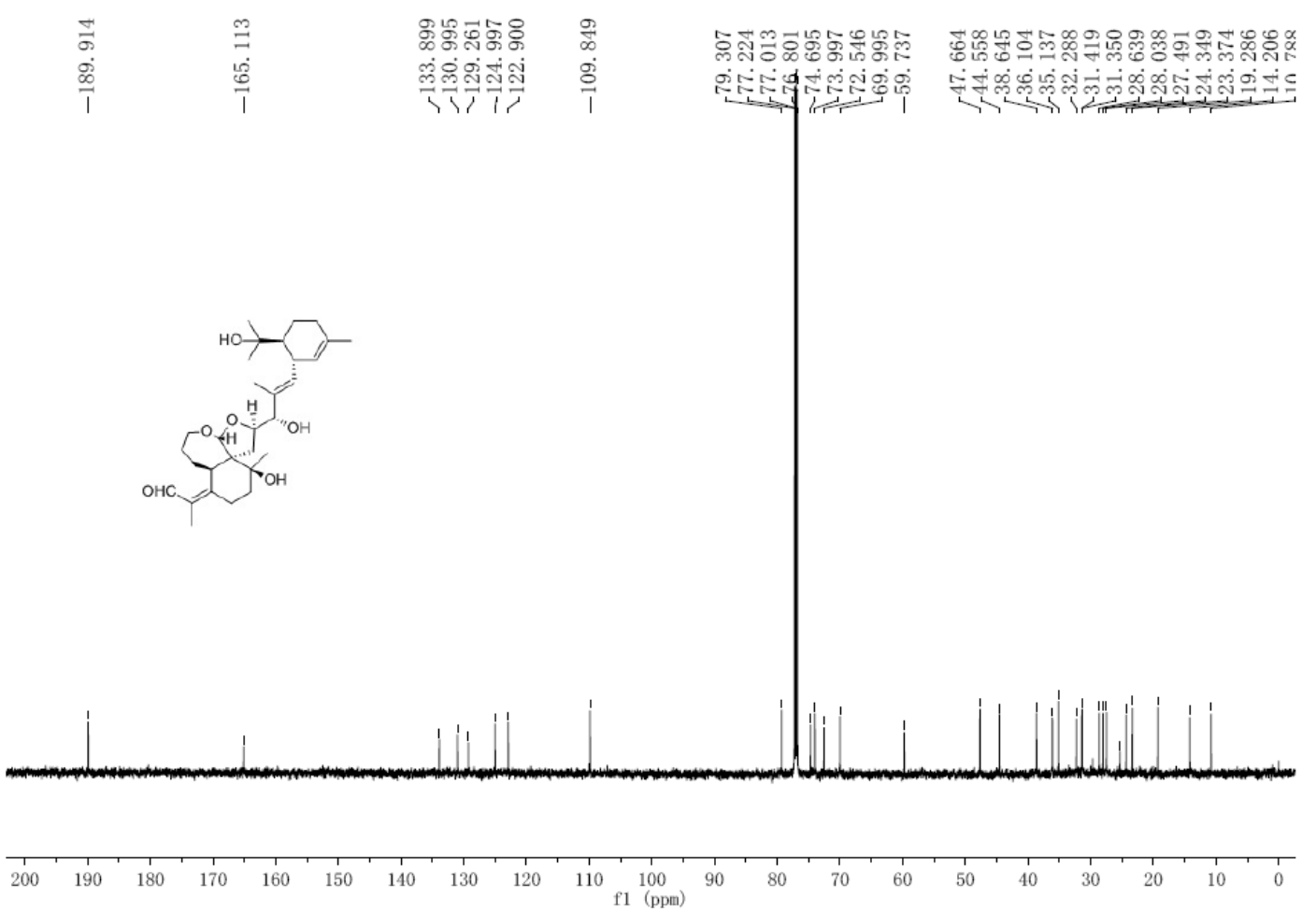

Figure S37. ${ }^{13} \mathrm{C}$ NMR spectrum of compound $4\left(150 \mathrm{MHz}, \mathrm{CDCl}_{3}\right)$ 


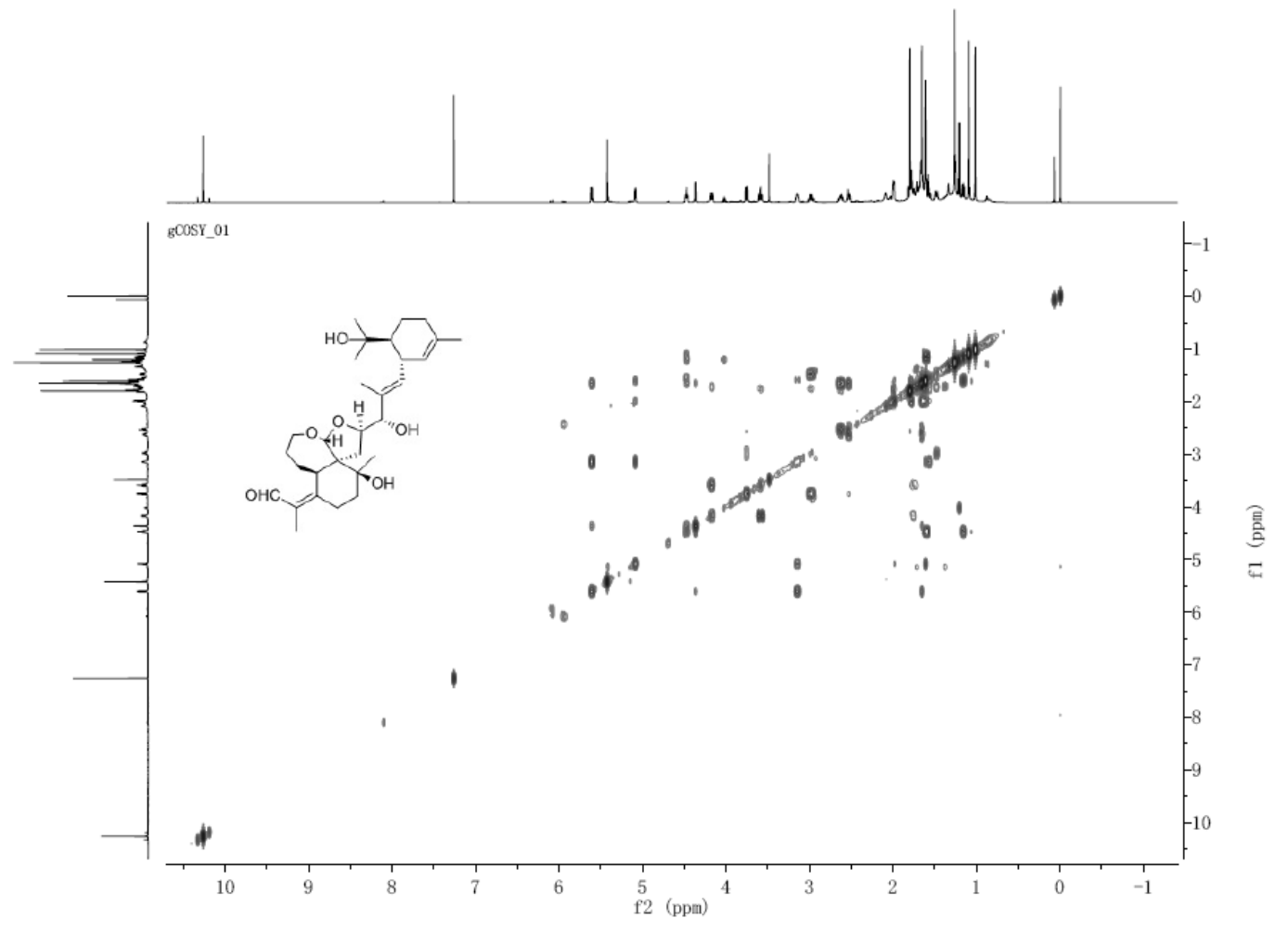

Figure S38. ${ }^{1} \mathrm{H}-{ }^{1} \mathrm{H}$ COSY spectrum of compound 4

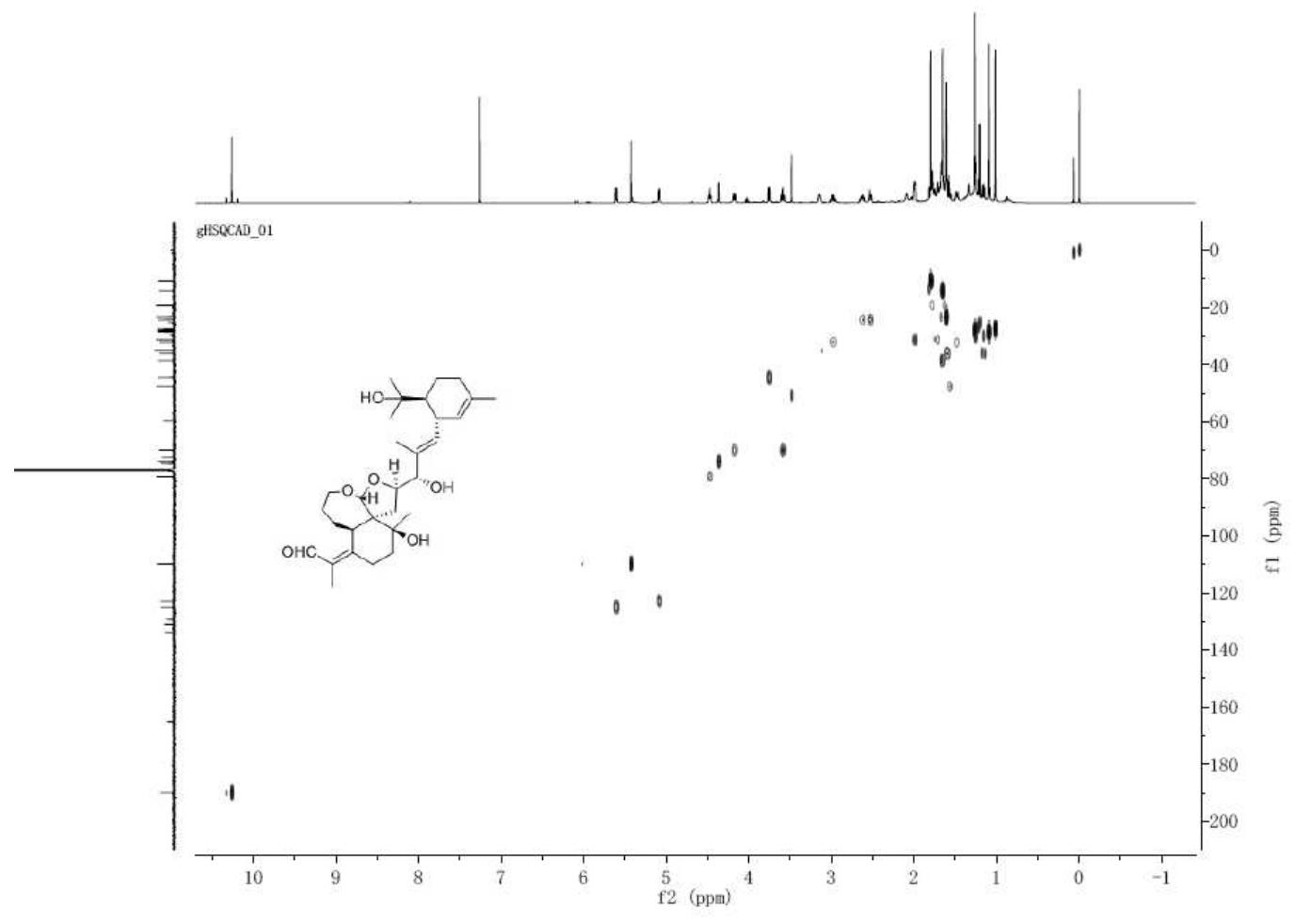

Figure S39. HSQC spectrum of compound 4 


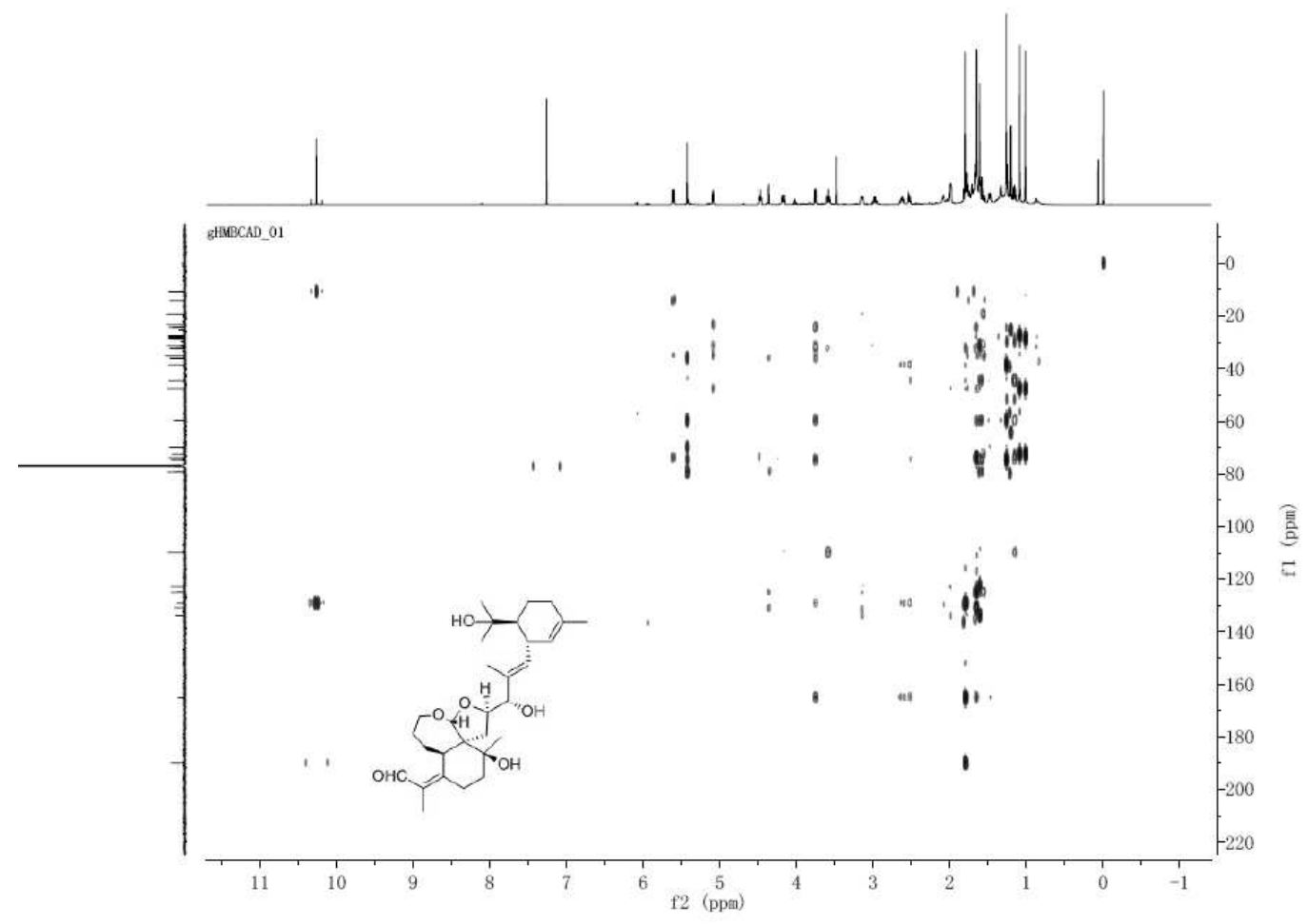

Figure S40. HMBC spectrum of compound 4

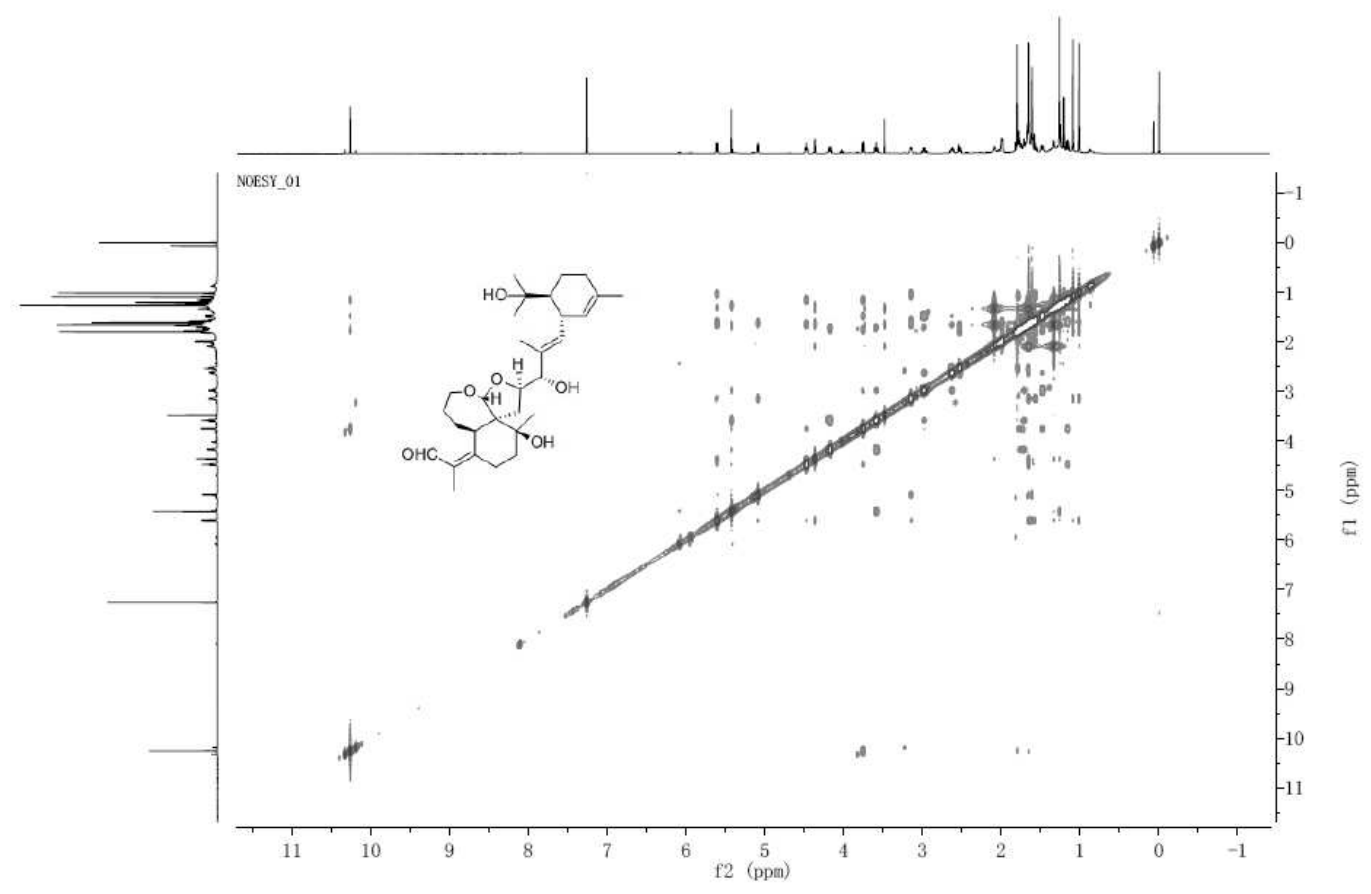

Figure S41. NOESY spectrum of compound 4 
Qualitative Analysis Report

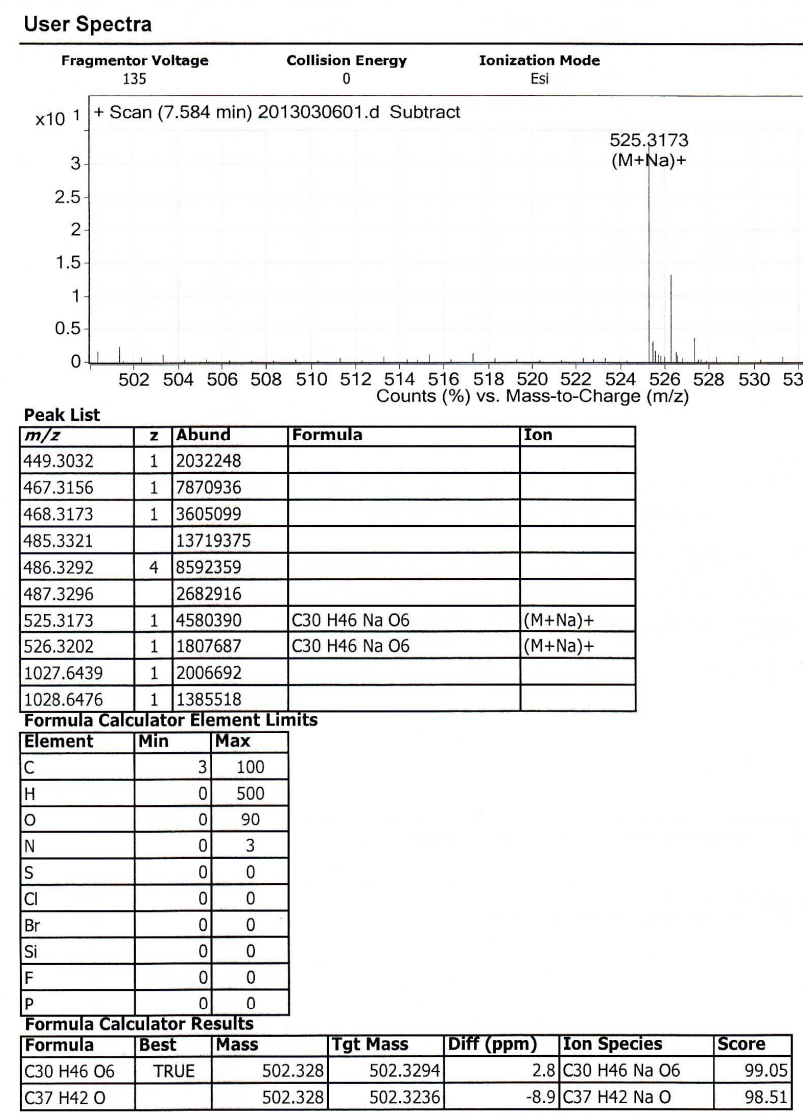

--- End Of Report --

Figure S42. HRESIMS spectrum of compound 4

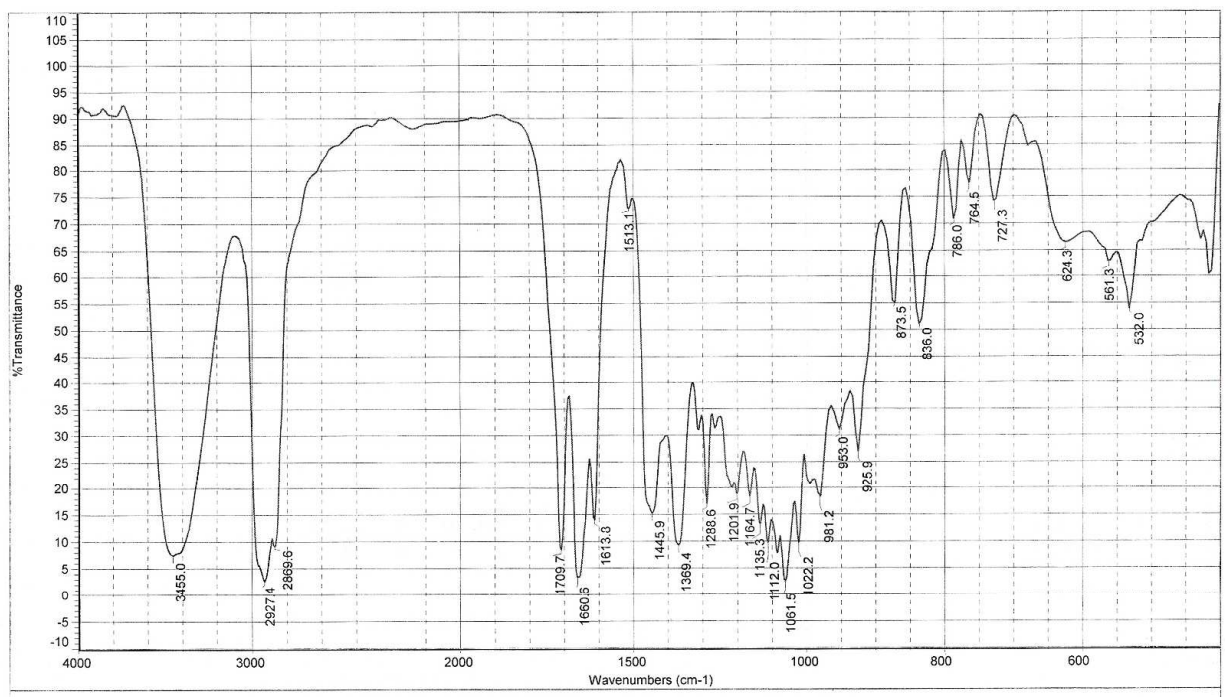

Figure S43. IR spectrum of compound 4 


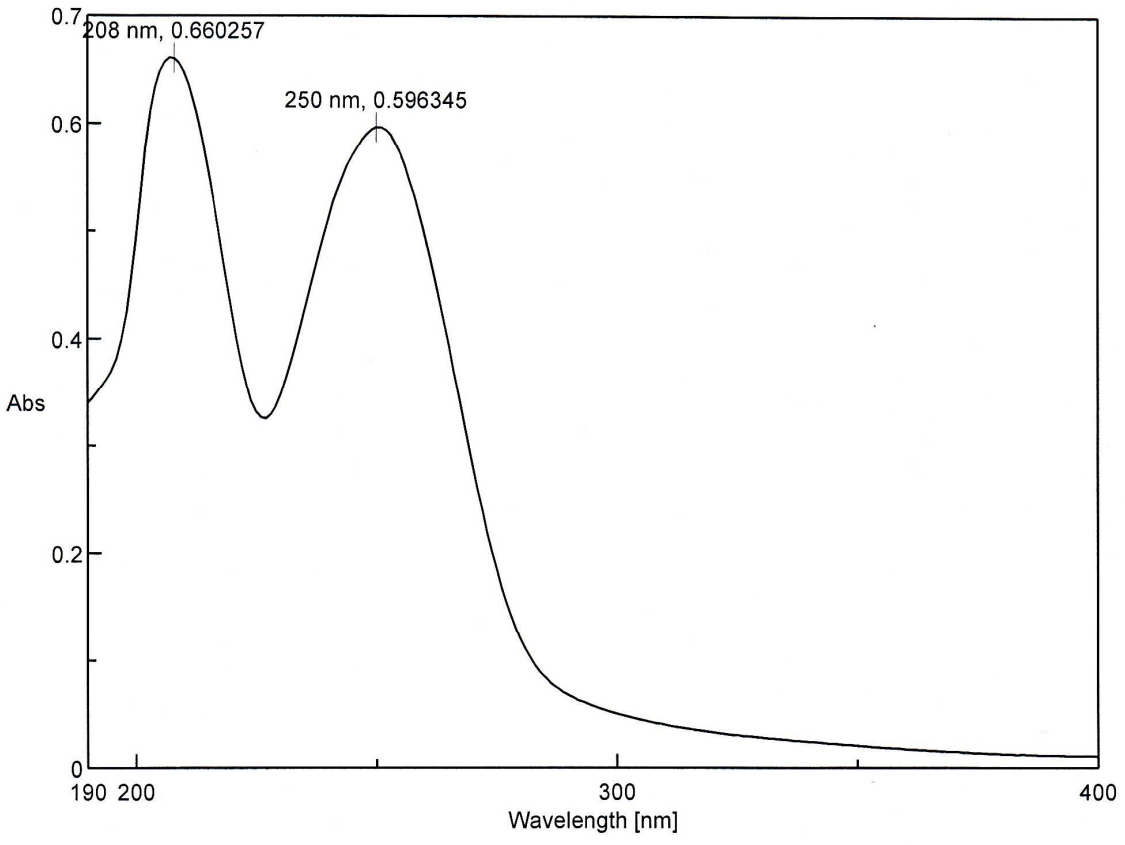

Figure S44. UV spectrum of compound 4

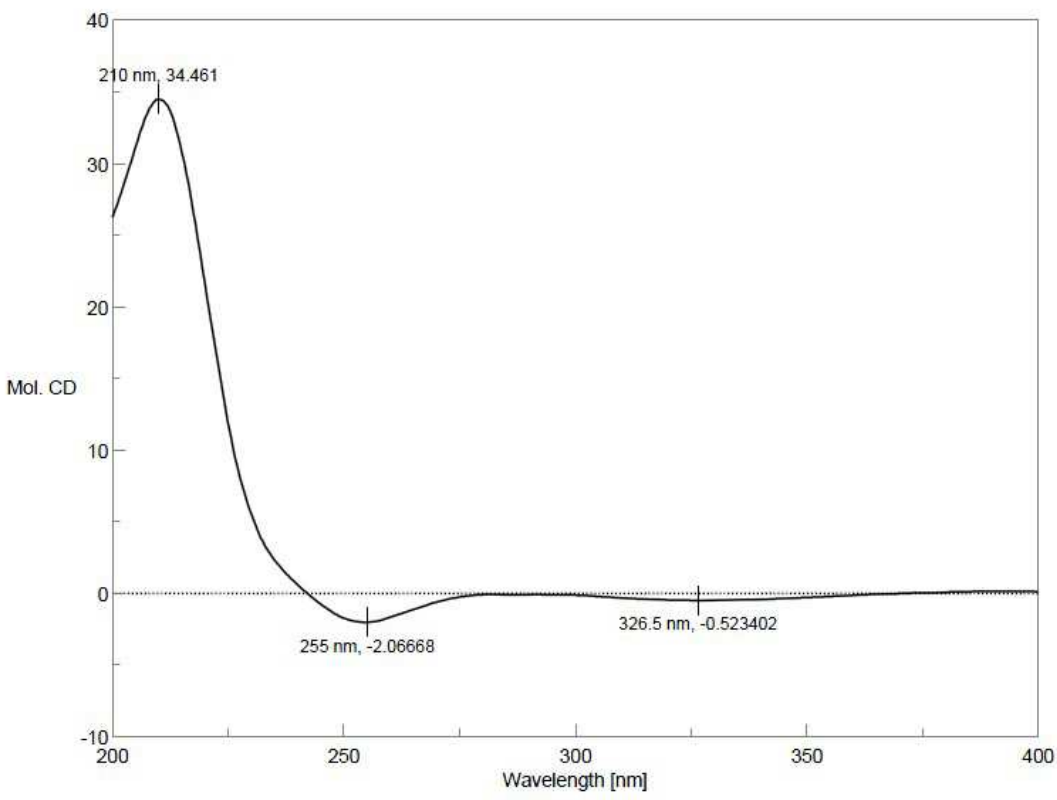

Figure S45. CD spectrum of compound $4(\mathrm{MeOH})$ 


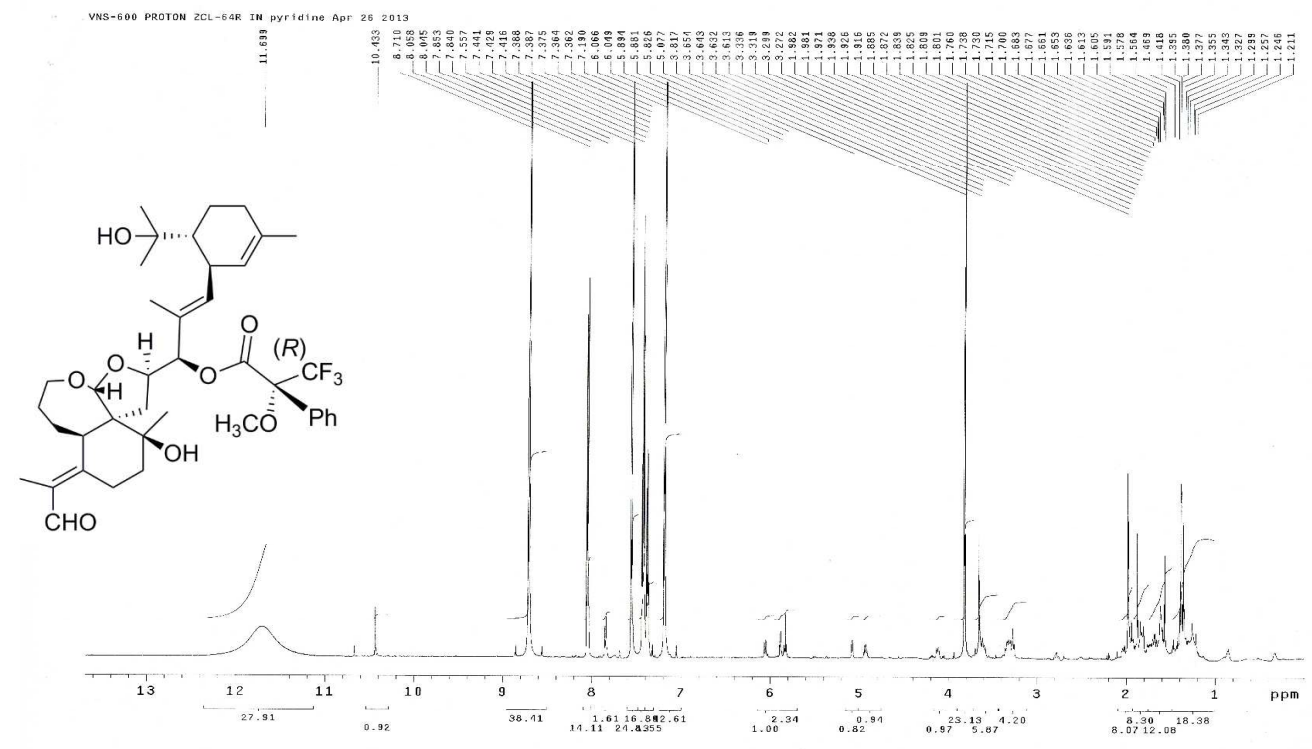

Figure S46. ${ }^{1} \mathrm{H}$ NMR Spectrum of the (R)-MTPA ester (1r) of $1(600 \mathrm{MHz}$, pyridine- $d_{5}$ )

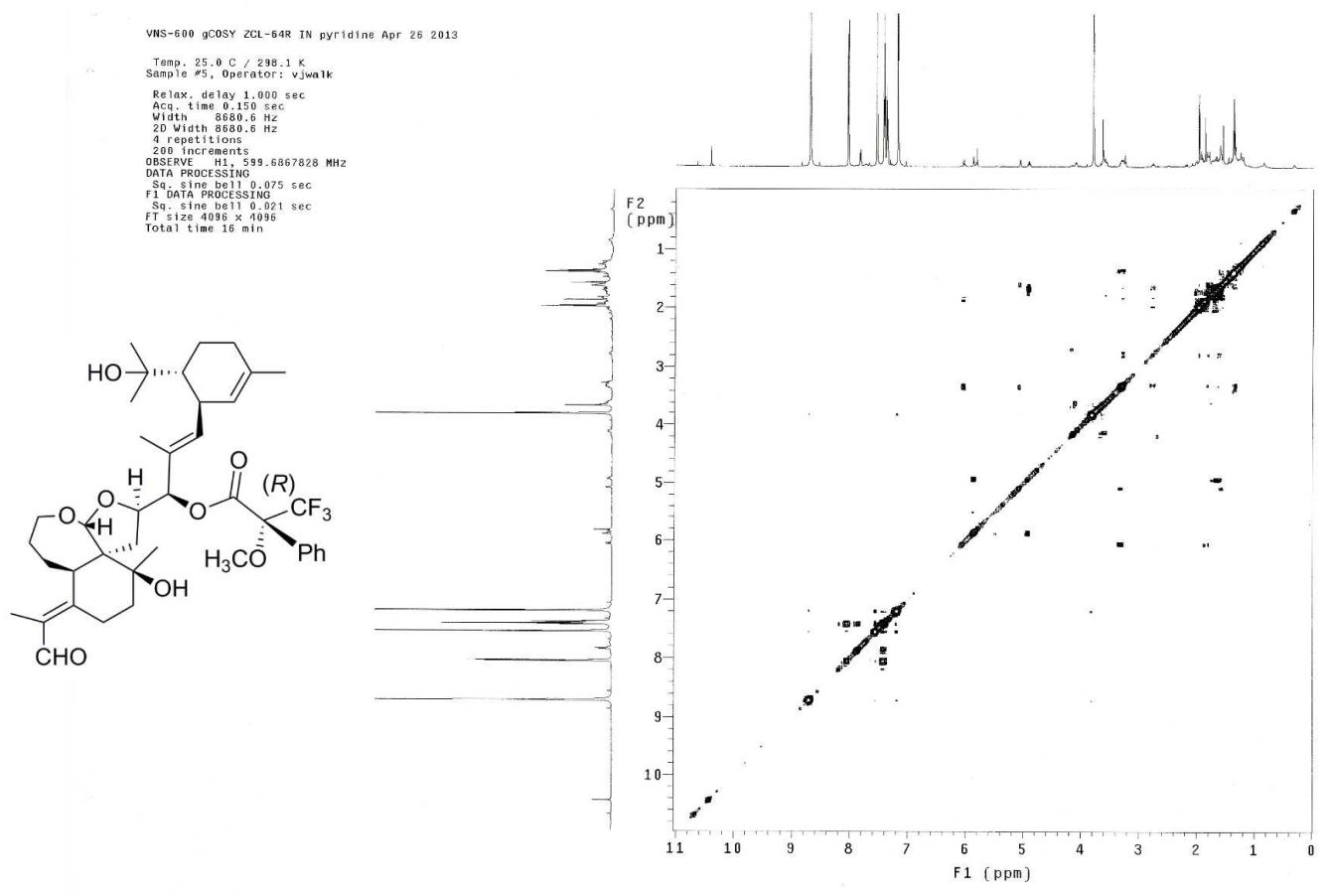

Figure S47. ${ }^{1} \mathrm{H}-{ }^{1} \mathrm{H}$ COSY Spectrum of the (R)-MTPA ester (1r) of 1 


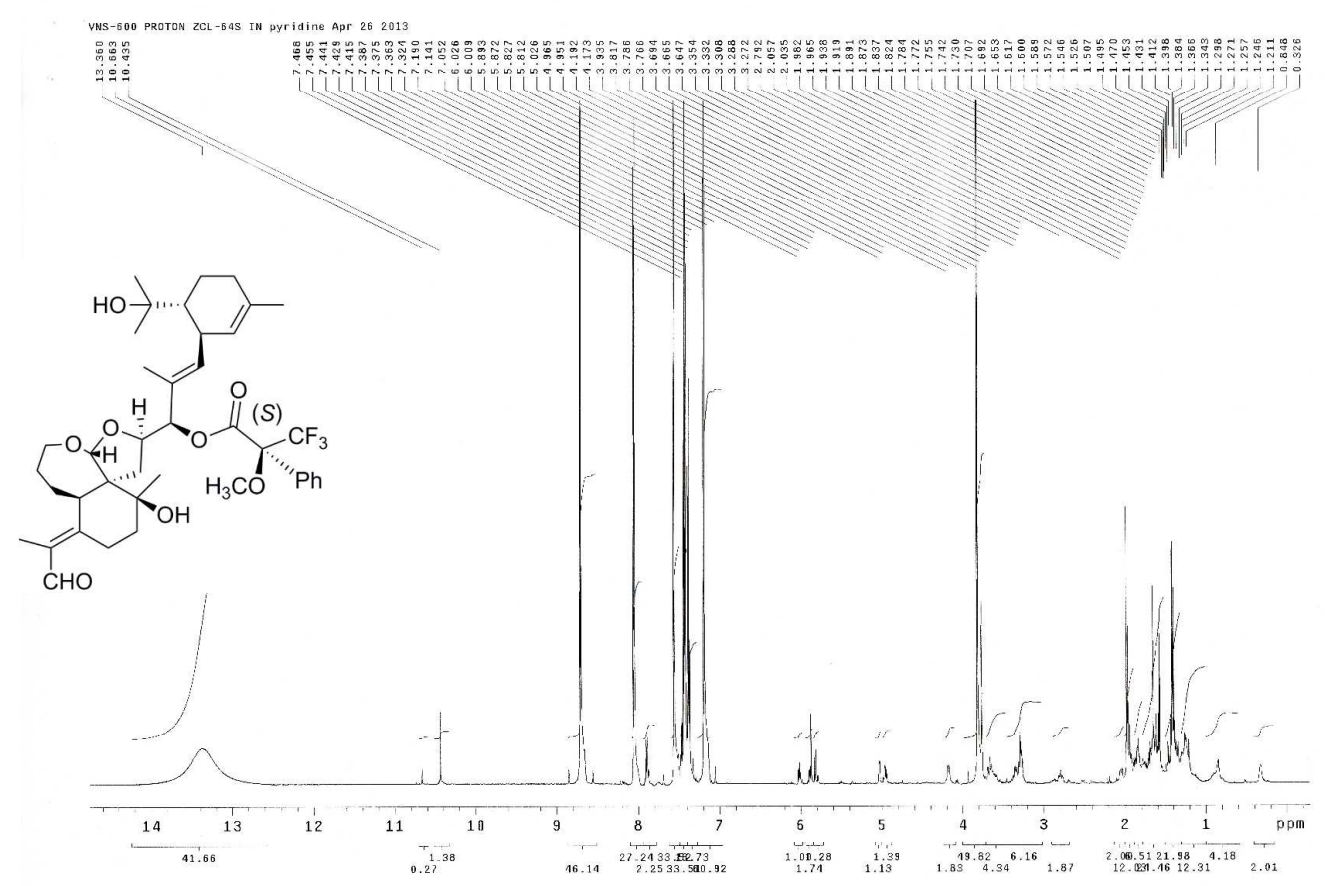

Figure S48. ${ }^{1} \mathrm{H}$ NMR Spectrum of the (S)-MTPA ester (1s) of $1(600 \mathrm{MHz}$, pyridine- $d_{5}$ )

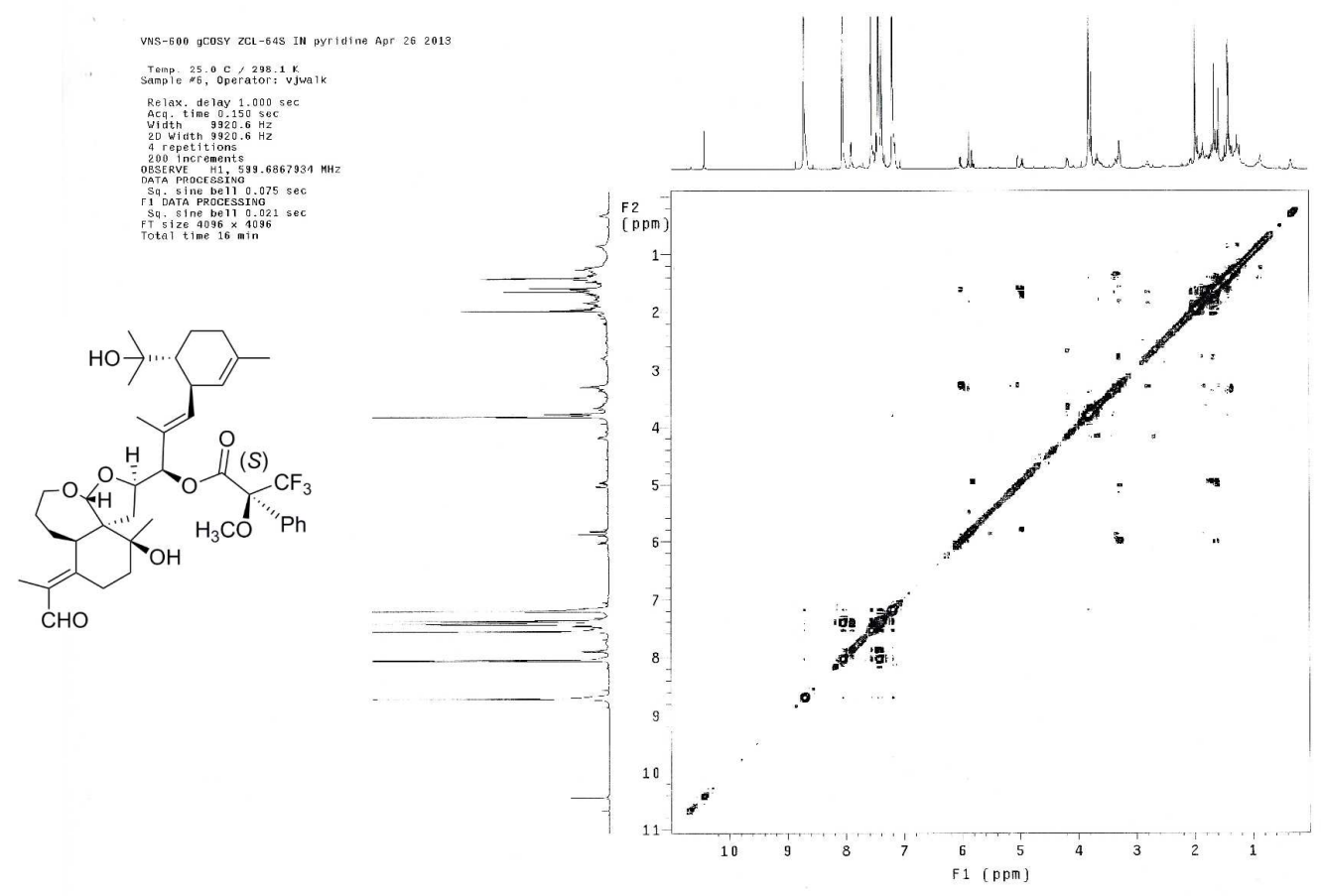

Figure S49. ${ }^{1} \mathrm{H}-{ }^{1} \mathrm{H}$ COSY Spectrum of the (S)-MTPA ester (1s) of 1 